MARCELO FREIRE DE BARROS

PROPOSTA DE INTERCONEXÃO DO PADRÃO ISO 11783 COM REDES DE SENSORES SEM FIO PADRÃO ZIGBEE 
MARCELO FREIRE DE BARROS

\title{
PROPOSTA DE INTERCONEXÃO DO PADRÃO ISO 11783 COM REDES DE SENSORES SEM FIO PADRÃO ZIGBEE
}

\author{
Dissertação apresentada à Escola \\ Politécnica da Universidade de São Paulo \\ para a obtenção do título de Mestre em \\ Engenharia Elétrica
}


MARCELO FREIRE DE BARROS

\title{
PROPOSTA DE INTERCONEXÃO DO PADRÃO ISO 11783 COM REDES DE SENSORES SEM FIO PADRÃO ZIGBEE
}

\author{
Dissertação apresentada à Escola \\ Politécnica da Universidade de São Paulo \\ para a obtenção do título de Mestre em \\ Engenharia Elétrica \\ Área de Concentração: \\ Sistemas Digitais \\ Orientador: Professor Livre-Docente \\ Carlos Eduardo Cugnasca
}

São Paulo

2010 
Este exemplar foi revisado e alterado em relação à versão original, sob responsabilidade única do autor e com a anuência de seu orientador.

São Paulo, de julho de 2010.

Assinatura do autor

Assinatura do orientador

FICHA CATALOGRÁFICA

Barros, Marcelo Freire de

Proposta de interconexão do padrão ISO 11783 com redes de sensores sem fio padrão Zigbee / M.F. de Barros. -- ed.rev. -- São Paulo, 2010.

$115 \mathrm{p}$.

Dissertação (Mestrado) - Escola Politécnica da Universidade de São Paulo. Departamento de Engenharia de Computação e Sistemas Digitais.

1.Ciência da computação 2.Protocolos de comunicação 3.Wireless 4.Comunicação digital 5.Redes locais de computadores 6 .Engenharia agrícola 7.Modernização da agricultura 8.Agricultura de precisão I.Universidade de São Paulo. Escola Politécnica. Departamento de Engenharia de Computação e Sistemas Digitais II.t. 


\section{DEDICATÓRIA}

Aos meus pais José e Hilda, à minha esposa Mercia e aos nossos filhos Ana Carolina e Guilherme, pela sustentação, carinho e apoio em cada momento desta jornada. 


\section{AGRADECIMENTOS}

Ao meu orientador Professor Livre-Docente Carlos Eduardo Cugnasca, pelo conhecimento transmitido, pelo interesse, pelo profissionalismo e pela dedicação exemplar com que me acompanhou no desenvolvimento deste trabalho. Orientador no sentido mais amplo da palavra ofereceu caminhos seguros para que esta pesquisa fosse conduzida, fomentando, neste pesquisador, o entusiasmo pela área e pela tecnologia.

Aos demais professores do Laboratório de Automação Agrícola da Escola Politécnica, pelos ensinamentos oferecidos e por incentivarem a busca incessante de novas fronteiras do conhecimento e à Professora Maria Cristina Vidal Borba pela revisão do texto em inglês.

Aos meus colegas que de alguma maneira participaram deste importante projeto de minha vida, em especial a Wilson Carnieto Junior e a Bruno Pereira Bueno pela ajuda no desenvolvimento do simulador, a Luiz Otávio Lamardo Alves Silva pelos ensaios com o TinyOS e a Juan Carlos Congona Benavente, pelas relevantes discussões que tivemos em prol deste trabalho.

Por fim, agradeço ao CNPq pelo apoio financeiro, projeto $\mathrm{n}^{\circ} 484125 / 2006-0$, e à FAPESP, projeto 04/15801-0, pelos recursos fornecidos para o desenvolvimento do trabalho, como também o apoio do Instituto Nacional de Ciência e Tecnologia Sistemas Embarcados Críticos (INCT-SEC), projeto 573963/2008-8 (CNPq) e projeto 08/57870-9 (FAPESP). 


\section{EPÍGRAFE}

Pela ciência enchem-se os celeiros de todo bem precioso e agradável.

(Provérbios 24,4) 


\section{RESUMO}

Entre os avanços tecnológicos que visam recuperar o trato da variabilidade espacial e temporal nas culturas agrícolas está a Agricultura de Precisão que busca, além de outros benefícios, melhorar $\mathrm{o}$ aproveitamento dos insumos aplicados e a produtividade, e reduzir o custo de produção e o impacto ambiental causado pelo excesso desses insumos. Para alcançar estes benefícios, recursos de tecnologia da informação e comunicação estão disponíveis em equipamentos agrícolas, tais como sistemas computacionais, sistemas de comunicação de dados sem fio, orientação por satélite por meio dos sistemas de posicionamento global e redes ISO 11783. Também as Redes de Sensores Sem Fio têm sido introduzidas para monitoração do ambiente agrícola. Acredita-se que o desempenho dessas tecnologias possa ser melhorado com a interconexão de ambas as redes, de modo que os dados dos sensores possam ser coletados diretamente pelo computador embarcado no veículo, a partir do instante que este entre no alcance do sinal dos sensores. Neste contexto, este trabalho tem por objetivo propor e demonstrar a viabilidade da interconexão dessas duas redes dentro do contexto da Agricultura de Precisão. Apoiando-se em pesquisa bibliográfica, realizou-se uma comparação entre os modelos ISO/OSI de ambas as redes e identificou-se quais dispositvos de interconexão seriam mais adequados, porpondo-se, então, a interconexão. Para demonstrar a sua viabilidade à Agricultura de Precisão, desenvolveu-se um simulador que permitiu realizar um grande número de simulações que consideraram mais de sessenta cenários distintos. Os resultados foram apresentados sob a forma de gráficos, os quais foram analisados considerando-se as limitações impostas por uma aplicação agrícola. Da análise pôde-se concluir que há viabilidade na interconcxão de forma que unidades computacionais ISO 11783 recebam, em tempo real, dados do ambiente obtidos de Redes de Sensores Sem Fio.

Palavras-chave: ISO 11783, Redes de Sensores sem Fio, Agricultura de Precisão, ISOBUS, RSSF, Simulação. 


\begin{abstract}
Precision Agriculture is one of the technological advances used to recoup the treatment of spatial and temporal variability in agricultural crops. Besides other benefits, it tries to improve the exploitation of applied inputs, improve the productivity and reduce production cost as well as lessen the impact on environment caused by excess of input. To achieve these benefits, information and communication technology are available in agricultural equipment such as computational systems, wireless communication, satellite orientation by the global positioning systems and ISO 11783 networks. Recently, Wireless Sensor Network has been introduced for agricultural environment monitoration. It is believed that the performance of these technologies can be improved with the interconnection of both networks. In this way, sensor data can be collected by the computer embedded in the vehicle, at the moment that the vehicle goes into the sensor signal area. The objective of this work is to propose and demonstrate the viability of this interconnection between the networks ISO 11783 and WSN in the Precision Agriculture context. Based on bibliographical research, both network ISO/OSI models were compared, the most adequate interconnection devices were identified and the interconnection was proposed. To demonstrate the interconnection viality in Precision Agriculture systems a simulator was denveloped which permited hundreds of simulations to be done in dozens of distint scenes. The results were shown in graphs which were analysed considering the agriculture application limitations. From this analisis, it was possible to conclude that the interconnection is viable, so that ISO 11783 computation units receive environmental data obtained by the Wireless Sensor Network in real time.
\end{abstract}

KEYWORDS: ISO 11783, Wireless Sensor Network, Precision Agriculture, ISOBUS, WSN, Simulations. 


\section{LISTA DE ILUSTRAÇÕES}

Figura 1-1 - Proposta de arquitetura em que, num computador, são centralizados os dados.

Figura 1-2 - Proposta de arquitetura em que os sensores enviam as informações diretamente aos tratores.

Figura 2-1 - Camadas definidas pelo protocolo ISOBUS (física, enlace, rede e aplicação) segundo o modelo ISO/OSI.....

Figura 2-2 - Camadas definidas pelo protocolo ZigBee (física, enlace, rede, aplicação e o framework de ligação GOF) segundo o modelo ISO/OSI..

Figura 2-3 - Campos dos frames CAN 2.0A e 2.0B (Adaptado de SOUSA, 2002). ............... 37

Figura 2-4 - Campos do frame ZigBee, adaptado de Farahani (2008). 39

Figura 2-5 - Principais elementos dos Identificadores ISOBUS. Adaptado de Inamasu e Sousa (2004).

Figura 2-6 - Topologias definidas pelo padrão ZigBee. (Adaptado de Nascimento, 2007). . 45

Figura 3-1 - Topologia com sensores posicionados em fila simples.................................. 54

Figura 3-2 - Topologia com sensores posicionados em clusters ..................................... 54

Figura 3-3 - Interconexão de uma rede ISOBUS a uma rede ZigBee. Elementos gráficos adaptados de LAV, DIN 9684-LBS (2000).

Figura 3-4 - Modelo ISO/OSI da Interconexão ISOBUS a uma rede ZigBee por meio da camada de Aplicação.

Figura 3-5 - Diagrama em blocos de uma ECU de sensoriamento (à esquerda) e de uma NIU de interconexão ISOBUS/ZigBee (à direita).......................................... 59

Figura 4-1 - Apresentação Visual do Simulador da interconexão.....................................66

Figura 4-2 - Apresentação Visual da barra de menu do simulador.....................................67

Figura 4-3 - Apresentação Visual da Área de Trabalho do Simulador.................................67

Figura 4-4 - Janela de Propriedades de um Sensor sem Fio no Simulador......................... 68

Figura 4-5 - Distribuição dos sensores na topologia estrela utilizada na simulação. ............. 74

Figura 4-6 - Distribuição dos sensores na topologia cluster tree. ....................................... 74

Figura 5-1 - Exemplo de relatório Log de eventos gerado na tela do simulador, durante uma das simulações............................................................................ 79

Figura 5-2 - Exemplo de relatório da rede gerada pelo simulador.................................... 79

Figura 5-3 - Exemplo de relatório de resultados gerado pelo Simulador. ........................... 80

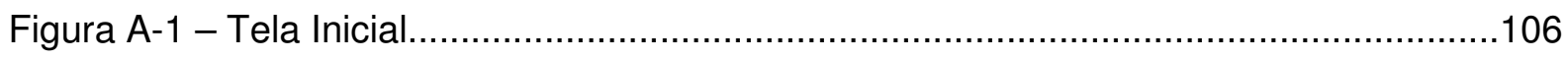

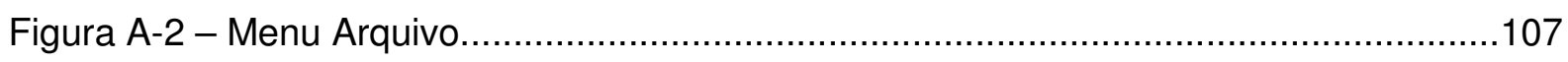

Figura A-3 - Janela para definir um novo projeto.......................................................108

Figura A-4 - Janela para confirmar o salvamento das alterações de um novo projeto........109

Figura A-5 - Janela para abrir um projeto..................................................................109

Figura A-6 - Janela para confirmar o salvamento do projeto...........................................109

Figura A-7 - Lista dos últimos seis projetos abertos..................................................109 
Figura A-8 - Janela de confirmação para salvar arquivo...............................................110

Figura A-9 - Janela para salvar arquivo com novo nome.............................................110

Figura A-10 - Janela de confirmação de salvamento das modificações em arquivo antes de fechar o programa simulador...........................................................110

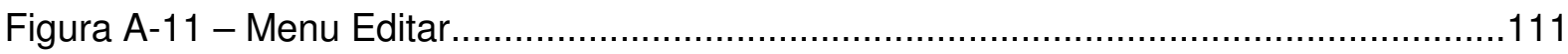

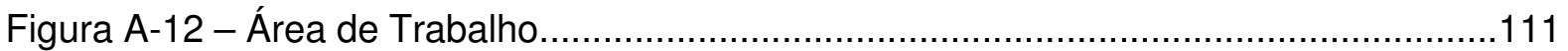

Figura A-13 - Janela para configurar o ambiente de trabalho ........................................112

Figura A-14 - Tipos de grids: pontos (à direita), cruzes (ao centro) e linhas (à esquerda).112

Figura A-15 - Opções do menu Ferramentas..............................................................113

Figura A-16 - Janela com a versão do simulador....................................................113

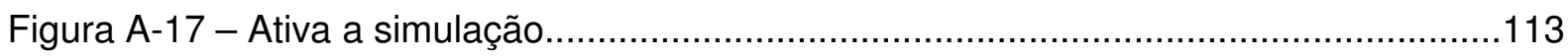

Figura A-18 - Nó Coletor percorrendo área de trabalho................................................113

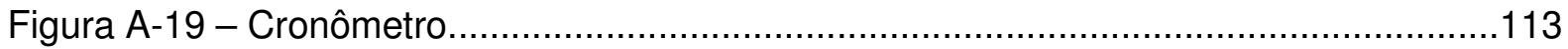

Figura A-20 - Relatório Log de eventos...................................................................114

Figura A-21 - Relatório da rede gerada pelo simulador.................................................115

Figura A-22 - Relatório de resultados gerado pelo Simulador .........................................115 


\section{LISTA DE GRÁFICOS}

Gráfico 5-1 - Tempo médio de transmissão em função do Intervalo entre os dados gerados com a topologia estrela.

Gráfico 5-2 - Tempo médio de transmissão em função do Intervalo entre os dados gerados com a topologia cluster tree.

Gráfico 5-3 - Tempos máximos de transmissão em função do Intervalo entre os dados gerados.

Gráfico 5-4 - Média de dados perdidos em função do alcance dos sensores colocados a $11 \mathrm{~m}$ do trajeto do veículo coletor a $20 \mathrm{~km} / \mathrm{h}$.

Gráfico 5-5 - Média de dados perdidos em função da velocidade do veículo com os sensores com $30 \mathrm{~m}$ de alcance.

Gráfico 5-6 - Média de frames recebidos pelo dispositivo ISOBUS em função do tamanho do buffer dos sensores (FIFO) na topologia estrela.

Gráfico 5-7 - Média de frames recebidos pelo dispositivo ISOBUS em função do tamanho do buffer dos sensores (FIFO) na topologia cluster tree......

Gráfico 5-8 - Amostras recebidas em função de milhares de amostras geradas nos sensores.

Gráfico 5-9 - Tempo de comunicação em função da taxa de ocupação do barramento ISOBUS (topologia estrela).

Gráfico 5-10 - Tempo de Comunicação em função do intervalo entre leituras para taxas de ocupação do barramento ISOBUS de 10\%, 20\% e $40 \%$.

Gráfico 5-11 - Média de frames recebidos pelo dispositivo ISOBUS por ciclo em função do tempo de simulação, com uma troca de rota após 5 min de teste...90 


\section{LISTA DE TABELAS}

Tabela 5-1 - Compilação dos dados obtidos pelas simulações com variação do intervalo entre as leituras de dados pelos sensores

81

Tabela A-1 - Descrição dos códigos de tipos de eventos..................................................114 


\section{LISTA DE QUADROS}

Quadro 2-1 - Síntese das principais diferenças da Camada Física entre os padrões ZigBee e ISOBUS.

Quadro 2-2 - Síntese das principais diferenças da Camada de Enlace entre os padrões ZigBee e ISOBUS.

Quadro 2-3 - Síntese das principais diferenças da Camada de Rede entre os padrões ZigBee e ISOBUS.

Quadro 4-1 - Cenários criados visando ao estudo de operabilidade da interconexão. 75

Quadro 4-2 - Cenários criados visando ao estudo de perdas de informação na interconexão.

Quadro 4-3 - Cenários criados visando ao estudo da influência da velocidade do veículo na interconexão.

Quadro 4-4 - Cenários criados visando ao estudo da influência do tráfego no barramento ISOBUS.

Quadro 4-5 - Cenários criados visando ao estudo de operabilidade da interconexão durante troca de rota de um dos sensores.

Quadro A-1 - Descrição dos códigos de eventos. 


\section{LISTA DE ABREVIATURAS E SIGLAS}

$\begin{array}{ll}\text { ABNT } & \text { Associação Brasileira de Normas Técnicas } \\ \text { ACK (ZigBee) } & \text { Acknowledge Frame } \\ \text { ACK (CAN) } & \text { bit de separação } \\ \text { AODV } & \text { Ad hoc On-demand Distance Vector } \\ \text { CAN } & \text { Controller Area Network } \\ \text { CD } & \text { Collision Detection } \\ \text { CRC } & \text { Cyclic Redundancy Check } \\ \text { CSMA-CA } & \text { Carrier Sense Multiple Access With Collision Avoidance } \\ \text { CSMA-CD/NDA } & \text { Carrier Sense Multiple Access with Collision Detection and Non- } \\ \text { DA } & \text { Destructive Arbitration } \\ \text { DIN } & \text { Destination Address } \\ \text { DSSS } & \text { Deutsches Institut für Normung } \\ \text { ECU } & \text { Direct Sequence Spread Spectrum } \\ \text { FFD } & \text { Electronic Control Unit } \\ \text { FMIS } & \text { Full Fuction Device } \\ \text { GOF } & \text { Farm Management Information System } \\ \text { GPS } & \text { General Operation Framework } \\ \text { IDE } & \text { Global Positioning System } \\ \text { IEEE } & \text { Identifier Extension (bit) } \\ \text { ISM } & \text { Institute of Electrical and Electronics Engineers } \\ \text { ISO } & \text { Industrial, Scientific and Medical } \\ \text { LAA } & \text { International Organization for Standardization } \\ \text { LAV } & \text { Laboratório de Automação Agrícola } \\ \text { LLC } & \text { Landtechnik-Vereinigung } \\ \text { MAC } & \text { Logical Link Control } \\ \text { MAC-ID } & \text { Medium Access Control } \\ \text { MCPS } & \text { Medium Access Control Identifier } \\ \text { MIS } & \text { Management Information System } \\ \text { MLME } & \text { NAC Layer Management Entity } \\ \text { NC } & \text { Network Interface Unit } \\ \text { NIU } & \text { Offere Phase-Shift Keying } \\ \text { O-QPSK } & \end{array}$




\begin{tabular}{|c|c|}
\hline OSI & Open Systems Interconnection \\
\hline PAN-ID & Personal Area Network Identifier \\
\hline PDA & Personal Digital Assistants \\
\hline PDU & Protocol Data Unit \\
\hline PGN & Parameter Group Number \\
\hline PHY & Physical Layer \\
\hline PSDU & PHY Service Data Unit \\
\hline QPSK & Quadrature Phase-Shift Keying \\
\hline RFD & Reduced Function Device \\
\hline RF-ID & Radio-Frequency Identification \\
\hline RSSF & Rede de Sensores sem Fio \\
\hline RTR & Remote Transmission Request \\
\hline SA & Source Address \\
\hline SAE & Engineering Society for Advancing Mobility Land Sea Air and Space \\
\hline SOF & Start of Frame \\
\hline SRR & Substitute Remote Request \\
\hline sscs & Service Specific Convergence Sublayer \\
\hline TBC & Terminal Bus Conector \\
\hline TC & Task Controller \\
\hline TDI & Transductor Digital Intelligent \\
\hline USB & Universal Serial Bus \\
\hline VDMA & $\begin{array}{l}\text { Verband Deutscher Maschinen- und Anlagenbau - German } \\
\text { Engineering Federation }\end{array}$ \\
\hline VT & Virtual Terminal \\
\hline
\end{tabular}




\section{SUMÁRIO}

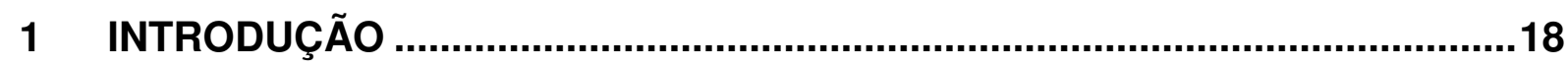

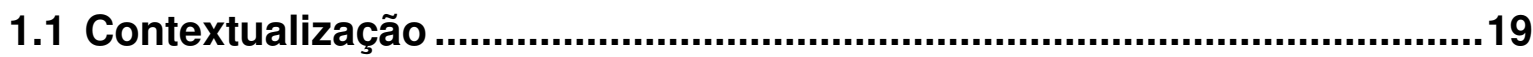

1.2 Identificação do Tema ..................................................................................20

1.3 Justificativa para a Escolha do Tema ..........................................................22

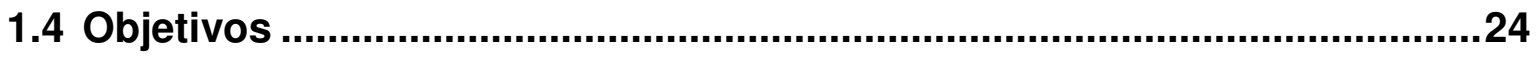

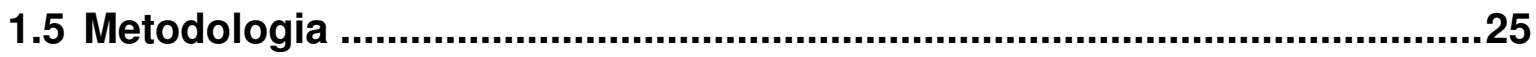

1.6 Estruturação do Trabalho ......................................................................26

2 TECNOLOGIAS E PROTOCOLOS DE COMUNICAÇÃO APLICÁVEIS NA

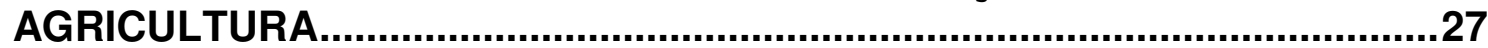

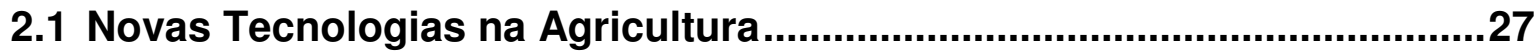

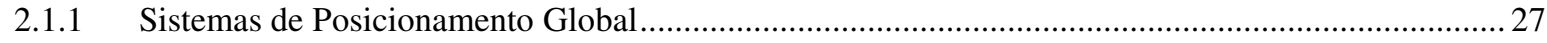

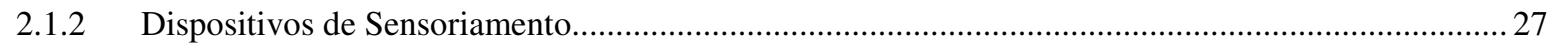

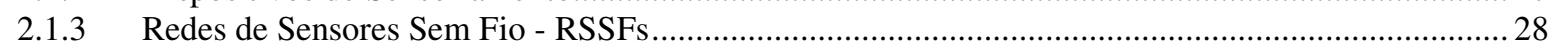

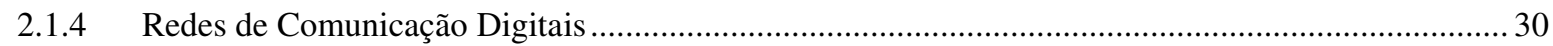

2.2 Comparação entre os Protocolos ISOBUS e ZigBee..................................32

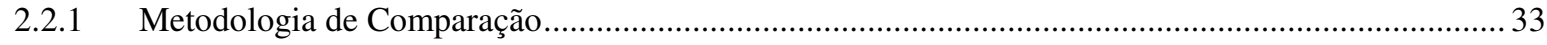

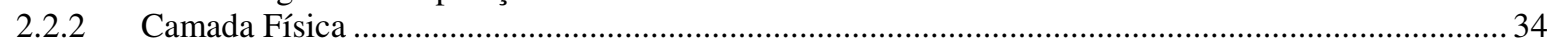

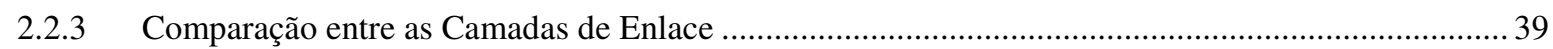

2.2.4 Comparação entre as Camadas de Rede ..................................................................................... 43

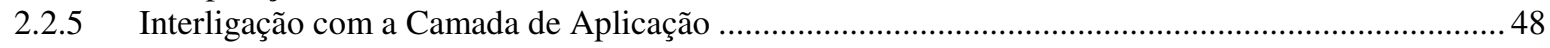

2.2.6 Comparação entre as Camadas de Aplicação ..........................................................................49

2.3 Considerações sobre o Capítulo..............................................................51

3 PROPOSTA DE INTERCONEXÃO ENTRE REDES DO PADRÃO ZIGBEE E ISOBUS

3.1 Elementos da Aplicação Considerados na Interconexão ….......................52

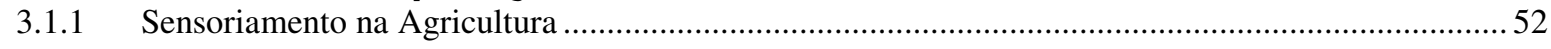

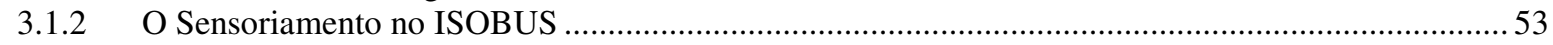

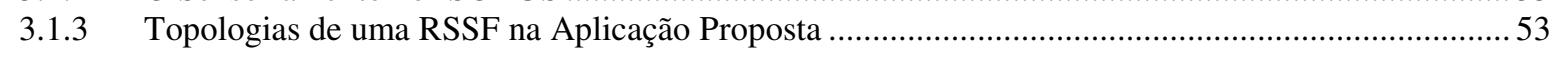

3.2 Elementos para Interconexão de Redes...............................................55

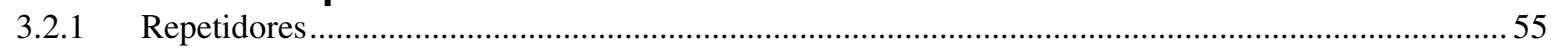

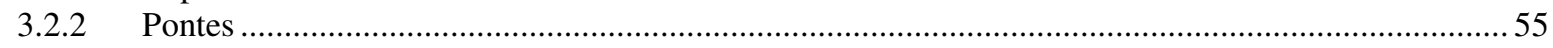

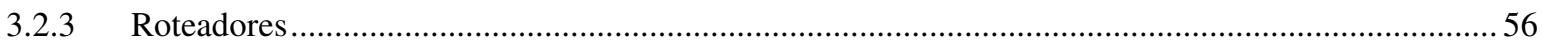

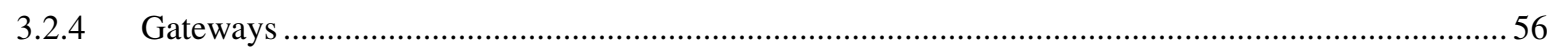




\subsection{Elemento Proposto para a Interconexão de Redes Padrão ZigBee e}

ISOBUS.

3.4 Considerações sobre a Conexão Proposta..............................................58

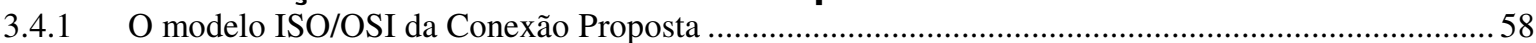

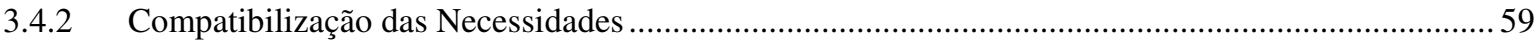

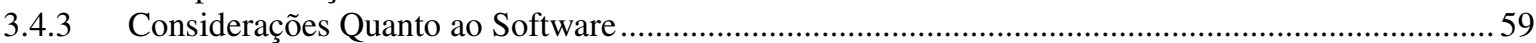

3.5 Limitações da Interconexão Proposta .......................................................60

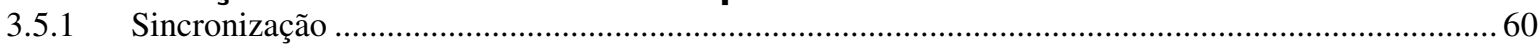

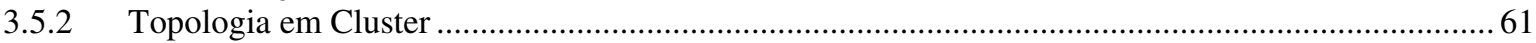

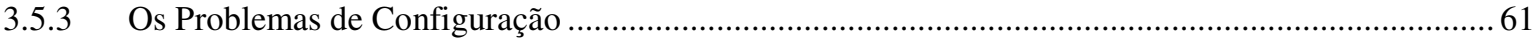

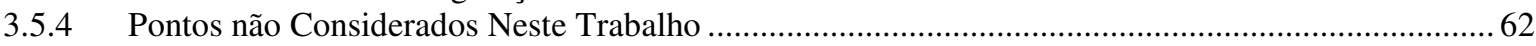

3.6 Considerações sobre o Capítulo...............................................................62

4 SIMULAÇÃO DA INTERCONEXÃO ENTRE REDES DO PADRÃO ZIGBEE E

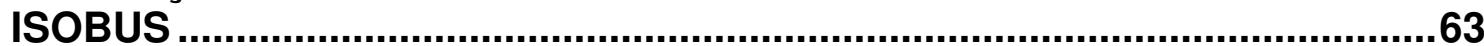

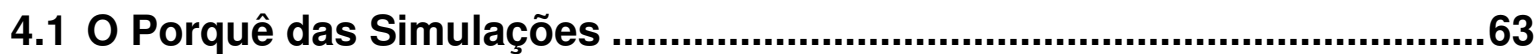

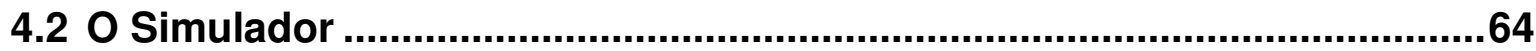

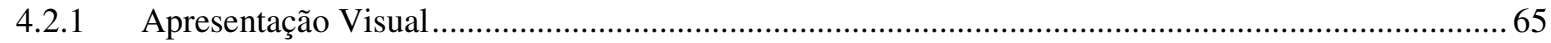

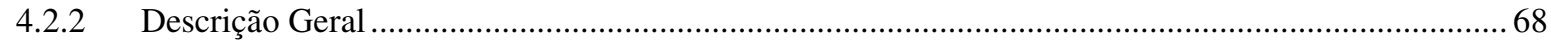

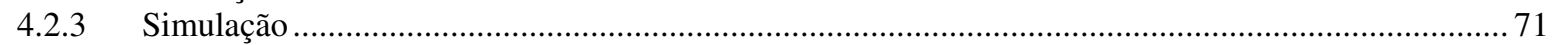

4.3 Caracterização das Simulações Executadas ..........................................73

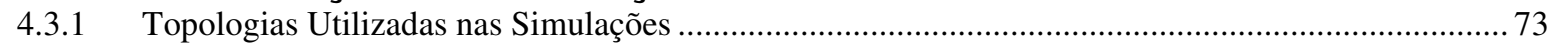

4.3.2 Teste de Operabilidade e Temporização …........................................................................ 74

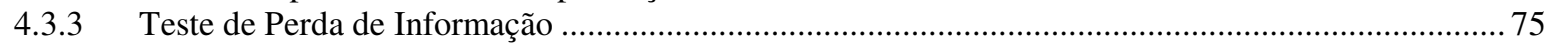

4.3.4 Teste da Influência da Velocidade do Veículo ................................................................................75

4.3.5 Teste da Influência da Densidade de Tráfego da Rede ISOBUS...................................................76

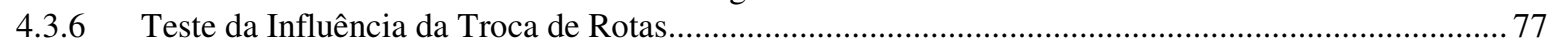

4.4 Considerações sobre o Capítulo.............................................................77

5 RESULTADOS DAS SIMULAÇÕES DA INTERCONEXÃO ENTRE REDES DO PADRÃO ZIGBEE E ISOBUS ...............................................................

5.1 Apresentação dos Resultados ...................................................................78

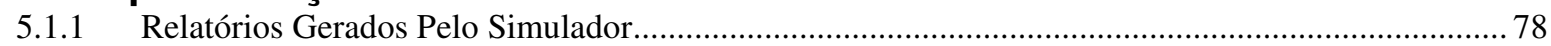

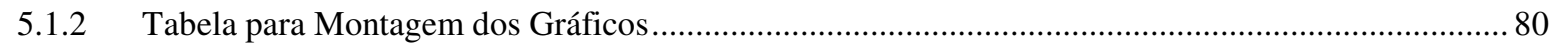

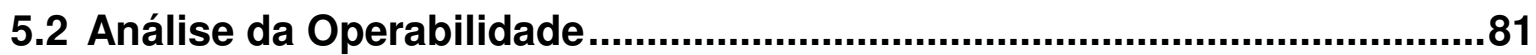

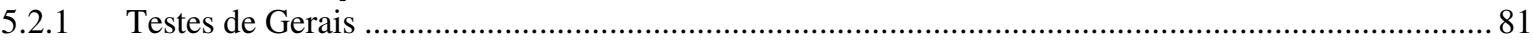

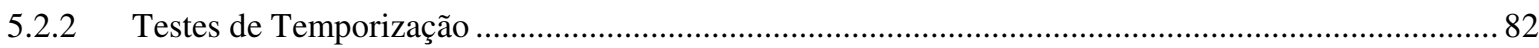

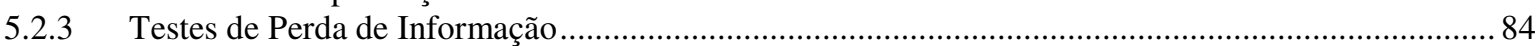

5.2.4 Análise da Influência das Trocas de Rota ............................................................................. 89

5.3 Considerações Gerais sobre os Resultados...........................................90

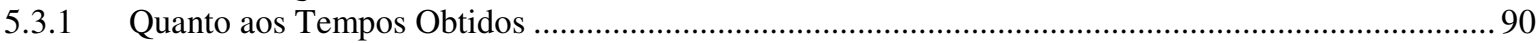

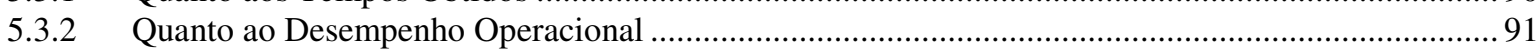

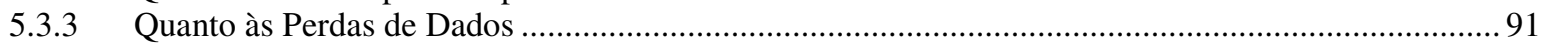

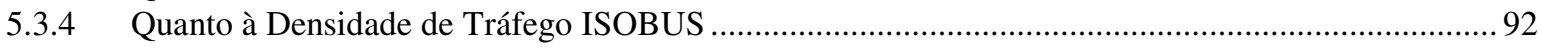

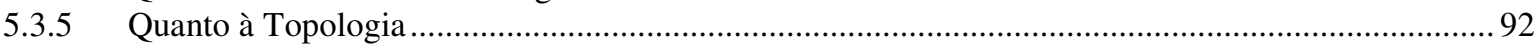




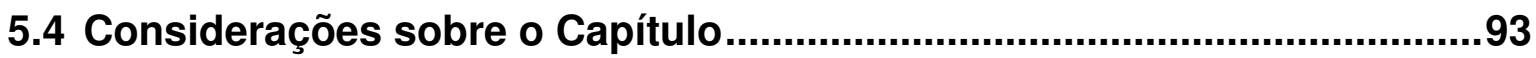

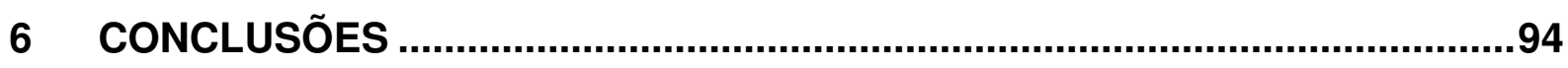

6.1 Quanto ao Desempenho da Interconexão Proposta....................................94

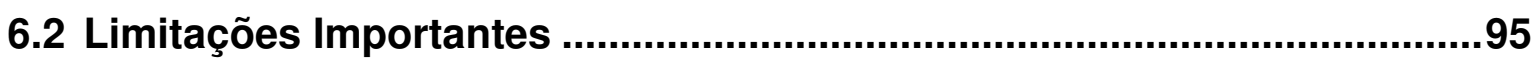

6.3 Sugestões Para Discussão nos Comitês da Norma ISO 11783.................96

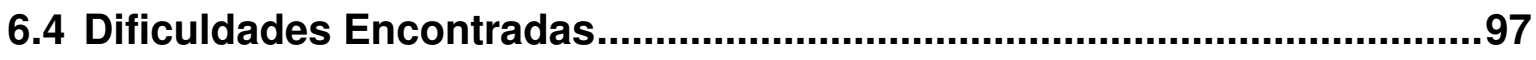

6.5 Trabalhos Futuros Recomendados..........................................................97

6.6 Considerações Finais..................................................................................98

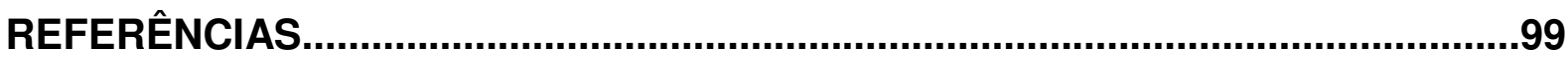

APÊNDICE A - Guia do Usuário do Simulador ...................................................106 


\section{INTRODUÇÃO}

Os últimos sensos demográficos brasileiros têm mostrado uma população tipicamente urbana que aumenta continuamente em relação à população do campo. Tem-se, com isto, a necessidade de se produzir mais, com mais qualidade, menor custo e com menos mão-de-obra, o que tem levado à necessidade crescente de mecanização e automação das atividades agrícolas (COELHO, 1998).

A agricultura brasileira, ainda que venha ocupando um papel de destaque na economia do país, tem enfrentado inúmeras adversidades, largamente divulgadas pelos meios de comunicação, dentre as quais se destacam, segundo Carvalho e Silva (2005):

- constantes subsídios governamentais oferecidos nos países do primeiro mundo;

- altos impostos a que o produtor brasileiro é submetido;

- oscilações do câmbio (real/dollar);

- altas taxas de juros nos financiamentos agrícolas;

- alto custo da mecanização;

- crescente aumento no preço dos insumos agrícolas;

- baixa qualidade da infra-estrutura de transporte.

Entre as alternativas possíveis para que o setor agrícola do país enfrente tais adversidades e responda com maior produtividade estão os avanços tecnológicos que visam recuperar o trato da variabilidade espacial e temporal nas culturas agrícolas, buscando melhorar o aproveitamento na aplicação dos insumos e a produtividade e reduzir o custo de produção e o impacto ambiental causado pelo excesso desses insumos (FARIAS et al., 2003).

Como potenciais tecnologias para essa área têm-se a Agricultura de Precisão, os avanços nos computadores embarcados, as redes de comunicação de campo, a comunicação digital sem fio, os sistemas de posicionamento global e os novos dispositivos de sensoriamento (PIERCE; NOWACK, 1999), os quais são objetos do presente trabalho. 


\subsection{Contextualização}

Em parte, a eficiência na produção no campo passa pela recuperação do conhecimento e da experiência do antigo agricultor capaz de avaliar individualmente cada pequena área plantada e promover ações corretivas específicas para cada uma.

Neste contexto surgiu a Agricultura de Precisão definida por Pierce e Nowack (1999) como "a aplicação de tecnologias e princípios de gerenciamento da variabilidade espacial e temporal associada com todos os aspectos da produção agrícola, com o propósito do aumento do desempenho das colheitas e da qualidade ambiental [...]".

Segundo Molin (2004), a Agricultura de Precisão busca a otimização dos custos de produção, a diminuição da contaminação da natureza pelos defensivos utilizados e o aumento da produção. Para isto, a Agricultura de Precisão define um processo cíclico e contínuo dividido em cinco fases: colheita de informações; geração de mapas de variabilidade; análise e geração de mapas de aplicação; e aplicação de insumos a taxa variável (MOLIN, 2000). A Agricultura de Precisão vem ganhando impulso com o uso de ferramentas computacionais que permitem simular e avaliar os mais diferentes cenários, inclusive consolidando as informações obtidas em campo durante cada fase do processo produtivo agrícola (COELHO, 2003).

Em sua pesquisa, Borba e Torres (2003) concluíram que apesar do baixo uso da tecnologia de informação nas pequenas unidades de produção agrícolas, nas unidades com mais de 500 hectares faz-se uso de um elevado padrão tecnológico, com uso intensivo de computadores destinados, principalmente, a áreas administrativas. Identificam ainda que tem crescido o uso de computadores pessoais para gerenciamento da produção, com o desenvolvimento de softwares cada vez mais adequados a cada cultura e de baixo custo.

\footnotetext{
"A informática poderá auxiliar para facilitar a gerência dos novos sistemas produtivos que surgirão e para agilizar o processo decisório, permitindo um melhor planejamento das atividades agropecuárias, em busca da otimização da aplicação dos conceitos embutidos nesses sistemas. A tecnologia da informação vem se difundindo no meio rural, nos últimos anos, e verifica-se que ela pode contribuir positivamente nos aspectos econômicos e ambientais" (MEIRA et al., 1996).
} 
Os equipamentos agrícolas de hoje também sofreram profundas alterações em relação aos equipamentos do passado. Além de estarem providos de diversos itens de conforto como ar-condicionado, cabinas fechadas, sistemas hidráulicos, dispositivos eletrônicos de controle e redutores de vibração entre outros (SCHLOSSER et al., 2002), dispõem ainda de diversos recursos de tecnologia da informação como dispositivos computacionais, sistemas de comunicação de dados sem fio e orientação por satélite por meio dos sistemas de posicionamento global.

Molin (2000) afirma que na Agricultura de Precisão toda informação de variabilidade temporal ou espacial pode ser útil, em especial as informações obtidas de mapas de produtividade. O adequado aproveitamento dessas informações pode trazer resultados finais tão melhores quanto melhor qualidade tiver as informações.

Portanto, a troca de informações entre os mais diversos equipamentos usados no ambiente agrícola ganha especial importância. Para isto, é necessário que as tecnologias de comunicação em rede sejam adequadas ao ambiente agrícola e permitam 0 acesso às informações, de modo simples e prático, tanto pelas ferramentas de gerenciamento, quanto pelos equipamentos automatizados usados no campo. Dentro deste contexto é que se define o tema deste trabalho.

\subsection{Identificação do Tema}

As redes de comunicação de campo não são uma tecnologia recente. O protocolo Controller Area Network (CAN), por exemplo, foi proposto em 1983 e seu uso intenso vem ocorrendo desde então. Seu desenvolvimento vem se dando a partir dos sistemas automobilísticos, industriais, comercias e até mesmo aeroespaciais, chegando mais recentemente à área agrícola (JOHANSSON et al., 2005). Nos tratores e implementos usados na agricultura é comum encontrar redes de comunicação baseadas no protocolo CAN (INAMASU; SOUSA, 2004). Equipamentos como um Gerenciador de Tarefas embarcados nos tratores podem receber por rádio ou por dispositivos de memória móveis - discos, pen drives, entre outros - um conjunto de tarefas gerado por um computador no escritório da fazenda e ativar os demais equipamentos conectados à rede de tal modo que executem as partes que lhe cabem de cada tarefa.

Com o objetivo de monitoração ambiental, outra tecnologia que vem sendo proposta 
são as Redes de Sensores sem Fio (CAMILLI et al., 2007), discutidas no Capítulo 2. A Figura 1-1 apresenta uma possível arquitetura para o uso conjunto de redes embarcadas baseadas no protocolo CAN e de rede de sensores sem fio. Nesta configuração, uma espécie de gateway funciona como nó sorvedouro de uma Rede de Sensores sem Fio (denominada neste trabalho apenas por RSSF), a qual recebe as informações de toda a rede e as envia ao computador, por um canal de comunicação RS232, USB ou Ethernet. Após a análise de tais informações, são geradas listas de tarefas, as quais são enviadas aos Gerenciadores de Tarefas dos tratores por uma rede $\mathrm{Wi}-\mathrm{Fi}$ que interconecta o computador aos tratores $\mathrm{e}$ finalmente, o Gerenciador de Tarefa controla as ações dos implementos por uma rede baseada no protocolo CAN.

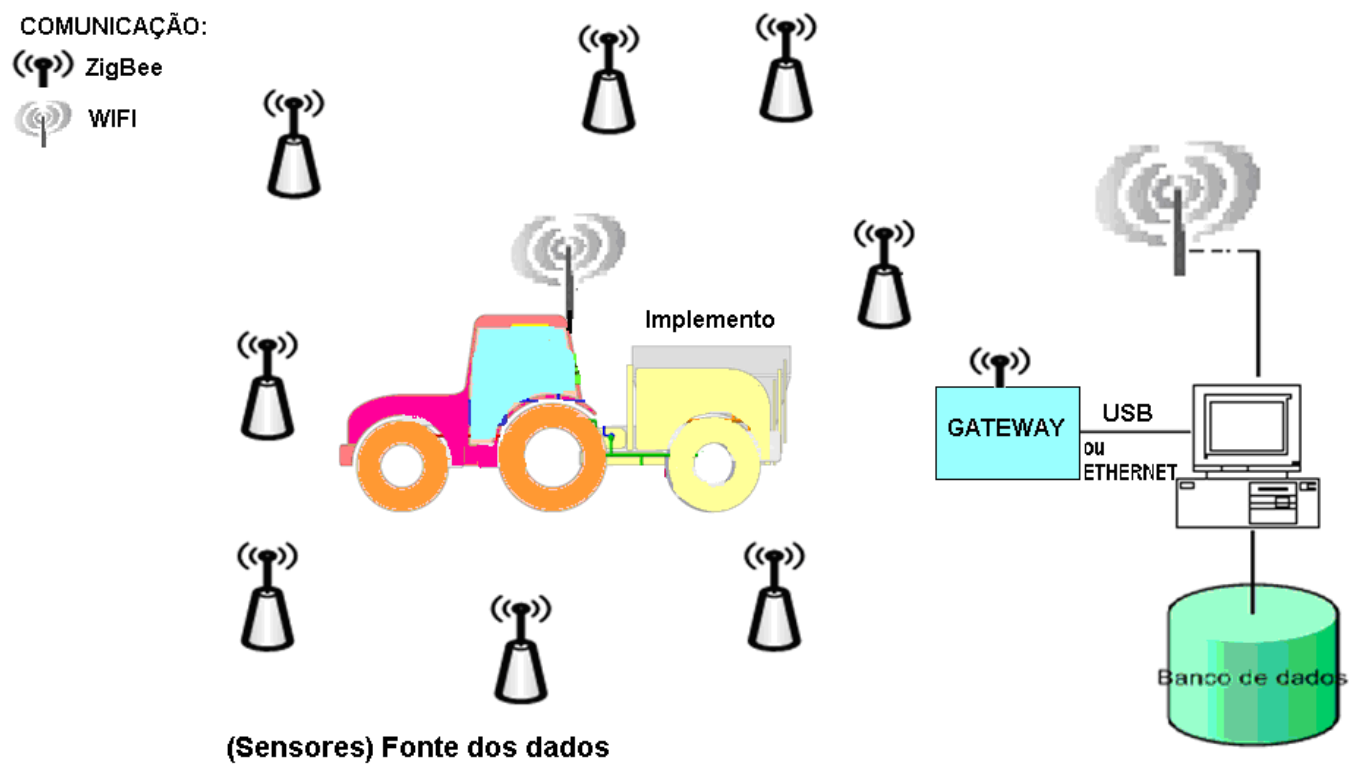

Figura 1-1 - Proposta de arquitetura em que os dados são centralizados em um computador.

Acredita-se que esta configuração possa proporcionar outros benefícios, se os dados dos sensores puderem ser coletados diretamente pelo computador embarcado no veículo, a partir do instante que este entre no alcance do sinal dos sensores. Isto possibilitaria que as tarefas a serem executadas fossem definidas no próprio computador do veículo. Como não existe um único protocolo que seja adequado aos dois ambientes (ambiente de campo, onde os sensores se comunicam pelo ar e o ambiente embarcado dos veículos, onde a comunicação ocorre por meio de cabos), é necessário que se realize a conexão das redes, sendo este o objeto deste trabalho. 
A conexão de um lado emularia um ou mais nós em uma rede embarcada nos tratores (possivelmente baseada no protocolo CAN), como um banco de dados de informações obtidas dos sensores e, de outro lado, funcionaria como nó coletor de dados, uma espécie de gateway, trabalhando como nó central da RSSF, como ilustra a Figura 1-2.

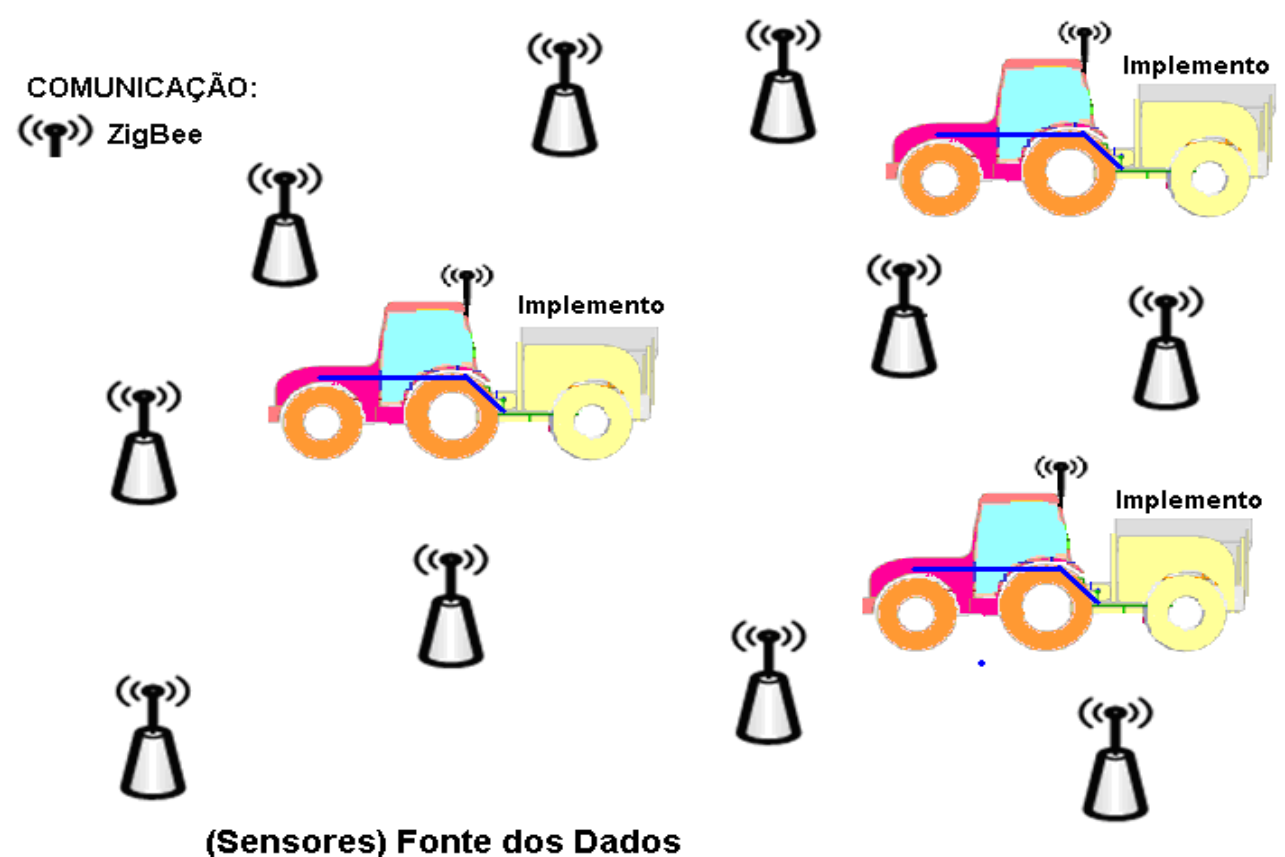

Figura 1-2 - Proposta de arquitetura em que os sensores enviam as informações diretamente aos tratores.

\subsection{Justificativa para a Escolha do Tema}

Nos últimos anos, diversos trabalhos de pesquisa têm sido desenvolvidos sobre tecnologias aplicadas à agricultura envolvendo RSSFs, alguns dos quais serviram de motivação para este trabalho e que serão citados ao longo do texto. Este trabalho também está em consonância com as linhas de pesquisa do Laboratório de Automação Agrícola (LAA), do departamento de Engenharia de Computação e Sistemas Digitais da Escola Politécnica da Universidade de São Paulo (http://www.pcs.usp.br/ laa/html/pagina.php?p=apresentacao). Entre os assuntos de maior interesse do LAA, destacam-se: instrumentação inteligente e redes baseadas em padrões abertos (CAN, LonWorks, ISO 11783); RSSF; sistemas de monitoração e controle de processos; sistemas de informações e de suporte a decisão; e sistemas para biodiversidade. 
Dentre as diversas linhas de pesquisa do LAA, o trabalho está inserido na de rede de sensores e instrumentação inteligente. Esta linha aborda, em especial, as novas aplicações de RSSFs e instrumentação inteligente nos setores do agronegócio como em casas de vegetação, na criação animal e na Agricultura de Precisão. Dentre as diversas atividades realizadas por seus pesquisadores, destaca-se a sua participação na aplicação e avaliação dos padrões já existentes para a área como a IEEE1451, o ZigBee, o CAN, a LonWorks e do padrão para sistemas embarcados em máquinas agrícolas ISO 11783. Alguns dos pesquisadores do LAA fazem parte do comitê da ABNT para a normalização da ISO 11783 (CE 04:015.15) e da ForçaTarefa ISOBUS-Brasil, cujas atividades foram destacadas por Cugnasca e Saraiva (2007).

Entre os estudos recentes do grupo destacam-se:

- as RSSFs estudadas por Benavente e Gonda com várias publicações como Gonda e Cugnasca (2006), Gonda, Cugnasca e Camilli (2005), Batistas et al. (2009), Benavente et al. (2009a), Benavente et al. (2009b) e Najm et al. (2009);

- a rede LonWorks pesquisada por Alves Filho e Kaneshiro com as seguintes publicações como Alves Filho et al. (2009), Kaneshiro et al. (2007a), Kaneshiro et al. (2007b) e Villani e Miyagi (2004);

- a monitoração ambiental pesquisada por Costa e publicada em Costa e Cugnasca (2009);

- a ISO 11783 estudada por Saraiva e Cugnasca e publicada em Saraiva e Cugnasca (2006) e Guimarães e Saraiva (2003).

Diversos outros pesquisadores estão envolvidos com o tema e têm destacado a necessidade de sistemas cada vez mais integrados entre si e distribuídos pelo campo. Para isto, é necessário que todos os sistemas estejam interconectados e possam trocar dados de modo prático e eficiente. Zhang e Wang (2006) e Liu et al. (2007), cujos trabalhos propõem a interconexão da tecnologia de RSSF com a tecnologia RFID, usam como motivação para o trabalho "a necessidade de interconexão das diversas tecnologias de redes, de modo a tornar o mundo mais pervasivo [...]". Na mesma linha, Jensen et al. (2007), cujo trabalho propõe a conexão da RSSF à internet, destaca a necessidade de distribuir o processamento entre máquinas agrícolas. 
O estudo da conexão de redes sem fio de baixo alcance, como as RSSFs com equipamentos alocados em veículos nos quais estão instaladas as redes ISO 11783, passa pela problemática da comunicação dos sensores com os pontos móveis. Vieira et al. (2003) e Nakamura et al. (2004), por exemplo, ao abordarem as RSSFs, concluem suas pesquisas indicando que suas propostas precisam ser complementadas por trabalhos que considerem a mobilidade dos nós. Dulman et al. (2003), por sua vez, propõem uma técnica de roteamento para RSSF direcionada a nós móveis; Ye et al. (2002), ao avaliarem a comunicação de redes de sensores em grandes áreas, propõem como solução a existência de nós móveis.

Com base nestes e em outros trabalhos, acredita-se que um trabalho, cujo foco seja a conexão de RSSF como um nó de uma rede ISO 11783, seja relevante para o desenvolvimento da tecnologia no setor agrícola.

\subsection{Objetivos}

O objetivo principal deste trabalho é demonstrar que se um nó ZigBee estiver conectado à rede ISO 11783, poderá responder a esta como um seu nó, permitindo que dispositivos ISO 11783 tenham acesso automático aos dados da ZigBee.

Além deste objetivo, buscou-se propor requisitos para uma interconexão entre as RSSFs, padrão ZigBee como um ou mais nós ISO 11783 dentro do contexto de Agricultura de Precisão. Buscou-se também propor uma possível extensão à norma ISO 11783, que permita implementar nela um ou mais nós que recebam e considerem os dados gerados por uma rede ZigBee, pela qual um equipamento móvel transita fisicamente, sem perda de informação.

Em suma, espera-se responder as seguintes questões:

- Quando e como (em que situações) ocorre perda de dados?

- O que acontece quando o protocolo ZigBee troca de rota?

- O que acontece quando o veículo está fora do alcance dos sensores?

- Quais limitações a ISO 11783 poderá ter ao acessar a RSSF?

- Quais os limites de uso da aplicação?

- Quais os ganhos de confiabilidade? 
Por fim, são propostas algumas funções complementares à rede ISO 11783, de modo a tornar viável a conexão de ambas as redes em um sistema agrícolas.

Este trabalho não visa projetar todos os subsistemas envolvidos na nova arquitetura, nem desenvolver um projeto de um dispositivo de conexão, e sim definir as necessidades e especificações para que se possa desenvolver um projeto de uma conexão.

\section{$1.5 \quad$ Metodologia}

Para que se pudesse atingir os objetivos propostos, inicialmente foi feita uma revisão da literatura disponível sobre os temas: RSSF, ZigBee, ISO 11783 e Agricultura de Precisão. Os trabalhos fundamentais da área foram considerados e, na sequência foi feita uma revisão bibliográfica levantando-se os artigos publicados em revistas e eventos nacionais e internacionais. Teve-se especial atenção com os trabalhos que tratam das interconexões das redes ZigBee e ISO 11783 com outras e que tratam de nós móveis em redes ZigBee. A revisão permitiu fazer a proposta inicial de arquitetura ou arranjo das conexões da rede.

Em uma segunda etapa, foi feita uma comparação entre as características da rede ISO 11783 e as da RSSF, visando definir as funções dos protocolos que se complementavam ou competiam entre si. Isto permitiu definir as limitações da interconexão, assim como os problemas que deveriam ser resolvidos para que a conexão pudesse ser eficiente.

Foi então desenvolvido um simulador para testar a comunicação dentro da rede ZigBee. Ele foi desenvolvido em linguagem Delphi, permitindo trabalhar com uma distribuição de sensores padronizada ou customizada pelo usuário, ou mesmo gerar automaticamente distribuições aleatórias.

Na sequência, passou-se a desenvolver simulações que envolvem uma rede de sensores distribuídos de diversos modos, com o alcance do sinal de cada sensor diferente e todos tentando estabelecer comunicação com um possível nó móvel que cruza a rede. Com as simulações, foram obtidos dados para estimar os limites e alcances da proposta, considerando um possível trabalho colaborativo entre os sensores. 
Os resultados obtidos nas simulações foram organizados em gráficos e, por meio da análise destes gráficos, avaliou-se o desempenho da conexão proposta.

\subsection{Estruturação do Trabalho}

O trabalho foi dividido em quatro partes. Na primeira (Capítulo 2), por meio da revisão bibliográfica, procura-se mostrar o estágio em que se encontra o uso de algumas das tecnologias emergentes na agricultura. A revisão bibliográfica foi baseada em uma comparação entre as RSSFs baseadas no padrão ZigBee e na ISO 11783. Como resultado desta comparação, foi feita uma proposta de interconexão entre as duas redes (Capítulo 3) pressupondo uma aplicação agrícola.

Na segunda parte (Capítulo 4) foram feitos testes do comportamento da rede ZigBee com o nó receptor móvel, por meio de simulações executadas com o auxílio de um software especialmente desenvolvido para este fim. $O$ simulador reproduz algumas das funções de uma rede ZigBee, de um nó ISO 11783 e de uma interconexão móvel. Ele gera distribuições de sensores, de modo aleatório ou não, em uma área padronizada. Simula a comunicação destes sensores com um ponto móvel que cruza a área e levanta dados do comportamento da comunicação. O simulador é descrito, assim como as simulações executadas. Com isto foi possível determinar os limites de espaço e tempo para a comunicação.

$\mathrm{Na}$ terceira parte (Capítulo 5) mostra-se o resultado das simulações efetuadas, organizadas em gráficos. Para esta terceira parte faz-se uso dos relatórios gerados pelo simulador, criando-se tabelas com o comportamento dos frames gerados pelo simulador. Finalmente, a partir das tabelas, gerou-se os gráficos que são apresentados. Os resultados são então discutidos e comparados com os obtidos em trabalhos semelhantes.

Finalmente, no Capítulo 6 são apresentadas as conclusões. São retomados os objetivos e o quanto de cada um foi alcançado. Também são apresentadas as duas maiores dificuldades encontradas durante o desenvolvimento deste trabalho e as sugestões de sua continuidade. 


\section{TECNOLOGIAS E PROTOCOLOS DE COMUNICAÇÃO APLICÁVEIS NA AGRICULTURA}

Neste capítulo são apresentados e comentados alguns tópicos das tecnologias de eletrônica embarcada e protocolos de comunicação aplicáveis ao campo. O capítulo é dividido em duas partes. Na primeira, descrevem-se brevemente as tecnologias envolvidas e, na segunda, é feito um comparativo entre os protocolos ISO 11783 e ZigBee, com o objetivo de explicitar os pontos que devem ser considerados para se estabelecer uma interconexão entre ambos.

\subsection{Novas Tecnologias na Agricultura}

\subsubsection{Sistemas de Posicionamento Global}

Molin (1998) demonstra as vantagens dos Sistemas de Posicionamento Global (GPS) na Agricultura de Precisão, uma vez que o controle espacial é fundamental, tanto para referenciar as variáveis monitoradas, quanto para a aplicação localizada de insumos (SCHUELLER; WANG, 1994) e (MOLIN, 2004).

Coelho (2005) afirma que o GPS, desenvolvido pelo Departamento de Defesa dos EUA, é uma tecnologia que possibilita determinar a posição em qualquer parte do globo terrestre, o que permite que a Agricultura de Precisão seja uma realidade. 0 sistema consiste em um rádio receptor que recebe informações de um conjunto de satélites distribuídos ao redor da Terra e cruzando estas informações, consegue determinar a sua posição geográfica (MONICO, 2000).

\subsubsection{Dispositivos de Sensoriamento}

Outra tecnologia que teve um grande desenvolvimento nos últimos anos foi a de sensoriamento, a qual permite monitorar variáveis em todo o ciclo da produção agrícola. A tecnologia de sensores teve um incremento significativo, de modo que é possível que sejam instalados em equipamentos específicos, embarcados em máquinas agrícolas ou diretamente no solo. Molin (1997) divide os dispositivos de sensoriamento em dois grandes grupos: 
- sensoriamento direto dentre os quais estão os de produtividade (normalmente embarcados em máquinas), como os de umidade de grãos (MOLIN, 1997), os de impacto (medem fluxo mássico), os ópticos e os nucleares (BORGELT et al., 1992; PAGNANO; MAGALHÃES, 2001). Para monitoramento de solo são usados sensores de umidade, de nível de acidez $(\mathrm{pH})$, de textura, de salinidade, de matéria orgânica, de nitrato/nitrogênio. Alguns deles, como 0 sensor de nitrato/nitrogênio, são instalados diretamente nos aplicadores, fornecendo informação para se obter as dosagens ideais (MOLIN, 1997);

- sensoriamento remoto é feito por imagens obtidas por satélites ou fotografias aéreas. Possuem alto custo individual e necessitam de software e mão de obra especializada para interpretação das imagens.

Alguns sensores podem ser associados a um GPS, o qual facilita as condições para se obter mapas da variabilidade espacial; porém, normalmente, para redução de custos, o sensoriamento é feito com poucos sensores que se alternam em alguns poucos pontos, o que resulta em poucas amostragens e o resultado final é obtido por interpolação dos pontos amostrados (MOLIN, 1997).

\subsubsection{Redes de Sensores Sem Fio - RSSFs}

Entre as tecnologias emergentes, uma que poderá permitir o monitoramento e controle das variabilidades espaciais propostos pela Agricultura de Precisão, com menores custos e mais exatidão, são as RSSFs (GONDA; CUGNASCA; CAMILLI, 2005). Camilli (2004) afirma que a tecnologia das RSSFs pode ser utilizada na construção de mapas de informações que, ao serem correlacionados com mapas de colheita, permitem obter as causas da variabilidade da produtividade agrícola em determinados pontos da área de cultivo.

Geralmente, uma RSSF é formada por centenas de pequenos dispositivos autônomos chamados de nós sensores que possuem um transceptor para comunicação sem fio, fonte de energia, unidade de sensoriamento, memória e processador. O componente lógico de um nó sensor é o software que é executado no processador (LANE; CAMPBELL, 2006).

Individualmente, os nós possuem pouca capacidade computacional e de energia; mas, o esforço colaborativo entre os mesmos permite a realização de grandes tarefas 
(CHENG et al., 2006). Os nós sensores formam uma rede sem fio ad hoc que, após um reduzido processamento local, dissemina as informações para um ponto de acesso em um esquema de comunicação multi-hop.

Existem diversos protocolos para comunicação de RSSF e muitos outros estão sendo propostos pelos meios acadêmicos, em especial protocolos para roteamento ou acesso ao meio; porém, um dos mais usados é o ZigBee, padronizado pela ZigBee Alliance que abrange desde o acesso ao meio até as interfaces para as aplicações. A maioria dos protocolos possui um algoritmo de roteamento capaz de trabalhar com um grande número de nós, o que permite a uma RSSF cobrir grandes áreas, sendo adequada para o uso em aplicações agrícolas (CABRINI, 2006).

Com uma RSSF é possível monitorar, em tempo real, a temperatura ambiente, a quantidade de água, os nutrientes do solo, a luminosidade, entre outras variáveis, gerando uma base de dados sólida para que o agricultor possa ajustar a sua estratégia de produtividade a qualquer tempo, desde que se faça uso de sensores adequados ao ambiente e às aplicações.

Uma das vantagens do uso de RSSFs na agricultura é a possibilidade de instalar os sensores em áreas que seriam impraticáveis com outra tecnologia, em especial pela eliminação de cabos e pela grande área de cobertura (ZANG et al., 2006). Pode-se citar outras vantagens como a ausência de cabos, a redução dos custos de mão de obra para a instalação após a semeadura e para a retirada após a colheita. Mesmo assim, o uso das RSSFs tem-se restringido a culturas de alto valor agregado.

Fatores como desconhecimento da tecnologia, a inexistência de produtos comerciais adequados a cada aplicação agrícola e a necessidade de uma engenharia de aplicação têm dificultado a sua disseminação (WANG; ZHANG; WANG, 2006). Soluções pré-formatadas, com indicações de quais seriam os produtos adequados, com manuais de instalação, com a maioria dos problemas de engenharia de aplicação resolvidos poderiam atenuar esta situação. Em especial em implementações tipo “on-the-go", seriam um grande incentivo à popularização das RSSFs na agricultura. 


\subsubsection{Redes de Comunicação Digitais}

Diversas tecnologias de comunicação em rede vêm sendo desenvolvidas e disseminadas nos últimos anos. Porém, poucas podem ser consideradas adequadas ao ambiente agrícola, permitindo o acesso às informações de campo de modo simples e prático, tanto pelas ferramentas de gerenciamento, quanto pelos equipamentos automatizados usados no campo (SIGRIMIS et al., 1999). Entre elas destacam-se Ethernet, Wi-Fi e a ISO 11783, cujas principais características são apresentadas na sequência.

a) Ethernet: vem se consolidando como a rede preferida nas áreas de gerenciamento e supervisão, com uso praticamente obrigatório na automação de escritórios. Segundo Moreiras e Cugnasca (2003), seu amplo uso na interligação de computadores pessoais reduziu preços de componentes e gerou um aumento no número de profissionais especializados. Estes fatores levaram a Ethernet a áreas para qual não fora inicialmente concebida, como a automação industrial (DECOTIGNIE, 2001). Antes ela era tida como muito complexa e com alto overhead, devido ao uso do protocolo TCP/IP. Isso deixou de ser um problema, pois existem fabricantes de microcontroladores que oferecem dispositivos capazes de implementação simples e barata deste protocolo, entre os quais são citados a Zilog, com o processador eZ80 (ZILOG, 2007) e a Dallas, com o DS80C400 (DALLAS, 2009). Atualmente, a Ethernet está presente tanto nos escritórios das fazendas, como em sistemas de gerenciamento e de supervisão e permite acesso tanto à rede mundial quanto a algumas máquinas agrícolas (MOREIRAS; CUGNASCA, 2003).

b) Wi-Fi: é uma variação da rede Ethernet, de uso sem fio. Vem sendo considerado o sistema ideal para comunicação de dados entre dispositivos que podem se deslocar dentro de uma área relativamente pequena. Isso tem levado a um grande número de aplicações nas áreas industriais, serviços e logística. Seu baixo alcance limita seu uso em máquinas agrícolas para simples carregamento de dados nos computadores da unidade agrícola, ainda que de modo eficiente (SZILAGYI; HERDON, 2006). Porém, diversos projetos na área agrícola foram desenvolvidos utilizando equipamentos como os Personal Digital Assistants (PDA) em redes que empregam tecnologia Wi-Fi. Como exemplo, tem-se o projeto de McKinion et al. (2003) que usa 
a versão industrial da norma IEEE 802.11, permitindo alcançar uma cobertura de até $90 \%$ de uma unidade de produção agrícola de 650 hectares.

c) ISO 11783: é uma norma de comunicação desenvolvida para ser embarcada em máquinas agrícolas, em especial em um trator e nos seus implementos. Enquanto o trator fornece a potência em quase todos estes processos, os implementos possuem aplicações específicas, existindo muitas variações no conjunto trator/implemento. Para execução de suas tarefas, grande parte dos dados coletados em campo está disponível em parte no trator, em parte nos implementos. São informações como velocidade e posição do maquinário em relação ao terreno, quantidade de sementes plantadas, quantidade de adubo depositado, quantidade de insumos aplicados e, até mesmo, eventuais falhas nos implementos ou no trator, entre outras (GUIMARÃES, 2003). No decorrer dos trabalhos, estas informações são coletadas por sensores específicos e são armazenadas num equipamento localizado no próprio trator, de onde são retiradas posteriormente para as devidas análises. Um grande problema é o acesso a todos estes dados, pois as redes de comunicação de dados são normalmente desenvolvidas para um ambiente mais favorável que o das condições de trabalho do trator. Segundo Strauss et al. (1999), uma rede para uso em uma aplicação agrícola requer alguns requisitos mínimos a serem observados, dentre os quais se destacam:

- trabalhar em ambientes móveis, sendo resistente a elevada vibração dos equipamentos;

- ser resistente a situações extremamente nocivas, como as condições climáticas adversas (exposição aos raios solares e à chuva) e à exposição a produtos químicos;

- facilitar a conexão de equipamentos à rede;

- ser imune às interferências eletromagnéticas;

- permitir um cabeamento reduzido.

- ser capaz de transmitir altas taxas de informação, uma vez que os sistemas podem operar com informações em tempo real;

- ter adequada flexibilidade das linhas de comunicação;

- ser capaz de interligar diversos nós, garantindo futuras expansões do sistema;

- ter um gerenciamento da rede descentralizado; 
- ser capaz de detectar e tratar eventuais falhas geradas por problemas em hardware e software ou, interferências externas como as eletromagnéticas.

Dentre os vários protocolos de comunicação serial existentes, destaca-se o padronizado pela família de normas ISO 11783. Este protocolo foi desenvolvido considerando a comunicação entre os equipamentos, tanto do trator quanto do implemento, além da conexão física e elétrica entre ambos (GUIMARÃES, 2003). A norma procura contemplar o maior número de aplicações futuras, tanto as existentes quanto as que possam vir a aparecer (SIGRIMIS et al., 1999). Para isto, ela reúne as principais características das normas adotadas anteriormente pela área agrícola: a DIN9684-LBS (LAV, DIN 9684, 2000); a SAE J1939 (SAE, J1939/2, 2006) (SIGRIMIS et, al., 1999).

"[...] Como o padrão ISO (ISO 11783) é muito extenso e muito complexo para aplicação direta, uma especificação orientada à aplicação foi dele derivado: 0 ISOBUS" (VDMA, ISOBUS, 2003, pag. 1). Este padrão, que contempla as partes principais da norma ISO, foi criado para acelerar a adoção da padronização internacional por alguns setores da indústria de equipamentos agrícolas (VDMA, ISOBUS, 2003, pag. 1). Esta ação vem sendo empreendida pela força-tarefa ISOBUS e pelo seu braço no Brasil: a Força-Tarefa ISOBUS-Brasil, cujos trabalhos estão disponibilizados no site www.isobus.org.br/ft.php. Como o escopo deste trabalho contempla tanto a norma ISO 11783, quanto o padrão ISOBUS, por simplicidade, o termo ISOBUS será usado indistintamente daqui em diante.

\subsection{Comparação entre os Protocolos ISOBUS e ZigBee}

A interconexão proposta neste trabalho tem como seu maior desafio conciliar as diferenças existentes entre os protocolos ISOBUS e o ZigBee. Neste item são apresentadas as principais diferenças existentes entre os dois protocolos, ao comparar a solução que cada um deles oferece para atender suas aplicações. 


\subsubsection{Metodologia de Comparação}

Para comparar os protocolos faz-se uso do modelo de referência ISO/OSI, definido pela International Organization for Standardization (ISO) para conexão de sistemas abertos - Open System Interconection (OSI).

O modelo prevê uma pilha de sete camadas - física, enlace, rede, transporte, seção, apresentação e aplicação - e as funções de cada uma das camadas. Nem todas as camadas estão definidas nas pilhas dos protocolos em questão. Isto significa que para estabelecer uma comunicação efetiva, algumas funções são livres para que o usuário possa defini-las de acordo com a sua aplicação ou possa usar outro protocolo que defina as funções das camadas não definidas ou, até mesmo, possa não implementar as funções destas camadas em sua aplicação.

Devido a essa liberdade, é comum existirem protocolos em que parte das funções sejam definidas por outro. O ISOBUS, por exemplo, faz uso do protocolo Controller Área Network (CAN), padronizado pelas normas ISO 11898 e ISO 11519-1/2, para as camadas físicas e parte da camada de enlace (VOSS, 2008) e define também as funções das camadas de rede e de aplicação, como mostrado na Figura 2-1.

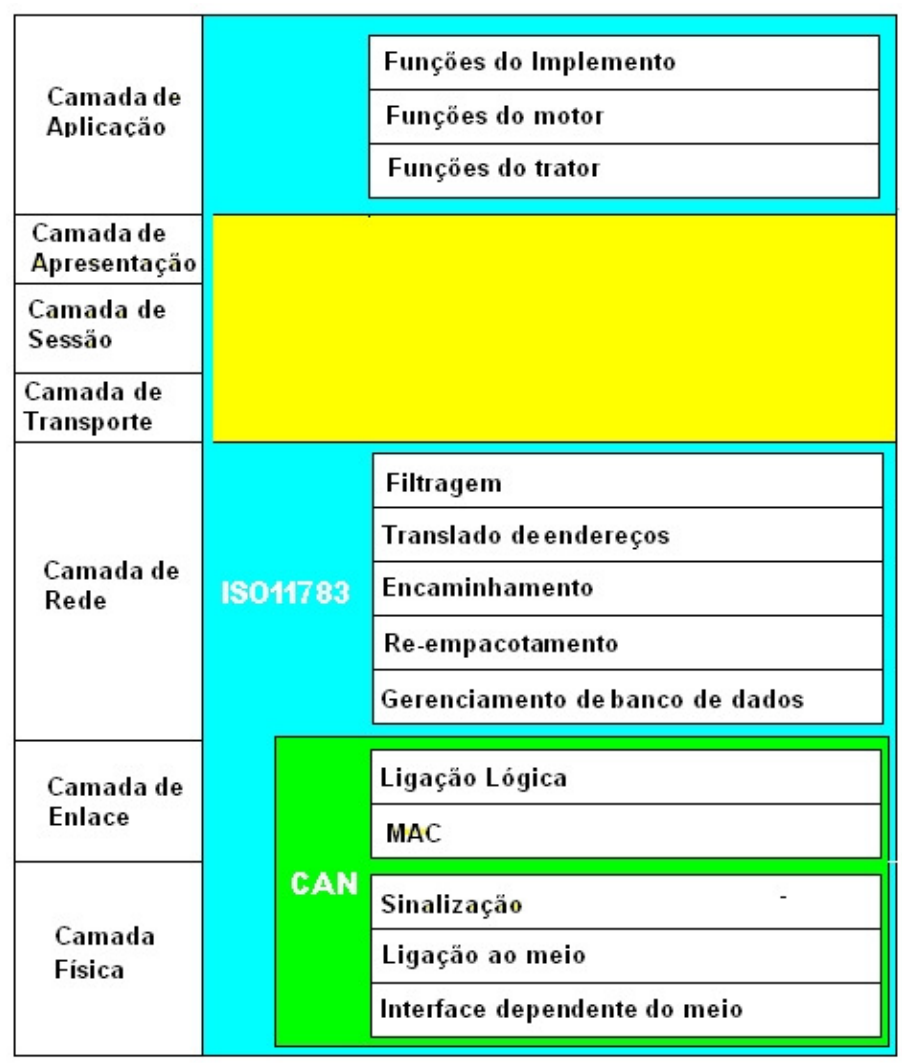

Figura 2-1 - Camadas definidas pelo protocolo ISOBUS (física, enlace, rede e aplicação) segundo o modelo ISO/OSI. 
O padrão ZigBee também é semelhante. Faz uso da norma IEEE 802.15.4 (que define um padrão para comunicação sem fio de baixa velocidade) para as camadas física, enlace e rede e define a camada de aplicação e um framework de ligação entre as camadas de rede e a de aplicação chamado General Operacional Framework (GOF) (HUANG, 2007), como mostra a Figura 2-2.

\begin{tabular}{|c|c|c|c|}
\hline CAMADAS & & SERVIÇOS ISO/OSI & $\begin{array}{l}\text { SERVIÇOS } \\
\text { NÄO ISO/OSI }\end{array}$ \\
\hline \multirow{2}{*}{ Aplicacão } & & Aplicação do Usuário & \\
\hline & & Suporte de aplicaçäo & \\
\hline Apresentaçäo & & & \multirow{3}{*}{\begin{tabular}{l}
\multicolumn{1}{c}{ GOF } \\
Framework \\
Operacional \\
Geral
\end{tabular}} \\
\hline Sessäo & & & \\
\hline \multicolumn{3}{|l|}{ Transporte } & \\
\hline \multirow{5}{*}{ Rede } & \multirow{5}{*}{$\begin{array}{l}\text { Padrão } \\
\text { ZigBee } \\
\text { Alliance }\end{array}$} & Filtragem & \\
\hline & & Translado de endereços & \\
\hline & & Encaminhamento & \\
\hline & & Re-empacotamento & \\
\hline & & Gerenciamento de banco de dados & \\
\hline Enlace & \multirow{4}{*}{$\begin{array}{l}\text { IEEE } \\
802.15 .4\end{array}$} & MAC & \\
\hline \multirow{3}{*}{ Física } & & Sinalizaçäo & \\
\hline & & Ligação ao meio & \\
\hline & & Interface dependente do meio & \\
\hline
\end{tabular}

Figura 2-2 - Camadas definidas pelo protocolo ZigBee (física, enlace, rede, aplicação e o framework de ligação GOF) segundo o modelo ISO/OSI.

Nos próximos itens, os protocolos são comparados camada por camada.

\subsubsection{Camada Física}

O Quadro 2-1 sintetiza as principais diferenças entre as camadas físicas de cada um dos protocolos, as quais são detalhadas em seguida. 


\begin{tabular}{|l|l|l|}
\hline Característica & \multicolumn{1}{|c|}{ ZigBee } & \multicolumn{1}{c|}{ ISOBUS } \\
\hline \hline Meio & Ar (ondas de rádio) & Cabo - par trançado \\
\hline \hline Frames & $\begin{array}{l}\text { Cabeçalho de Sincronização } \\
\text { Cabeçalho da camada física } \\
\text { PSDU - dados/serviços } \\
\text { (até 127 bytes) }\end{array}$ & $\begin{array}{l}\text { Identificador } \\
\text { Controle } \\
\text { Dados (até 8 bytes) } \\
\text { CRC }\end{array}$ \\
\hline \hline Sinalização & Modulação com DSSS & Sinal elétrico entre 1,5V e 3,5V (nominal) \\
\hline \hline Velocidade & até 250 Kbps & 250 Kbps \\
\hline \hline Recursos & Muitos nós & $\begin{array}{l}\text { Poucos nós } \\
\text { Sobreposição de bits } \\
\text { Stuffing bit } \\
\text { Time quantum }\end{array}$ \\
& O-QPSK & iime \\
\hline
\end{tabular}

Quadro 2-1 - Síntese das principais diferenças da Camada Física entre os padrões ZigBee e ISOBUS.

\subsubsection{O Meio Físico}

As primeiras diferenças entre os protocolos ISOBUS e o ZigBee estão no meio físico. Enquanto o primeiro usa o CAN 2.0B, que define o transporte de informações por meio de sinais elétricos em um cabo, o ZigBee faz uso de ondas de rádio por meio do ar.

O cabo elétrico padronizado pela norma CAN é um duplo par trançado de condutores, sendo dois para dados (CAN-H e CAN-L) e dois para alimentação dos dispositivos da rede, de modo a reduzir interferências eletromagnéticas. A norma padroniza as especificações do cabo, das conexões e das derivações, além dos possíveis comprimentos (ISO 11898-2, 2003).

O sinal elétrico de dados é um trem de bits, com os níveis lógicos chamados de "dominante" (CAN-H > 3,5 V e CAN-L < 1,5 V) e "recessivo" (CAN-H e CAN-L = 2,5

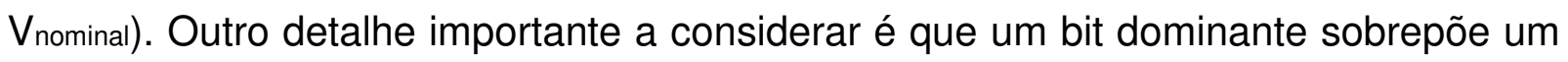
possível bit recessivo de outro dispositivo (ISO 11898-2, 2003).

Essa característica física é importante para que o CAN possa definir o acesso ao meio, descrito no Item 2.2.2.2.

O ZigBee faz uso da norma IEEE 802.15.4 que define as características físicas do transceptor como frequências de trabalho, modulação, alcance e potência. Define 
também dois serviços para a camada física: data service (transmissão e recepção de pacotes) e management service (seleção de canais, detecção do nível de energia, ativação/desativação-dorme/acorda).

O transceptor deve operar em métodos Direct Sequence Spread Spectrum (DSSS) que possibilita um baixo consumo de energia e trabalha em uma das seguintes bandas: Industrial, Scientific, Medical (ISM), com um canal a $868 \mathrm{MHz}$ ou com 10 canais a $915 \mathrm{MHz}$ e ISM1 com 16 canais a 2,4 GHz e com modulações tipo Quadrature Phase-Shift Keying (QPSK) e Offset Quadrature Phase-Shift Keying (OQPSK) (SHUAIB et al., 2003).

A modulação QPSK substitui cada par de bits de dado pelo sinal de uma portadora defasada, em uma de quatro possíveis fases, de acordo com o par de bits a ser substituído. Neste tipo de modulação podem existir transições de fase de até $+/-180^{\circ}$, enquanto na modulação O-QPSK são duas transições de +/-90․ Com a modulação O-QPSK reduz-se possíveis interferências entre os canais causadas pelas transições bruscas de fase (PIMENTEL, 2007).

O método DSSS substitui cada bit por uma sequência de 11 bits gerada pela multiplicação do bit por um código chamado de chipping code; por consequência, aumenta a frequência do sinal que, após modulado, irá gerar um sinal com uma banda mais larga. Esse processo é chamado de espalhamento espectral. Com o uso do chipping code é possível aumentar a imunidade com relação a ruídos, a interferências, a distorções devido a multipercursos e a desvanecimentos de banda estreita. Também é possível que vários usuários possam compartilhar a mesma banda de frequência e a "criptografação" dos sinais (ONDREJ et al., 2006).

A norma IEEE 802.15.11 possibilita velocidades de até $250 \mathrm{Kbps}$ e topologias tipo estrela, cluster tree ou malha (mesh), as quais são detalhadas no Item 2.2.4.1. Pela sua facilidade de espalhamento da informação por todo o ar, o ZigBee possibilita instalação física com menor custo e com menos mão de obra especializada do que as redes cabeadas (GESSINGER; HENNING, 2005), enquanto a ISOBUS requer todo um projeto para a sua instalação, com uso de mão de obra especializada e um custo significativo em cabeamentos e conexões. Outra diferença importante são as limitações que as conexões móveis impõem sobre o cabeamento, caso do ISOBUS. 
Entretanto, a comunicação com o ZigBee pode sofrer com obstáculos que possam aparecer em seu caminho. Ainda que possua um mecanismo de troca de rota, detalhado nos próximos itens, isto nem sempre é possível, em especial quando se tem uma rede com um número limitado de nós.

\subsubsection{Codificação dos Bits}

Neste item é feita uma apresentação geral dos frames de ambos os protocolos. Os frames ISOBUS seguem o padrão CAN estendido ou com 29 bits de identificação (CAN 2.0B) que co-existe com o padrão antigo de 11 bits (CAN 2.0A). A Figura 2-3 mostra ambos os padrões, destacando-se os seguintes campos: identificador 1 e 2; controle; data; CRC; ack slot (separação) (SOUSA, 2002).

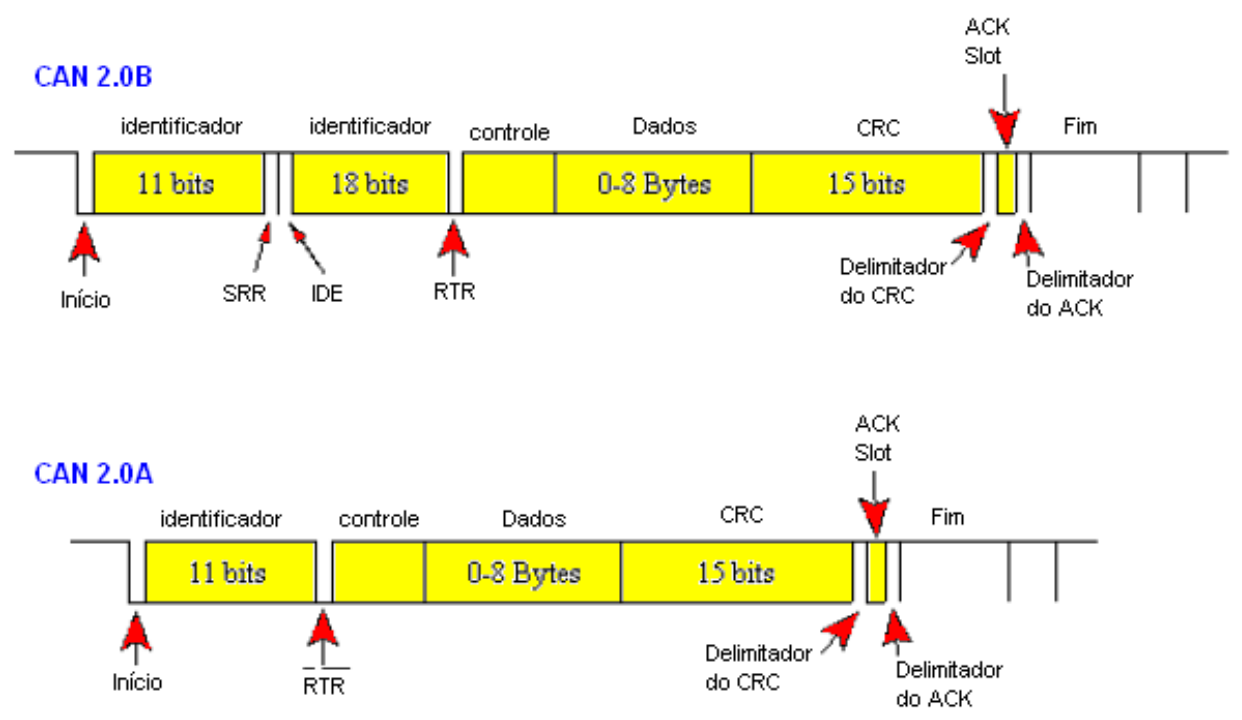

Figura 2-3 - Campos dos frames CAN 2.0A e 2.0B (Adaptado de SOUSA, 2002).

Além dos campos citados, Sousa, (2002) identifica os seguintes bits no frame do CAN:

- SOF: bit de início do frame;

- RTR: requisição de transmissão remota;

- IDE: presença de identificador estendido;

- SRR: requisição remota substituta.

O receptor, ao receber um bit do frame, não sabe se este é do padrão 2.0B ou 2.0A até chegar o bit IDE. Caso este exista, ele passa a esperar os demais bits do identificador, totalizando 29 bits; caso contrário, assume que o identificador é de 11 
bits e que os próximos bits pertencem ao campo de controle. Um recurso usado pelo CAN para reduzir os problemas de sincronização é o stuffing bit (SOUSA, 2002). Este bit é incluído no frame todas as vezes que se tem uma sequência de 5 bits iguais. $O$ stuffing bit possui a polaridade inversa da sequência de bits repetidos. Também para ajudar na sincronização dos bits, o tempo de cada bit é dividido em quatro campos e, cada campo, em uma quantidade de uma unidade temporal chamada time quantum (tq). Os campos de um bit são:

- sincronizador: possui um único tq e determina a velocidade do frame, pois possui tamanho fixo;

- propagação: compensa atrasos causados pelo meio físico, incluindo tempo de transmissão, propagação do sinal no barramento e tempo para recepção do dado. Possui tamanho de 1 até 8 tq;

- $\underline{\text { fase 1: }}$ intervalo em que deve ser feita a leitura do valor do bit. Também pode ter tamanho de 1 até 8 tq;

- fase 2: transmissões ocorrerão após este segmento. Pode ser configurado de 1 até 8 tq.

O frame ZigBee é dividido em três campos, definidos pela norma 802.15.4: cabeçalho de sincronização; cabeçalho da camada física e unidade de dados e serviços. Os dois primeiros campos são tratados pela camada física, enquanto os demais pela camada MAC, como mostrado na Figura 2-4. O cabeçalho de sincronização é composto por dois subcampos:

- sequência de preâmbulo com 4 bytes, possibilita ao receptor reconhecer a sequência de bytes do frame (sincronização);

- byte delimitador de inicio do frame.

Logo após a sincronização tem-se um byte que indica o comprimento do frame, limitado a 127 bytes. 
Total 128 bits

\begin{tabular}{|c|c|c|c|c|}
\hline 4 octetos & 1 byte & \multicolumn{2}{|c|}{ 1byte } & Variável \\
\hline preâmbulo & $\begin{array}{c}\text { Delimitador de início } \\
\text { de frame }\end{array}$ & $\begin{array}{c}\text { Comprimento do } \\
\text { frame }\end{array}$ & Reservado 1 bit & PSDU \\
\hline \multicolumn{2}{|c|}{ Cabeçalho de Sincronização } & Cabeçalho da Camada Física & $\begin{array}{c}\text { Dados e } \\
\text { serviços }\end{array}$ \\
\hline
\end{tabular}

Figura 2-4 - Campos do frame ZigBee, adaptado de Farahani (2008).

\subsubsection{Comparação entre as Camadas de Enlace}

A camada de enlace pode ser dividida em duas outras, a camada Media Access Control (MAC) e a Link Logical Control (LLC), como mostrado no Quadro 2-2

\begin{tabular}{|l|l|l|}
\hline \multicolumn{1}{|c|}{ ZigBee } & \multicolumn{1}{c|}{ ISOBUS } \\
\hline MAC & $\begin{array}{l}\text { Non-beacon (CSMA_CA) } \\
\text { Beacon (superframes) } \\
\text { Segurança }\end{array}$ & CSMA-CD/NDA \\
\hline LLC & Acesso direto & $\begin{array}{l}\text { Filtragem dos identificadores } \\
\text { (PDU1 e PDU2) }\end{array}$ \\
$\begin{array}{l}\text { Reconhecimento dos campos } \\
\text { Tratamento de erros }\end{array}$ \\
\hline
\end{tabular}

Quadro 2-2.- Síntese das principais diferenças da Camada de Enlace entre os padrões ZigBee e ISOBUS.

\subsubsection{A Camada Media Access Control (MAC)}

Ao definir as condições para que um dispositivo possa acessar o meio físico, a Camada MAC:

- determina os tipos de dispositivos permitidos na rede;

- define a estrutura de frames admissível;

- determina a sincronização e transmissão;

- gerencia o consumo de energia.

No ZigBee, a comunicação é permitida de dois modos: modo non-beacon que faz uso do mecanismo de prevenção de colisão Carrier Sense Multiple Access - Collision Avoidance (CSMA-CA) e modo beacon, no qual é enviado um frame chamado beacon em intervalos de tempo para dividir o tempo de acesso ao meio de cada 
dispositivo. No mecanismo CSMA-CA todos os dispositivos permanecem em escuta. Ao detectarem a presença de uma portadora (de algum dispositivo que está transmitindo), bloqueiam a própria transmissão. Como todo dispositivo antes de transmitir disponibiliza a informação na rede, de por quanto tempo irá usar a rede, os dispositivos somente tentam transmitir após este tempo, evitando a colisão. Este mecanismo reduz muito os problemas de colisão (RUBINSTEIN; REZENDE, 2003).

No modo beacon tem-se um coordenador da rede que transmite periodicamente 0 frame beacon, que é utilizado pelos dispositivos para a sincronização e determinação do envio e recebimento das mensagens dos dispositivos a um coordenador. Os dados são transmitidos apenas em intervalos definidos, utilizando transferência de dados indireta, ou seja, toda transferência sempre passa pelo coordenador (EADY, 2007). O intervalo entre os beacons é denominado Superframe que, além das trocas normais de dados, possuem slots para dados de dispositivos assíncronos e o mapeamento de dispositivos novos. A camada de aplicação irá definir qual o melhor modo de acesso ao meio: com ou sem os beacons periódicos (EADY, 2007).

Dois serviços são oferecidos para gerenciar os mecanismos citados: O MAC Layer Management Entity (MLME) e o MAC Common Part Layer (MCPS). O MLME gerencia todos os comandos, respostas, indicações e confirmações usadas para gerenciar uma unidade 802.15.4. O MCPS, por sua vez, trata os comandos relacionados aos dados, tais como requisição, indicação e confirmação de dados (ATMEL, 2006).

O sinal do transmissor se espalha por toda uma região, estando mais suscetível a problemas de segurança; por isto, os recursos de segurança da rede ZigBee, provenientes da IEEE 802.15.4, são tratados diretamente na camada MAC e são uma simplificação do algoritmo de roteamento Ad hoc On-demand Distance Vector (AODV) (ERGEN, 2004). As funções de segurança implementadas na camada MAC são:

- controlar o acesso - apenas os dispositivos listados podem acessar a rede;

- criptografar dados - usa uma chave simétrica de 128 bits;

- garantir a integridade do frame;

- rejeitar frames que estejam fora da sequência. 
Apesar do processamento de segurança ser feito na camada MAC, as camadas superiores são as que o controlam, ajustam as chaves de criptografia e determinam os níveis de segurança que são usados. Para isto, a camada MAC transmite (ou recebe) um frame, verifica o destino (a fonte do frame), recupera a chave associada com esse destino (fonte) e, então, processa o frame com auxílio da chave. $O$ cabeçalho do frame MAC possui um bit que especifica se a segurança para o frame está habilitada ou não.

O CAN usa exclusivamente o mecanismo Carrier Sense Multiple Access - Collision Detected with Non-Destrutive Arbitration (CSMA-CD/NDA) (GUIMARÃES; SARAIVA, 2002). Como no CSMA-CA usado pelo ZigBee, no CSMA-CD os dispositivos só tentam acessar o meio quando este não está sendo usado. Porém, enquanto 0 CSMA-CA tenta evitar a ocorrência de colisão, impedindo que dois ou mais dispositivos tentem acessar ao mesmo tempo o meio físico, o CSMA-CD permite que as colisões ocorram, caso em que é feita uma nova tentativa de acesso, visto que a colisão destrói os frames.

O CSMA-CD/NDA também permite a ocorrência da colisão; mas, a mensagem prioritária sobrevive no meio físico, eliminando a necessidade de repetir o frame. Isto ocorre pelas características físicas do sinal elétrico em que um bit dominante pode sobrepor um recessivo. O mecanismo é o seguinte: um dispositivo CAN, ao verificar que a rede está disponível, inicia o envio dos bits do seu frame. Quando envia um bit recessivo e ele não sobrevive, subentende que foi sobreposto por um dominante de outro dispositivo que está tentando acessar o meio ao mesmo tempo. Neste caso, ele cancela a transmissão e aguarda a rede ficar desocupada para tentar novamente, enquanto o outro dispositivo continua com o seu frame, pois tem maior prioridade. $\mathrm{Ou}$ seja, como os primeiros bits a serem enviados são sempre do campo identificador, é possível priorizar o acesso ao meio para os frames que comecem com a maior sequência de bits dominantes.

Kato et al. (1994) demonstram que em aplicações veiculares o volume de tráfego na rede a 1 Mbps pode dobrar quando se faz uso do mecanismo CSMA-CD/NDA. 


\subsubsection{A Camada Link Logical Control (LLC)}

O Logical Link Control (LLC) é uma subcamada da camada de enlace que executa a multiplexação dos protocolos da camada MAC, controla o fluxo de dados, executa os mecanismos de detecções, realiza as retransmissões solicitadas e gerencia possíveis erros. A norma IEEE 802.15.4, entretanto, propõe que o acesso ao LLC seja executado por um serviço específico chamado de Service Specific Convergence Sublayer (SSCS) ou ainda que o LLC seja opcional, caso em que a subcamada MAC acessa diretamente a camada de rede, situação esta assumida pelo ZigBee.

O LLC do CAN confere os identificadores dos frames recebidos da subcamada MAC, rejeitando os que não estão configurados para este receptor. Também pode executar tarefas de validação dos dados e o reconhecimento dos tipos e campos dos frames. Enquanto o ZigBee usa os seguintes quatro tipos de frames: de dados; ACK; de comando MAC; e beacon, o CAN usa o de dados, para requisição de dados, para propagação de erros, e o de mensagens de notificação de sobrecarga.

O frame CAN pode ter dois tipos de identificadores: Protocol Data Unit 1 e 2, (PDU1 e PDU2, respectivamente), os quais fornecem as seguintes variáveis, ilustradas na Figura 2-5:

- Número do Parâmetro de Grupo - Parameter Group Number (PGN) determina a que tipos de variáveis ou comandos a mensagem se refere;

- Endereço de Destino - Destination Address (DA) - fornece o endereço específico do dispositivo de destino para a mensagem;

- Endereço de Origem - Source Address (SA) - determina o dispositivo que gerou a mensagem.

O formato PDU1 é usado para comunicação ponto a ponto, em que o número do parâmetro é de 8 bits e possui intervalo de 0 a 239. Fornece um endereço de destino específico, também de 8 bits, com intervalo de 0 a 255. O formato PDU2 é usado para comunicação em broadcasting e possui o número do parâmetro de grupo de 16 bits, variando de 61.440 a 65.535 . 


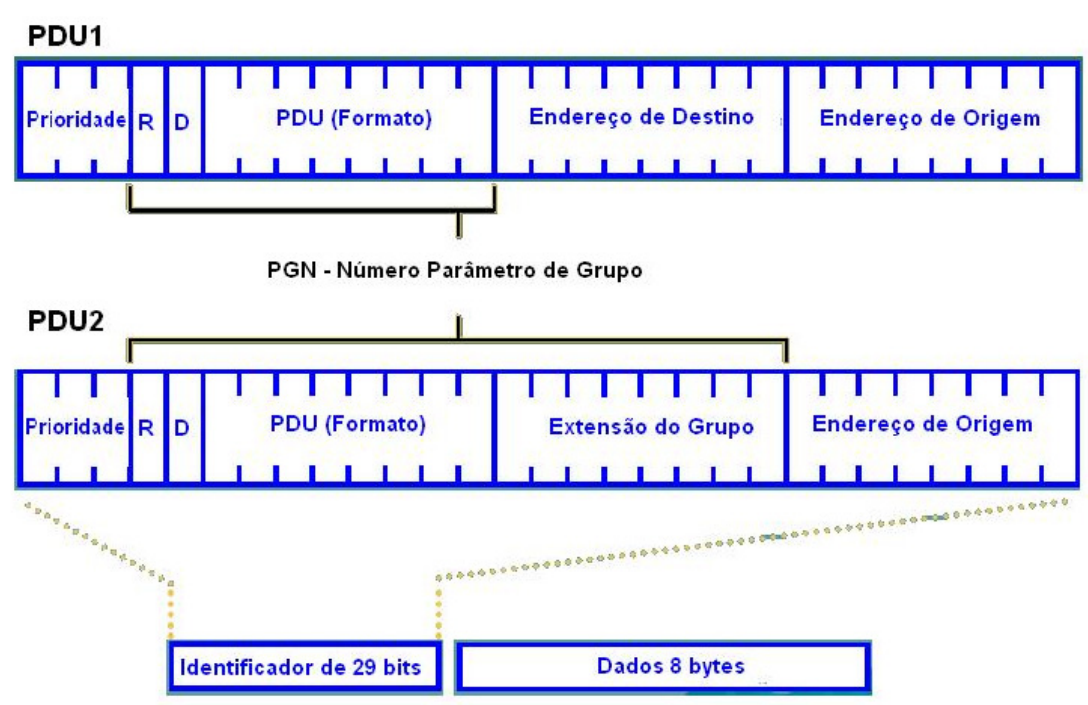

Figura 2-5 - Principais elementos dos Identificadores ISOBUS. Adaptado de Inamasu e Sousa (2004).

Outra atividade do LLC no CAN é o tratamento de erros. O CAN possui um sistema muito confiável de tratamento de erros, em que todos os erros globais ao sistema e todos os erros locais ao transmissor são detectáveis. Em uma mensagem pode-se ter até cinco erros distribuídos aleatoriamente; rajadas de erros com comprimento máximo de quinze bits ou de tamanho ímpar, que serão detectáveis no CAN. São quatro os tipos de erros detectáveis: de Bit; de codificação; no campo ACK; no barramento. O CAN também define contadores de erros de transmissão ou de recepção para permitir a rejeição de elementos que estejam constantemente em falha (SOUSA, 2002).

\subsubsection{Comparação entre as Camadas de Rede}

A camada de rede estabelece as relações com as sub-redes, definindo como é o endereçamento dos pacotes, a conversão de endereços lógicos e físicos, a determinação da rota, o encaminhamento, as interconexões da rede, o tratamento dos erros, a fragmentação dos dados e o sequenciamento dos pacotes. O Quadro 2-3 mostra como os protocolos ZigBee e ISOBUS trabalham a camada de rede. 


\begin{tabular}{|l|l|l|}
\hline & \multicolumn{1}{|c|}{ ZigBee } & \multicolumn{1}{c|}{ ISOBUS } \\
\hline \hline Topologia & $\begin{array}{l}\text { Estrela } \\
\text { mesh } \\
\text { Cluster Tree }\end{array}$ & $\begin{array}{l}\text { Barramento do trator } \\
\text { Barramento do implemento } \\
\text { Barramento do implemento } \\
\text { secundário }\end{array}$ \\
\hline \hline Roteamento & Acesso direto & $\begin{array}{l}\text { Filtragem dos identificadores } \\
\text { (PDU1 e PDU2) } \\
\text { Reconhecimento dos campos } \\
\text { Tratamento de erros }\end{array}$ \\
\hline \hline Endereçamento & MAC-ID (64 bits) & $\begin{array}{l}\text { Não Configurável; } \\
\text { Configurável em Manual; } \\
\text { Configurável por Comando; } \\
\text { Autoconfigurável }\end{array}$ \\
\hline
\end{tabular}

Quadro 2-3.- Síntese das principais diferenças da Camada de Rede entre os padrões ZigBee e ISOBUS.

\subsubsection{Topologias}

Para definir as topologias aceitas pelo ZigBee, o padrão estabelece três tipos de dispositivos:

- Network Coordinator (NC) - possui conhecimento de toda rede;

- Full Function Device (FFD) - possui todas as funções 802.15 .4 e pode operar como NC;

- Reduced Function Device (RFD) - não possui todas as funções implementadas.

Segundo Farahani (2008), Reduced Function Device (RFD) são destinados a áreas simplificadas, como dispositivos finais, ligados sempre ao final da rede e, portanto, comunicam-se apenas com dispositivos de função completa, podendo ser implementados em microcontroladores com recursos computacionais limitados, enquanto os demais (NC e FFD) são destinados a funções mais complexas e ao gerenciamento da rede.

As topologias aceitas pelo ZigBee, ilustradas na Figura 2-6, são:

- Estrela - um nó NC comunica-se diretamente com todos os demais nós RFD ou FFD, os quais são chamados de nós terminais. A coordenação e a inicialização da rede são feitas pelo nó NC. 
- Mesh - existe um único nó coordenador (NC) e os frames podem pular de nó em nó, antes de chegar ao coordenador. Os nós intermediários são chamados de nós roteadores (FFD); porém, não é necessário que a informação passe por eles. Os roteadores têm liberdade de estabelecer e alterar a rota.

- Cluster Tree - trabalha de modo semelhante ao modo mesh; porém, com a formação de cluster (conjunto de nós que trabalham como um único nó). Cada cluster possui o seu nó roteador e cada um dos nós terminais troca dados apenas com o seu nó roteador. Existe também um nó coordenador que recebe os dados dos nós roteadores, podendo também formar seu próprio cluster.

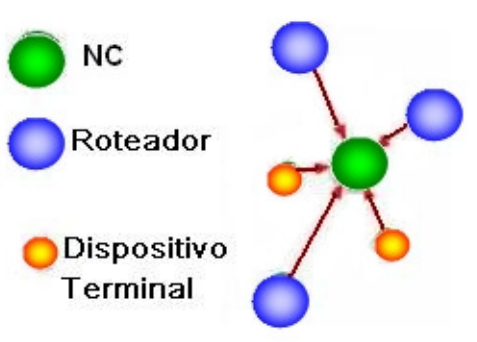

Estrela

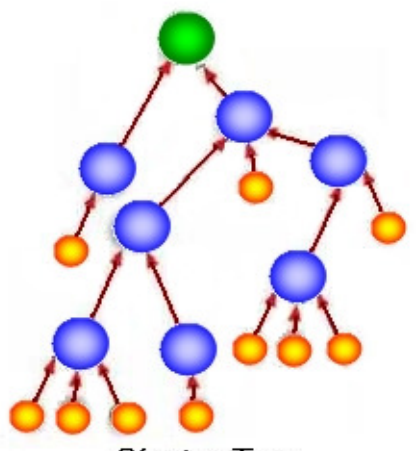

C/uster Tree

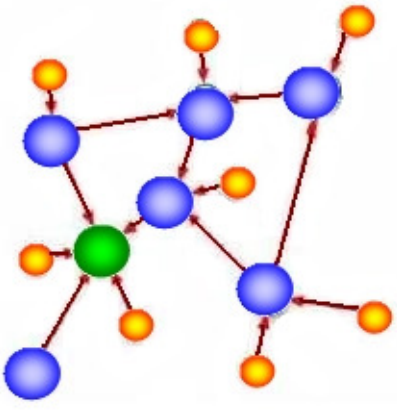

Mesh

Figura 2-6 - Topologias definidas pelo padrão ZigBee. (Adaptado de Nascimento, 2007).

Segundo Koubaa, Cunha e Alves (2007), com a topologia cluster tree é possível realizar uma estrutura que pode ser ampliada para a obtenção de melhor conservação de energia na rede de sensores.

O ISOBUS, por sua vez, usa sempre a topologia de barramento, a qual está presente nos três tipos de sub-redes definidos pela norma: do trator; do implemento e do implemento secundário. Os barramentos são interconectados por dispositivos chamados de Network Interconection Unit (NIU). Os elementos destas 3 sub-redes são classificados em cinco tipos:

- Electronic Control Unit (ECU) - é onde ocorre o processamento das informações. Entre as ECU mais comuns estão: do motor; da transmissão; do freio; do gerenciador de tarefas; de sensores; do GPS; do controlador de implementos dos atuadores; 
- Virtual Terminal (VT) - é uma ECU usada como interface padronizada para o operador;

- Transductor Digital Intelligent (TDI) - são os sensores e atuadores inteligentes;

- Terminal Bus Conector (TBC) - são as interconexões elétricas que permitem que fisicamente seja possível alterar o implemento em função da aplicação;

- Network Interconection Unit (NIU) - executam funções de repetidores, bridges, roteadores e gateways.

\subsubsection{Roteamento}

O ZigBee usa um complexo mecanismo de formação de rotas (LEE; KIN; PARK, 2007). Para isto, o nó coordenador armazena informações tais como: chaves seguras; número máximo de filhos dos nós roteadores; número máximo de roteadores filhos de um nó pai; e profundidade da rede.

Os nós roteadores contêm informações apenas sobre o seu pai (para quem passa os dados) e os seus filhos (de quem recebe os dados). A rede é formada automaticamente e o disparo da função de formação de rota é uma atribuição exclusiva do nó coordenador. Este faz uso de todos os seus canais para procurar dispositivos ZigBee que não estão associados a outro nó coordenador. Cria, então, uma comunicação com eles e solicita que os dispositivos encontrados se associem à rede, dando um identificador a cada um.

Os dispositivos usam um mecanismo chamado "inundação" para que as informações passem de um nó para outro até chegar ao nó coordenador. O mecanismo de inundação consiste em repassar em broadcasting os frames recebidos em broadcasting. Caso o frame retorne a ele mesmo, é ignorado. As comunicações que não usam o mecanismo de inundação seguem - de salto em salto - de um nó para outro, segundo uma rota pré-estabelecida. Os nós coordenadores e os roteadores podem ter a capacidade de estabelecer uma rota em conjunto. Para isto, são montadas tabelas internas a estes nós em que o nó origem é associado ao nó destino imediato (próximo salto), ou seja, quando um nó recebe um frame de um filho, ele consulta a tabela interna para saber quem é o pai e repassa o frame a este. As rotas são alteradas em intervalos de tempos pré-configurados. Cada ramo pode chegar a 264 nós e, usando endereçamento local, podem ser obtidos até 65.000 nós. 
Conforme Farahani (2008), este mecanismo permite que, na ocorrência de falha de comunicação com algum elemento da rota usada atualmente, a rota possa ser reestabelecida por meio de outro elemento roteador.

Como o ISOBUS usa a topologia de barramento, não existe a necessidade de mecanismos complexos de roteamento, exceto entre as sub-redes (rede do trator, rede de implemento e de implemento secundário). Para a interconexão entre os barramentos o ISOBUS faz uso das NIUs que, segundo Guimarães (2003), possuem as seguintes funções:

- Encaminhamento de mensagens: a mensagem é apenas repassada de uma rede para outra;

- Filtragem de mensagens: consiste em selecionar as mensagens que devem ser encaminhadas por meio de filtros pré-configurados;

- Translação de endereço: permite que um dispositivo possa ter endereços diferentes em função da sub-rede. Faz uso de uma tabela para converter;

- Remontagem de mensagem: consiste em alterar o campo de dados de uma mensagem, adicionando-se outros dados antes de transferi-la de uma subrede a outra;

- Administração de base de dados: consiste num conjunto padrão de regras para que se possa acessar e configurar as bases de dados das próprias NIUs.

Um tipo de sub-rede que pode ser incluída, prevista pela norma ISOBUS, é uma rede Fieldbus externa. Para esta sub-rede a norma prevê o uso de uma NIU especial para troca de mensagens entre o ISOBUS e a rede externa. Outra NIU especial é a NIU que interconecta a sub-rede do trator com a sub-rede de implemento, devendo estar implementada na ECU do trator. A norma também prevê uma ECU de Diagnóstico ou de Desenvolvimento (conectada ao barramento, com propósito de monitorar e analisar a rede a que está conectada).

\subsubsection{Endereçamento}

Como anteriormente salientado, o nó coordenador do ZigBee estabelece um canal de comunicação e um endereço de identificação com os dispositivos cujos rádios estejam ao alcance do rádio do coordenador e vice-versa. Este endereço de identificação é chamado de Personal Area Network Identifier (PAN-ID). Então, os dispositivos tentam se conectar à rede acessando o coordenador da PAN, por meio 
do mesmo canal utilizado pelo nó coordenador (FARAHANI, 2008). Os dispositivos presentes em uma rede ZigBee possuem duas formas de endereçamento:

- um endereço MAC de 64 bits, único para cada dispositivo no mundo;

- um endereço dinâmico de 16 bits, usado para identificar o nó dentro de uma rede, estabelecido pelo nó coordenador.

O ISOBUS, por sua vez, atribui um endereço a cada uma das ECU. Para isto, a norma define uma estrutura de campo de dados de mensagem denominada NAME. Esta estrutura possui a função de prover uma descrição funcional de uma ECU para outra e fornecer um valor numérico para o processo de anúncio e de disputa de endereço de origem durante a inicialização de uma ECU. No processo de inicialização ocorre troca de informações entre as ECU inicializadas e em operação normal, com a ECU em processo de inicialização. São especificadas quatro formas distintas de configuração de endereços em uma ECU, o que classifica as ECU em:

- de Endereço Não-configurável;

- de Endereço Configurável em Manual;

- de Endereço Configurável por Comando;

- de Endereço Autoconfigurável.

\subsubsection{Interligação com a Camada de Aplicação}

O ZigBee não define as funções das camadas de transporte, seção e apresentação do modelo ISO/OSI. Em seu lugar, cria uma camada de ligação entre a camada de aplicação e as demais, chamada General Operation Framework (GOF) (HUANG, 2007). Esta camada emprega um modelo de objeto para definir métodos, eventos, formato dos dados, comandos e respostas. Define também subendereços, modos de endereçamento e uma descrição dos dispositivos - tipo, fonte de alimentação, modos sleep e se é um nó coordenador.

Esta camada gerencia o consumo de energia ativando o modo sleep do transceptor. Para isto, no modo beacon com topologias cluster tree, mesh ou em redes muito extensas, o GOF determina quando cada um dos dispositivos irá para um estado de baixa atividade e quando irá transmitir ou receber dados, caso tenha alguma coisa para transmitir ou receber; caso contrário, volta ao estado de baixa atividade, 
situação esta que, neste trabalho, será referenciada como estado em que o sensor está "dormindo". Isto ocorre em intervalos pré-configurados que vão de 15 ms a 252 ms. No modo non-beacon, na topologia estrela, os nós - exceto o coordenador estão sempre "dormindo", transmitindo apenas quando ocorre um evento. Neste caso o nó coordenador está sempre "acordado" (não está “dormindo").

O ISOBUS também não implementa as camadas de transporte, seção e apresentação, sendo a ligação da camada de rede feita diretamente com a de aplicação.

\subsubsection{Comparação entre as Camadas de Aplicação}

O padrão ZigBee permite que o usuário construa a sua própria aplicação. Para isto, ele fornece uma interface que conecta esta aplicação às camadas inferiores, chamada Application Interface. A aplicação do usuário é desenvolvida na linguagem NesC, baseada na linguagem C (FLORIDO, 2008). Esta linguagem é desenvolvida a partir de um sistema operacional específico, o TinyOS. Existem outros sistemas operacionais e outras linguagens, assim como, outros protocolos para que se possam desenvolver aplicações para uma RSSF; porém, os anteriormente citados são os mais usados (CABRINI, 2006; LEVIS et al., 2005; BHATTI et al., 2005)

O TinyOS é um sistema operacional orientado a eventos cuja arquitetura é baseada em componentes que permitem uma rápida evolução, respeitando o aspecto modular (LEVIS et al., 2005). É constituído por um conjunto de serviços, interfaces e componentes que implementam os principais serviços de uma RSSF entre os quais:

- gerenciamento do rádio;

- componentes que implementam a pilha ZigBee (a camada MAC, as mensagens e o roteamento);

- interface com vários tipos de sensores;

- temporizadores;

- controle de energia.

O TinyOS fornece também ferramentas como o depurador de código e a interface Java, para fácil integração com softwares de visualização desenvolvidos em Java. 
Segundo Levis e Lee (2003), este sistema oferece, ainda, um protocolo de roteamento compatível com o ZigBee chamado TinyOS Beaconing.

A camada de aplicação do ISOBUS é muito específica e detalhada na norma ISO 11783. Na sequência são apresentados alguns itens, considerados relevantes para o desenvolvimento deste trabalho.

O Terminal Virtual, especificado na Parte 6 da norma, é uma ECU que permite ao operador comunicar-se com o sistema. Ele permite tanto receber dados de todos os dispositivos e visualizá-los na tela, como enviar dados digitados em um teclado ou ativados a partir de um menu. Desta forma, o operador pode: visualizar diferentes tipos de variáveis dos sistemas, das máquinas e dos processos; trocar informações diretamente com uma ECU ou grupos de ECU; receber informações do status do sistema; ser notificado sobre emergências (alarmes); e armazenar dados e configurações. Segundo Landi, Cugnasca e Camilli (2005), a norma adotou nas suas definições a orientação a objetos, o que permite armazená-los em bibliotecas (object pool). São organizados a partir de funções pré-definidas e inerentes a cada tipo de aplicação ou de implementos utilizados e são apresentados sob a forma de ilustrações gráficas, valores numéricos ou gráficos de barras.

Esta norma, na sua Parte 7, padroniza as mensagens entre 0 trator e seus implementos e os formatos das variáveis dos implementos; define grupos de variáveis; determina o formato das PDUs e PGNs para cada mensagem; estabelece o tempo de repetição; e estabelece a prioridade para cada tipo de mensagem.

Processo semelhante tem-se na Parte 8 da norma, voltado às mensagens relativas ao motor do trator. A ECU do trator, além da função gateway, descrita na Seção Camada de Rede, possui a capacidade de classificar as mensagens das ECU conectadas ao barramento e trabalhar apenas com as mensagens pertinentes a essas ECU e, ainda, por meio do Terminal Virtual, informa a classificação ao operador.

Na Parte 10 tem-se a especificação do Controlador de Tarefas. Este equipamento possui uma interface para receber uma lista de tarefas de um sistema de gerenciamento de informação, por meio de um dispositivo de memória não volátil (como cartões de memória, CDs, pen drives, etc.). Estas informações também podem ser recebidas on-line, caso exista uma interface de rádio conectada ao Controlador 
de Tarefas. Landi, Cugnasca e Camilli (2004) afirmam que é possível enviar informações sobre o processo para um Sistema de Gerenciamento de Informações Management Information System - (MIS) ou Farm Management Information System (FMIS) instalado em um computador no escritório da fazenda, destinado a dar apoio à tomada de decisão. As tarefas ativam bibliotecas de funções no Terminal Virtual e, ao comando do operador, são ativadas, podendo também ser disparadas pelo Controlador de Tarefas, em função da posição geográfica fornecida por um GPS (OKSANEN et al, 2005).

O ISOBUS também define os serviços de diagnóstico e de manipulação dos arquivos do Controlador de Tarefas, além de um dicionário de termos. Detalha a ECU de diagnóstico e sua conexão à rede.

Como constatado pelas comparações apresentadas, apesar de ambos os protocolos terem uma estrutura macro semelhante - camadas física, enlace, rede e aplicação as funções são muito diferentes, o que torna impossível uma conexão imediata de um protocolo para outro. O ISOBUS é um padrão em fase de consolidação e aceito pela indústria, visto que diversos equipamentos têm sido lançados com base no ISOBUS (AUERNHAMMER, 2002). O ZigBee ainda está em evolução, uma vez que são poucos os produtos comerciais que o utilizam e em geral destinam-se ao uso acadêmico.

\subsection{Considerações sobre o Capítulo}

Este capítulo procurou mostrar o contexto tecnológico no qual este trabalho esta inserido. Foi dividido em duas partes. Na primeira foram mostradas algumas tecnologias usadas dentro do cenário da Agricultura de Precisão como os Sistemas de Posicionamento Global, os sensores para monitoração do ambiente, e as redes de comunicação, em especial as RSSFs e o ISOBUS. Na segunda parte foram confrontados os padrões ZigBee e ISOBUS, camada por camada.

A partir deste cenário, no capítulo seguinte é feita uma proposta de conexão entre as redes ZigBee e ISOBUS. São apresentadas as possíveis interfaces que serão necessárias criar, para que a conexão entre ambos os protocolos seja viável. 


\section{PROPOSTA DE INTERCONEXÃO ENTRE REDES DO PADRÃO ZIGBEE E ISOBUS}

Neste capítulo apresenta-se uma alternativa de interconexão entre as redes ISOBUS e ZigBee, que permite aos dispositivos ISOBUS terem acesso a informações dos dispositivos ZigBee, em tempo real. Para isto, inicialmente são mostrados os elementos da aplicação importantes de serem resolvidos pela proposta a ser apresentada, os elementos de interconexão disponíveis na literatura, o elemento proposto neste trabalho e as topologias resultantes da interconexão recomendadas para as aplicações abordadas neste trabalho. No final do capítulo são feitas diversas considerações sobre a interconexão proposta.

\subsection{Elementos da Aplicação Considerados na Interconexão}

Uma aplicação típica de Agricultura de Precisão possui três fases: o sensoriamento (coleta de informações) que na aplicação proposta é executado por uma RSSF; o processo de tomada de decisão (comparação com modelos e geração de mapas corretivos); e a atuação (aplicação de corretivos a taxas variáveis). Neste item são apresentados os elementos dessa aplicação que devem ser considerados na interconexão proposta- o sensoriamento na agricultura e as topologias da RSSF.

\subsubsection{Sensoriamento na Agricultura}

Zang (2004) afirma que a RSSF é uma solução promissora para a prospecção de dados (data mining) na Agricultura de Precisão. Molin (1997), por sua vez, afirma que o sensoriamento agrícola, apesar de ter avançado muito nos últimos anos, encontra-se, ainda, em fase experimental, podendo ser dividido em três grupos: (1) remoto - pelo qual as amostras são obtidas e mapeadas a distância e analisadas a posterioris; (2) por amostras - no qual as amostras são retiradas do solo ou da planta, em diversas posições geográficas, mapeadas e analisadas posteriormente; (3) contínuo - no qual os sensores se deslocam continuamente capturando os dados.

As RSSFs não se enquadram em nenhum destes grupos, pois elas recolherem dados de pontos específicos distribuídos no campo, como o fazem os sensores que coletam 
amostras, os quais podem substituir com vantagem o sensoriamento continuo. Os sensores são capazes de fornecer informações, no instante em que o coletor de dados passa pelo local, como também podem montar um breve histórico das medições.

\subsubsection{O Sensoriamento no ISOBUS}

A norma ISOBUS propõe ECU dedicadas a sensoriamentos, conforme mostrado no Capítulo 2. Em geral, os sensores são conectados às portas da ECU por conversores $A / D$, uma vez que o elemento sensor, em geral, gera um sinal analógico que necessita de tratamento para que se torne uma informação válida e padronizada e, somente então, a informação é disponibilizada na rede pela ECU. O tratamento desse sinal pode envolver processos de linearização e conversão de escala que podem ser executados tanto pela ECU, quanto por interfaces acopladas diretamente ao elemento sensor.

Na proposta deste trabalho, os sensores sem fio possuem capacidade computacional para executar o tratamento do sinal; por isto, recomenda-se que este tratamento seja feito diretamente nos sensores sem fio e a informação pronta seja disponibilizada na rede ZigBee. Assim, distribui-se o processamento de modo a tornar o processo mais eficiente.

\subsubsection{Topologias de uma RSSF na Aplicação Proposta}

Este trabalho restringe-se a aplicações em culturas com manejo mecanizado, em que veículos agrícolas possam transitar entre as filas da plantação, que em geral são dispostas em curvas de nível, nos quais os sensores estejam espalhados próximos às ruas. Neste contexto, duas topologias são propostas: os veículos transitam entre as filas simples de sensores (Figura 3-1); e os veículos transitam entre filas múltiplas, formando agrupamentos conhecidos como clusters de sensores (Figura 3-2). 


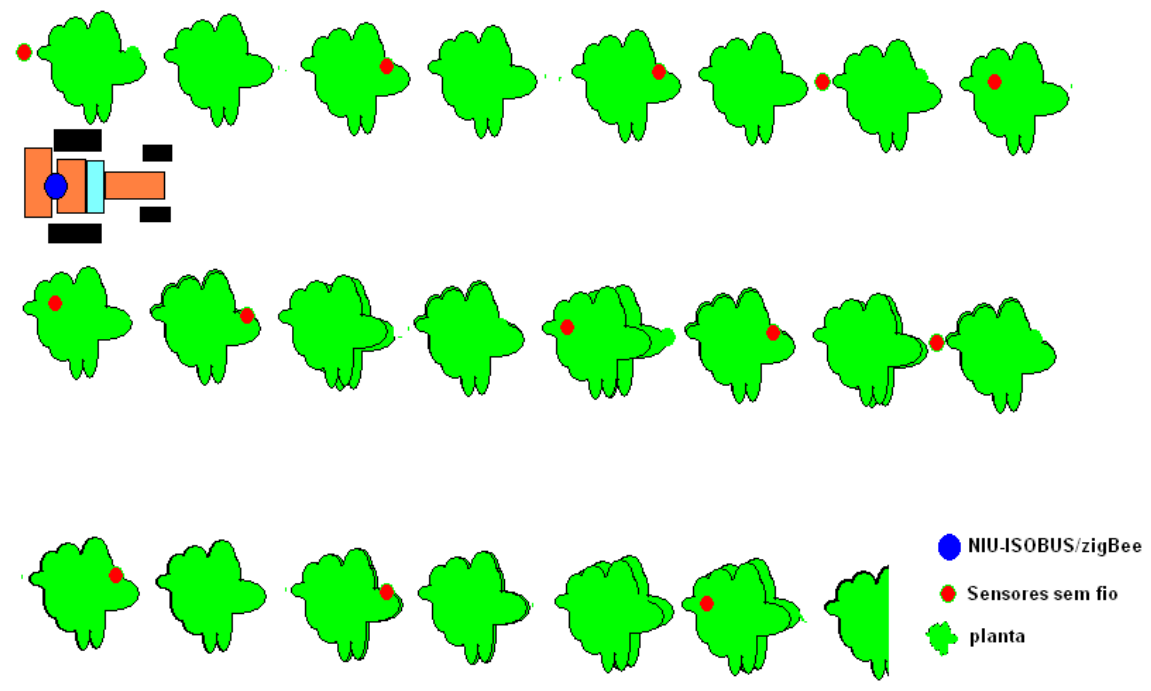

Figura 3-1 - Topologia com sensores posicionados em fila simples

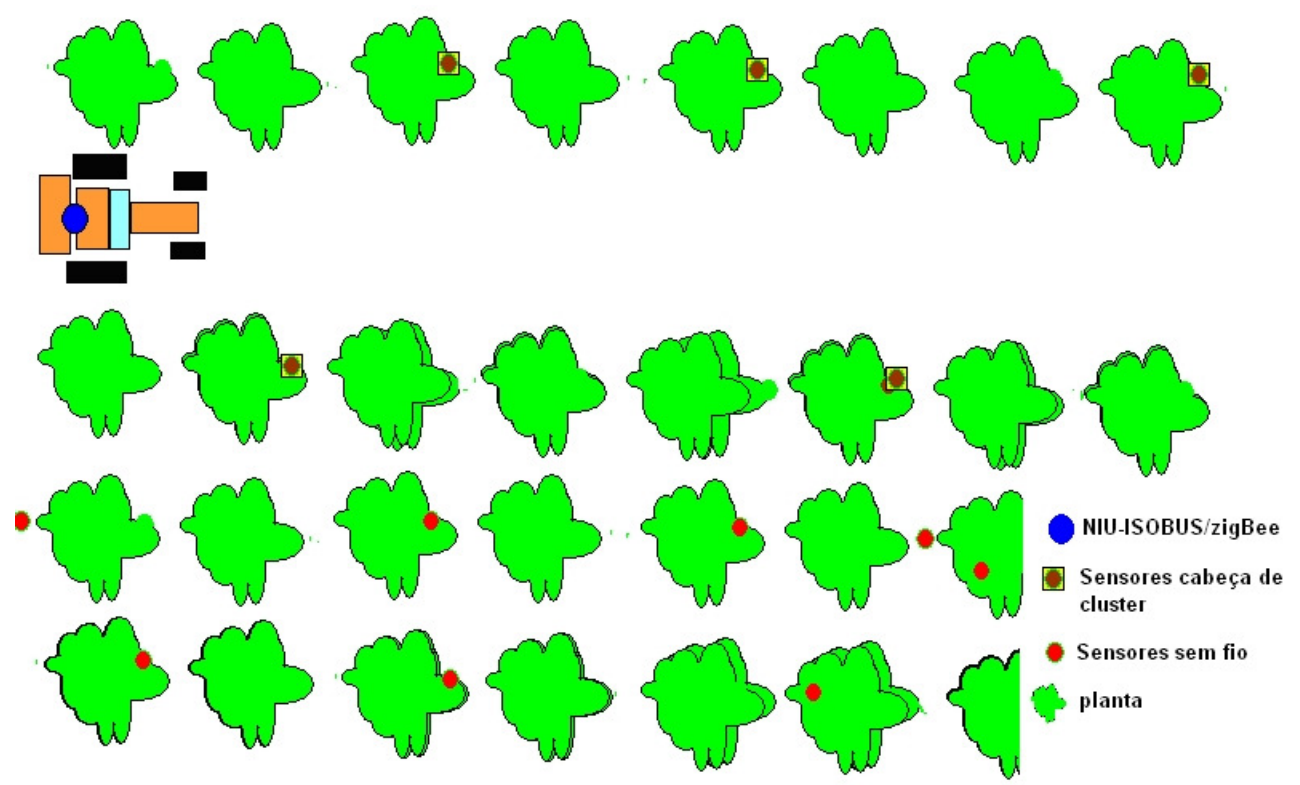

Figura 3-2 - Topologia com sensores posicionados em clusters

$\mathrm{Na}$ segunda topologia em que o veículo recolhe dados de sensores que podem não estar ao seu alcance, é proposta a formação de clusters. Cada cluster tem um nó denominado "nó cabeça de cluster" que recolheria as informações dos demais sensores do cluster e as repassariam ao nó coletor embarcado no veículo (trator). Ou seja, os nós cabeça de cluster teriam um pequeno histórico dos dados dos demais sensores que fazem parte do cluster, possibilitando-se, com isto, que o nó coletor do veículo receba as informações dos sensores que não estão ao seu alcance. 


\subsection{Elementos para Interconexão de Redes}

Neste item são mostradas as alternativas que a tecnologia computacional oferece para resolver a interconexão proposta.

A interconexão entre redes pode ser feita por um ou mais dos seguintes elementos: repetidores, pontes, roteadores e gateway, os quais possuem características específicas que levam a que sejam mais adequados a uma ou outra aplicação. Assim, para que se possa definir qual deles será utilizado serão caracterizados na sequência, fazendo-se, então, a escolha.

\subsubsection{Repetidores}

Em geral, esses elementos são utilizados para conexão de dois segmentos da mesma rede ou de duas redes do mesmo tipo. Os repetidores são empregados para reforçar o sinal, permitindo que a informação chegue a distâncias maiores. Eles podem interligar redes cujos dados trafegam em meios físicos diferentes, mas têm sido recomendados especialmente para aumentar o alcance de redes cujo meio físico seja o ar (como é o caso das redes que seguem o padrão IEEE 802.15.4). Os repetidores, além de permitirem o aumento do alcance do sinal de radiofrequência (RF), também reduzem o consumo de energia, como demonstrado por Rhee e Liu (2002). Esses autores apresentam como inconveniente dos repetidores o tempo gasto para recuperar o sinal, salientando que esse tempo pode comprometer 0 funcionamento da rede quando da conexão sequencial de múltiplos segmentos.

Como mostrado nas comparações no Capítulo 2, as diferenças existentes entre as camadas de enlace e de rede dos protocolos temas deste trabalho inviabilizam uma interconexão com repetidores, uma vez que estes atuam basicamente na camada física do modelo ISO/OSI.

\subsubsection{Pontes}

São comumente usadas para interligar redes que usam o mesmo protocolo na camada MAC. Acredita-se que tenham recursos interessantes para a aplicação proposta, como a capacidade de identificar os endereços de origem de cada subrede e montar tabelas contendo os endereços dos dispositivos de cada uma das sub-redes. Com isto consegue bloquear o envio de frames para sub-redes que não possuam o dispositivo de destino (BANZAL, 2007). As pontes atuam na camada 
MAC, gerenciando o acesso ao meio, e na camada física, porém são inadequadas para este trabalho, pois trabalham com um único protocolo na camada MAC, o que não é o caso da proposta.

\subsubsection{Roteadores}

Permitem a conexão de redes distintas, pois atuam nas camadas físicas e de rede. Identificam, em cada frame, o seu destino. Caso esse destino seja da rede interconectada, o roteador repassa o frame, caso contrário, envia a outro roteador. Os roteadores podem trabalhar com diversos protocolos - de enlace, de meio físico e de rede - além de poderem trabalhar com topologias e arquiteturas diferentes (BOURCIER et al., 2007), sendo uma das possíveis alternativas para a proposta deste trabalho

\subsubsection{Gateways}

Segundo Banzal (2007), os Gateways podem atuar em todas as camadas, desde a camada de aplicação até a física. Podem traduzir informações entre diferentes protocolos, formatos de dados e redes. Em geral, recebem os frames de uma das redes, isolam a informação útil e a empacotam com outro protocolo, transmitindo-as através de uma segunda porta. Durante esse processo, também remontam as informações que foram divididas em função das características do protocolo de recepção, interpretando-as em função da aplicação. Os gateways também podem ser uma alternativa para a proposta deste trabalho.

\subsection{Elemento Proposto para a Interconexão de Redes Padrão ZigBee e ISOBUS}

Como salientado no Capítulo 2, tem-se diferenças significativas em todas as camadas dos protocolos ZigBee e ISOBUS. Devido a essas diferenças, acredita-se que o elemento mais recomendado para a interconexão entre as duas redes seja um gateway que trabalhe a interconexão junto à camada de aplicação. Existem diversas formas de se projetar a interconexão proposta; porém, como colocado no Item 2.2.4.2, O ISOBUS já prevê conexões com outras redes "fieldbus", por meio de dispositivos chamados NIUs. Neste trabalho, propõe-se uma interconexão por meio de uma NIU especialmente projetada para este fim, de modo que de um lado se 
comporte como uma NIU ISOBUS e, de outro, como o nó coordenador de uma rede ZigBee. Na Figura 3-3 tem-se a representação de ambas as redes ISOBUS e ZigBee e em destaque o elemento de interconexão.

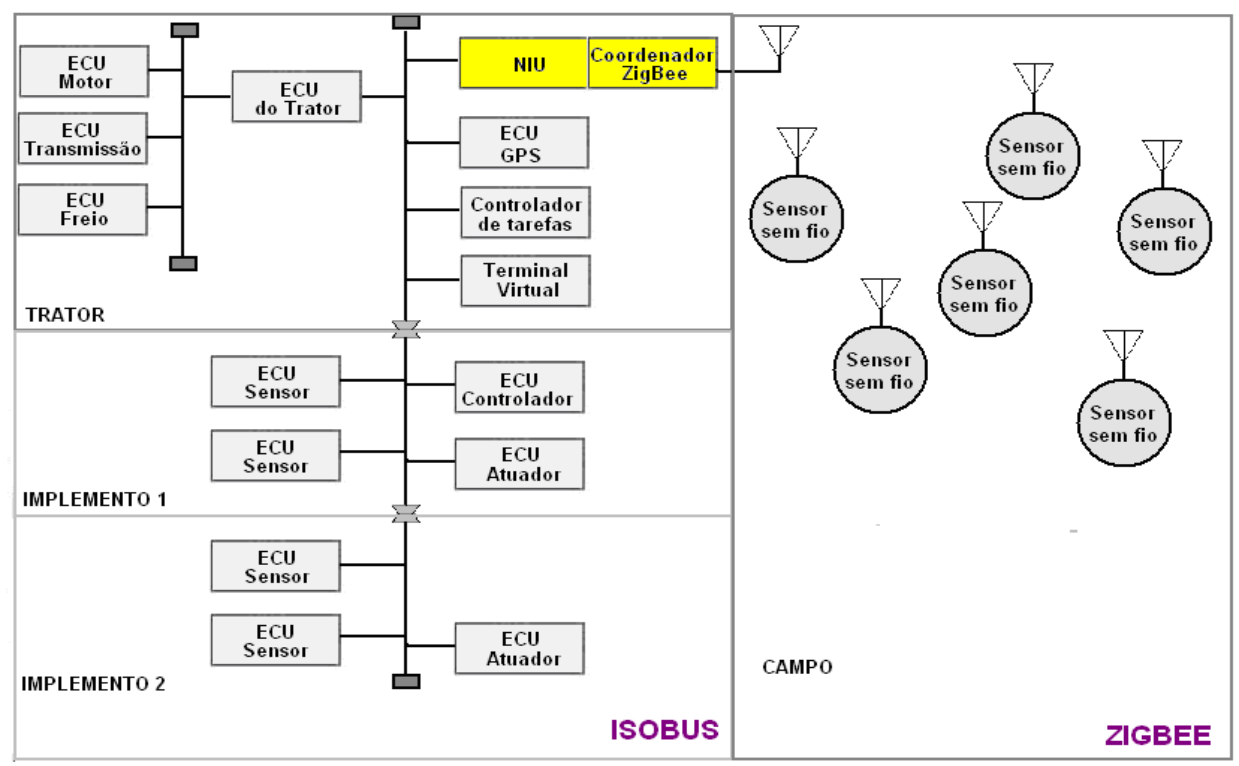

Figura 3-3 - Interconexão de uma rede ISOBUS a uma rede ZigBee. Elementos gráficos adaptados de LAV, DIN 9684-LBS (2000).

Segundo a norma ISO 11783-4 (1998), as NIUs possuem diversos recursos que simplificam a interconexão do ISOBUS com outras redes, como:

- encaminhamento de mensagens de uma rede para outra;

- filtragem de mensagens, de modo que sejam repassadas apenas as que tenham como destino os nós da outra rede;

- translação de endereço, de modo que cada uma das redes mantenha o seu mecanismo de endereçamento;

- remontagem de mensagens, que consiste em alterar o campo de dados de uma mensagem, adicionando-se outros dados antes de transferi-la de uma rede a outra;

- administração de base de dados, que consiste num conjunto padrão de regras para que se possa acessar e configurar as bases de dados das próprias NIU.

Resolver a interconexão física não é uma tarefa complexa, uma vez que existem chips com implementações dos protocolos. Em especial o protocolo CAN pode ser encontrado encapsulado em microcontroladores comerciais (MOREIRAS; CUGNASCA, 2003). 


\subsection{Considerações sobre a Conexão Proposta}

Neste item são apresentadas as considerações que o projetista da conexão deverá ter em mente, as quais visam listar os problemas que devem ser solucionados em um projeto de conexão, além de discutir as limitações de desempenho da conexão.

\subsubsection{O modelo ISO/OSI da Conexão Proposta}

A solução proposta pode ser representada segundo o modelo ISO/OSI (Figura 3-4), pelo qual todas as camadas de ambos os protocolos estão representadas de modo tradicional. Neste modelo, a interconexão dar-se-ia pela camada de aplicação de ambos os protocolos, cujas principais funções, necessárias para a aplicação agrícola proposta, são discutidas na sequência.

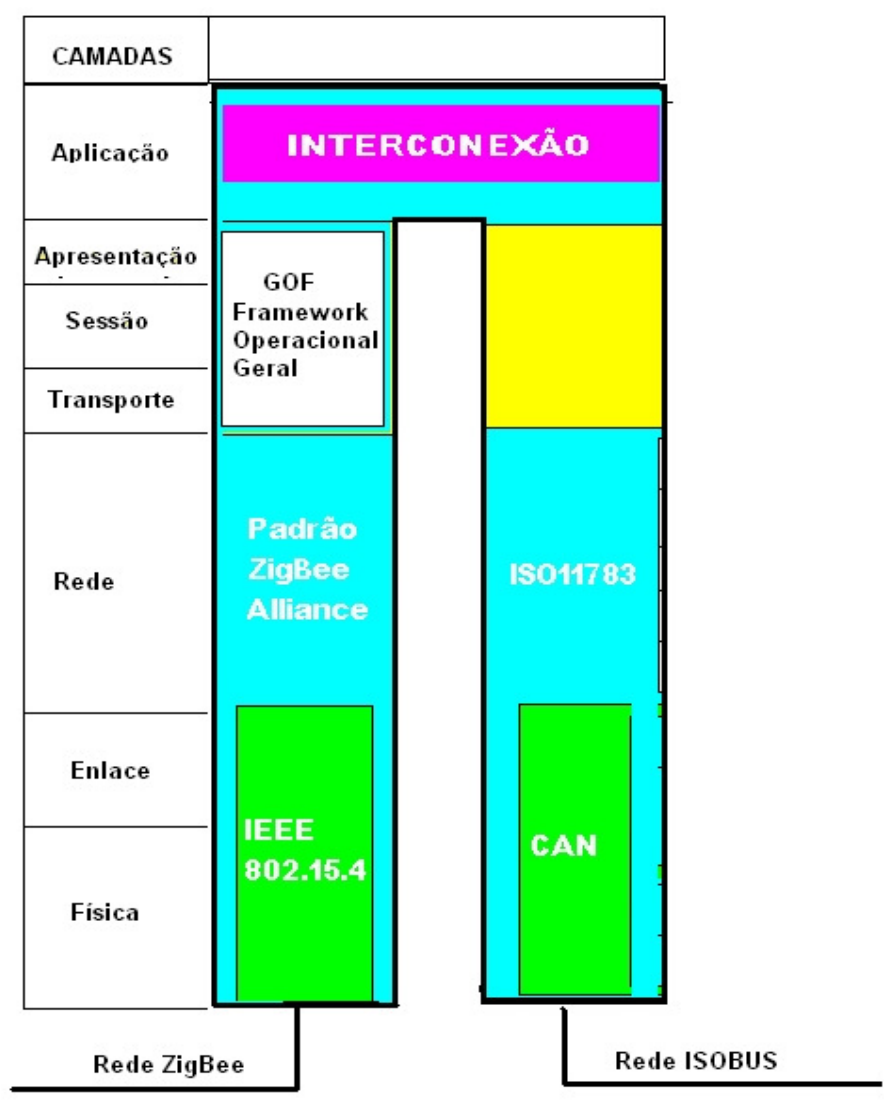

Figura 3-4 - Modelo ISO/OSI da Interconexão ISOBUS a uma rede ZigBee por meio da camada de Aplicação. 


\subsubsection{Compatibilização das Necessidades}

A implementação de uma NIU é feita, necessariamente, em uma arquitetura que contenha uma CPU, memórias e, pelo menos, duas portas seriais com ao menos uma interface CAN. Nesta arquitetura é possível implementar uma NIU de interconexão ZigBee em uma ECU de sensoriamento, em que as portas dos sensores são substituídas por uma interface serial e um rádio padrão IEEE 802.15.4, conforme a Figura 3-5. Para isto, é necessário que a CPU tenha capacidade para executar também o software para implementação do ZigBee.

Deve-se levar em consideração o dimensionamento da CPU e da memória, para que o hardware proposto execute tanto as funções de uma ECU de sensoriamento quanto as funções do protocolo ZigBee.
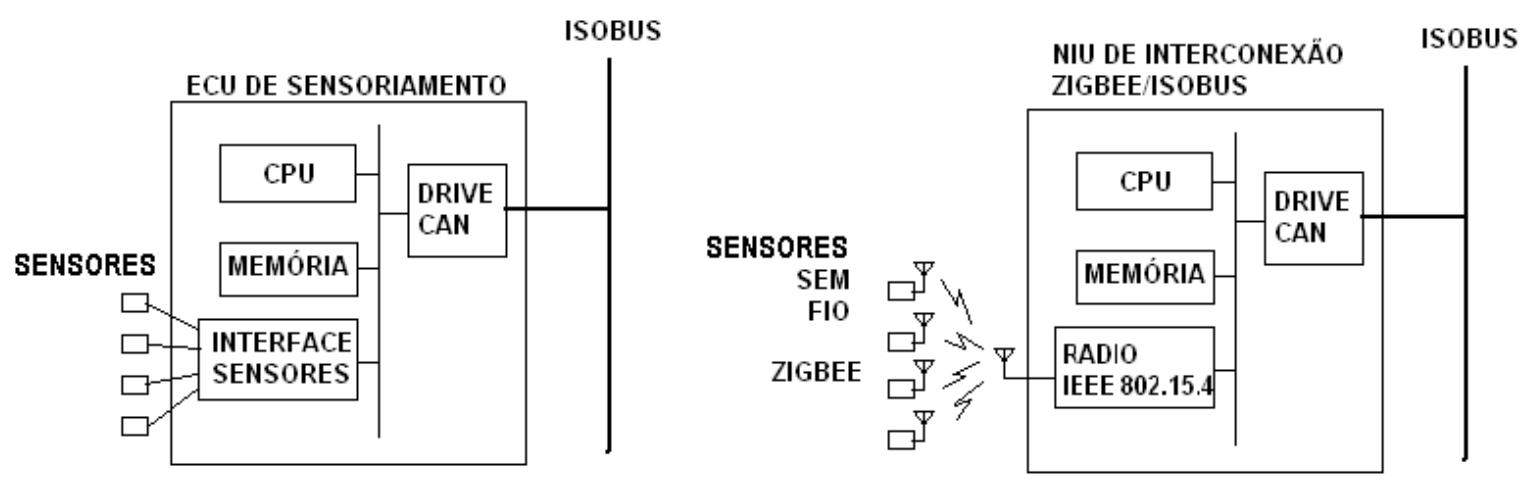

Figura 3-5 - Diagrama em blocos de uma ECU de sensoriamento (à esquerda) e de uma NIU de interconexão ISOBUS/ZigBee (à direita).

\subsubsection{Considerações Quanto ao Software}

Godoy; Porto; Inamasu (2008) discutem que, pela norma ISOBUS, as ECU poderiam ter a sua implementação simplificada por meio de uma arquitetura de software voltada a objetos, enquanto que, pelo que foi mostrado no Capítulo 2, o ZigBee possui uma arquitetura voltada a eventos. Como a arquitetura voltada a objetos prevê o uso de eventos, é possível criar, por exemplo, um objeto de software chamado "sensor sem fio" que represente cada um dos sensores da rede e que apresente campos contendo os valores de sensoriamento, suas propriedades e uma série de eventos ZigBee. Assim, por exemplo, um sensor de umidade, ao transmitir o valor pela rede sem fio, gera um evento no objeto de software, "sensor". Este dispara uma 
tarefa que recebe o valor e coloca-o no campo umidade, sendo possível, a partir dai, enviar o valor a outros dispositivos ISOBUS, como o Terminal Virtual ou 0 Controlador de Tarefas.

\subsection{Limitações da Interconexão Proposta}

Neste item são apresentadas as principais limitações da solução proposta e de sua aplicabilidade na agricultura.

\subsubsection{Sincronização}

A rede ZigBee, como detalhado no Capítulo 2, possui dois modos de operação, com beacon e sem beacon. Para monitoração ambiental, normalmente, trabalha-se no modo com beacon que permite um melhor gerenciamento do consumo de energia (LEE, KIN; PARK, 2007). Nesse modo, as transmissões e recepções do sensor permanecem inativas em intervalos de tempos relativamente longos, exigindo que todos os elementos que troquem dados entre si estejam perfeitamente sincronizados com os seus ciclos de transmissão e recepção. O mesmo deve ocorrer com a NIU de interconexão.

A sincronização pouco afeta o recebimento de dados dos sensores e a consequente pulverização na rede ISOBUS, exceto pela somatória dos atrasos e overheads de ambas as redes. Estes são pouco significativos para os tipos de aplicações deste trabalho, pois o intervalo necessário para se ter uma variação significativa de uma variável ambiental (temperatura, luminosidade, umidade, por exemplo) é muito maior que os possíveis décimos de segundos de atraso entre o instante que o dado é coletado pelo sensor e o instante que é reconhecido pelas ECU ISOBUS. O mesmo ocorre para as informações que os dispositivos ISOBUS enviam aos sensores. Em ambos os casos é necessário que a NIU monte um buffer intermediário para reter os dados até que a outra rede esteja pronta para recebê-los. Ou seja, os dispositivos ISOBUS estarão se comunicando com a NIU e trocando dados com o buffer intermediário sem o conhecimento da rede ZigBee, enquanto os sensores também estarão trocando dados com um buffer intermediário sem conhecimento da rede ISOBUS. Cabe à NIU a atualização de ambos os buffers com dados um do outro. 


\subsubsection{Topologia em Cluster}

Algumas dificuldades aparecem na topologia em cluster. A pequena quantidade de memória disponível nos sensores sem fio pode ser um limitante para o uso desta topologia, pois é necessário implementar um buffer relativamente pequeno, com poucas informações históricas e poucos sensores no cluster.

Esta limitação pode ser contornada projetando-se a aplicação de modo a criar maior número de clusters, com poucos sensores cada e com maior intervalo de amostragem das variáveis ambientais. Isto não compromete o sistema, uma vez que, a maioria das variáveis a serem monitoradas varia relativamente pouco ao longo do tempo.

Caso sejam exigidos sensores que necessitem trabalhar com intervalos de amostragem pequenos, devem-se considerar os tempos que a informação leva de um sensor para outro, até alcançar o nó cabeça de cluster, e deste para a NIU do veículo.

\subsubsection{Os Problemas de Configuração}

Considerando-se a utilização da topologia proposta, o ideal é o uso de um único sistema de configuração para a aplicação. No entanto, ainda que esta opção seja viável, diversas dificuldades devem ser contornadas.

Uma dificuldade nas topologias propostas é a configuração dos sensores sem fio, uma vez que são configurados a partir de um computador conectado ao nó coletor que, nas topologias propostas, é uma NIU de uma rede ISOBUS.

Ainda que se possa implementar as funções de configuração na própria NIU, ou em alguma outra ECU da rede ISOBUS, ou mesmo incluir temporariamente um dispositivo de configuração na rede ISOBUS, estas soluções, além de complexas, teriam um baixo desempenho pelas limitações de hardware e dos protocolos, que teriam que coexistir em um mesmo ambiente de hardware. E, devido à mobilidade do nó coletor, alguns elementos sensores poderão não ser alcançados.

Uma possível solução de implementação é criar um espelho do nó coletor em um computador portátil especialmente configurado para esta função. Desta forma, de um ponto fixo na rede é possível configurar todos os sensores por meio do processo de inundação, mecanismo este previsto no padrão ZigBee. 


\subsubsection{Pontos não Considerados Neste Trabalho}

A solução apresentada não pretende:

- que existam atuadores na rede ZigBee, uma vez que os tempos de respostas exigidos para o seu comando podem ser mais críticos. Os atuadores devem estar conectados às ECU da rede ISOBUS;

- que as topologias apresentadas resolvam problemas de interconexão entre as duas redes fora de aplicações agrícolas;

- que as velocidades usadas pelos veículos agrícolas sejam muito diferentes das usadas em uma aplicação agrícola típica;

- que os sensores executem outras funções além da coleta e transmissão dos dados ambientais;

- que seja adequada para todos os tipos de sensores usados na agricultura.

- que se otimize o consumo de energia dos nós sensores. Pressuposto que a preocupação com o consumo de energia é inerente a todo projeto com RSSF.

\subsection{Considerações sobre o Capítulo}

Neste capítulo foram apresentadas as alternativas de interconexão entre as redes ISOBUS e ZigBee, assim como a alternativa de interconexão proposta por este trabalho. Esta alternativa foi detalhada, especificada e discutida com base no seu modelo de referência, segundo o padrão ISO/OSI. Também foram mostrados os elementos da aplicação importantes, de serem resolvidos pela proposta e, finalmente, foram apresentados alguns dos pontos que a alternativa proposta não considera e que poderão ser tratados em trabalhos futuros.

No Capítulo 4 é descrito o simulador desenvolvido para testar a interconexão proposta neste capítulo. Também são apresentados os cenários em que as simulações foram executadas. 


\section{SIMULAÇÃO DA INTERCONEXÃO ENTRE REDES DO PADRÃO ZIGBEE E ISOBUS}

Neste capítulo são apresentados o simulador e as simulações realizadas para testar a interconexão entre as redes padrão ZigBee e ISOBUS, por meio de uma NIU especialmente desenvolvida para este fim. Simulou-se o envio de dados gerados pelos sensores de uma rede ZigBee e o seu recebimento por um Terminal Virtual de uma rede ISOBUS, passando por uma NIU de interconexão de ambas as redes, conforme descrito no Capítulo 3.

Inicialmente apresentam-se as justificativas para o uso da simulação como forma de testar a interconexão proposta (Item 4.1), na sequência é descrito o simulador desenvolvido para as avaliações (Item 4.2) e, finalmente, no Item 4.3, é feita a descrição das simulações.

\subsection{O Porquê das Simulações}

Entre as alternativas para se testar uma interconexão destacam-se:

- uma aplicação real em campo. Esta alternativa, além de ser economicamente custosa, envolve aspectos ambientais, como chuvas e ventos que complicam o controle dos testes;

- testes em laboratório com a montagem de protótipos - esta alternativa, além de demandar tempo, também envolve custos elevados;

- simulações do comportamento em determinados cenários - esta alternativa, comparada com as duas anteriores, é a que demanda menor tempo de execução, recursos financeiros e não depende de aspectos ambientais; porém, é baseada em um modelo teórico.

Levando-se em conta as vantagens e desvantagens de cada uma das alternativas anteriores, e tendo em vista que o trabalho ainda se encontra em fase exploratória, adotou-se a simulação, como forma de testar a interconexão entre as redes. Os simuladores propiciam um número variado de elementos, em especial quando se estuda tecnologias com características de ambientes muito específicos (GODOY, 
2007). Em função da proposta deste trabalho estar inserida em uma aplicação específica (conexão entre as redes ISOBUS e ZigBee) e topologia específicas (Estrela ou Cluster Tree) com nó coordenador móvel, optou-se por uma alternativa que pudesse proporcionar resultados com mais rapidez e custos menores. Desta forma, foi desenvolvido um simulador, também específico, para a análise do desempenho da conexão proposta.

\subsection{O Simulador}

Existem simuladores desenvolvidos para redes do padrão IEEE 802.15 .4 como, por exemplo, o Network Simulator (NS) (FALL; VARADHAN, 2010), utilizado por Sankarasubramaniam, Akan e Akyildiz (2003) para simular a confiabilidade de uma RSSF, porém não atendem a proposta deste trabalho, pois além de não considerarem a complexidade de implantar redes com mobilidade, não simulam as topologias específicas do ZigBee. Há também o simulador Georgia Tech Network Simulator (GTNetS), avaliado por Cheng, Zhang e Bourgeois (2006) como possuindo código "proprietário", ou seja, não permite adequá-lo às necessidades deste trabalho. O TinyOS Simulator (TOSSIM) (LEVIS; LEE, 2003) que, além de simular as camadas da IEEE 802.15.4, permite simular as diversas topologias do ZigBee. As interfaces de aplicação fornecidas por ele também não têm recursos para simulação envolvendo mobilidade dos nós. Silva (2008), por sua vez, avalia o desempenho de uma RSSF empregando uma plataforma de simulação para as camadas do padrão IEEE 802.15.4, desenvolvida especialmente para topologias que envolvem nós móveis.

Por fim, para simulação da parte referente à rede ISOBUS, Godoy et al. (2006) desenvolveram um simulador para o barramento ISOBUS, que também não foi considerado, pois para as necessidades deste trabalho, necessitaria ser complementado com as simulações da RSSF. Porém, muitos dos conceitos desenvolvidos por Godoy et al. (2006) foram usados no desenvolvimento do simulador proposto neste trabalho.

Pelas colocações anteriores fica claro que o desenvolvimento de um simulador foi necessário porque os existentes não contemplam as exigências deste trabalho, particularmente o funcionamento em ambientes com mobilidade e, como bem 
destaca Silva (2008), adaptar os simuladores existentes nem sempre é uma tarefa fácil e muitas vezes o resultado não é o esperado.

O simulador deste trabalho é uma ferramenta desenvolvida em linguagem Delphi para o sistema operacional Windows XP. Pode ser instalado tanto em computadores de mesa como em notebooks que suportem esse sistema operacional.

Ele consiste em uma área de trabalho na qual é representada a rede proposta, seus nós e a área de alcance do rádio de cada um dos nós. Nessa área existe uma linha horizontal que indica o caminho pelo qual o nó coordenador (móvel) deve passar, simulando as trocas de dados com os nós sensores. Para facilitar seu uso foram desenvolvidos menus que seguem o padrão Windows.

Todas as simulações apresentadas tiveram como base a geração de dados aleatórios, que correspondem a uma determinada função estatística. No entanto, gerar dados aleatórios em um computador não é possível devido à característica lógica de operação dos mesmos. Por isto, existem diversos algoritmos que geram dados pseudo-aleatórios. O algoritmo escolhido é o chamado linear congruente, adaptado para aumentar o ciclo de repetições, sendo implementado do seguinte modo:

- gera-se uma semente a partir da função time do sistema operacional, com os cinco dígitos menos significativos da hora em centésimos de segundos;

- gera-se uma segunda semente pelo resto da divisão do quadrado da semente anterior por 100;

- para cada uma das sementes aplica-se o algorítimo linear congruente, multiplicando-se as sementes por 742939 e dividindo-se por 49999;

- o valor aleatório é obtido pela soma dos restos das divisões do item anterior;

- para novos valores, repete-se apenas os dois últimos itens, usando como sementes o resto das divisões do calculo anterior.

\subsubsection{Apresentação Visual}

O simulador foi desenvolvido de modo a permitir ao usuário rapidez na descrição da aplicação, simplicidade de operação e facilidade para que possa exportar os resultados para outras ferramentas. 
Visualmente, o simulador apresenta uma grande área de trabalho, na qual é desenvolvida a topologia da rede sem fio, janelas de propriedades dos objetos, barras de menus interativos semelhantes aos usados nos aplicativos mais comuns e um gerenciador de projeto. A Figura 4-1 mostra a tela do simulador com as suas principais áreas.

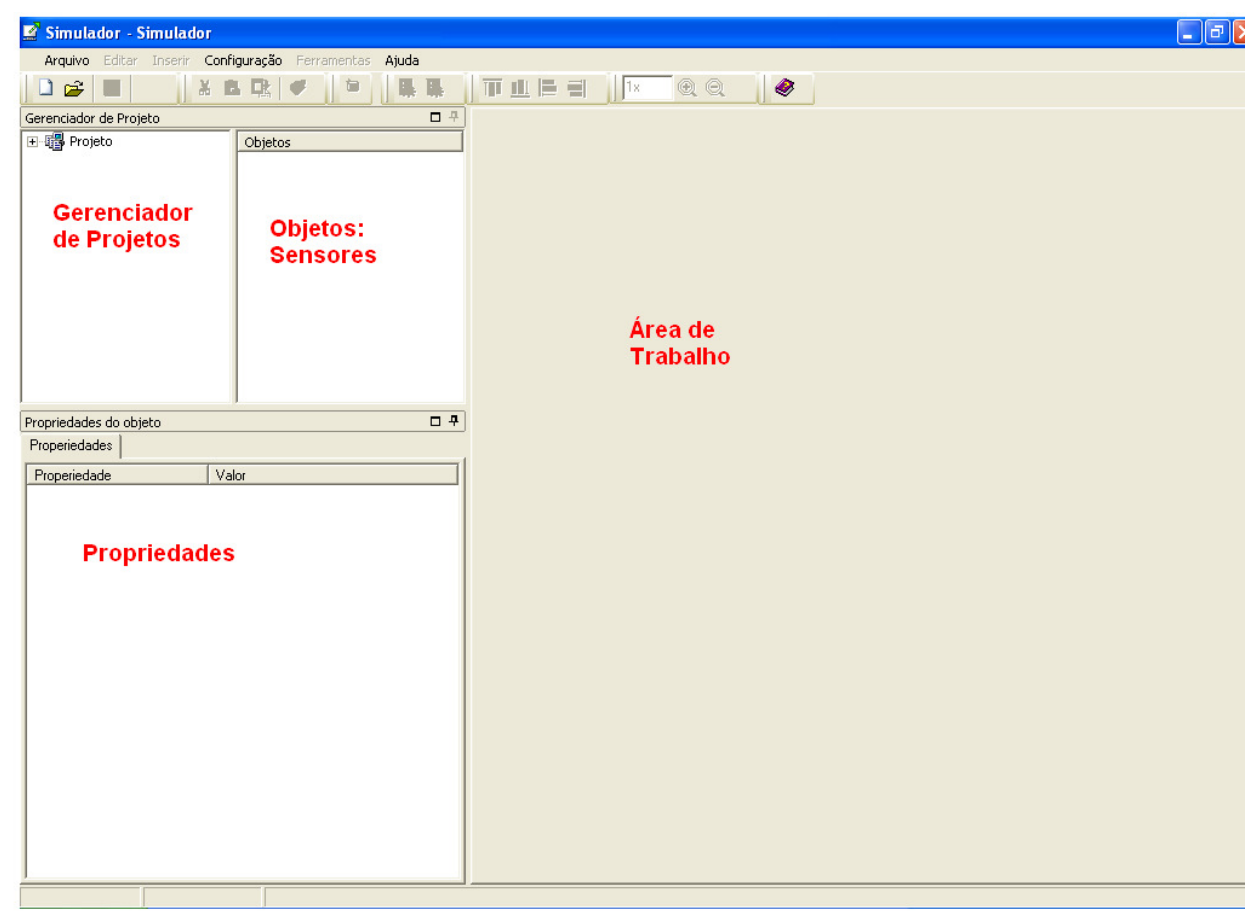

Figura 4-1 - Apresentação Visual do Simulador da interconexão.

\subsubsection{Barra de Menus}

A barra de menu, detalhada na Figura 4-2, possui as seguintes as opções:

- Arquivo: Novo Projeto; Abrir Projeto; Reabrir; Salvar; Salvar como; Fechar; Sair.

- Editar: Recortar; Copiar; Colar; Excluir; Desfazer; Alinhar acima; Alinhar abaixo; Alinhar esquerda; Alinhar direita.

- Inserir: Sensor.

- Configuração: Ambiente; Modelos.

- Ferramentas: Iniciar Simulação; Finalizar simulação.

- Ajuda: Ajuda; Sobre Simulador. 


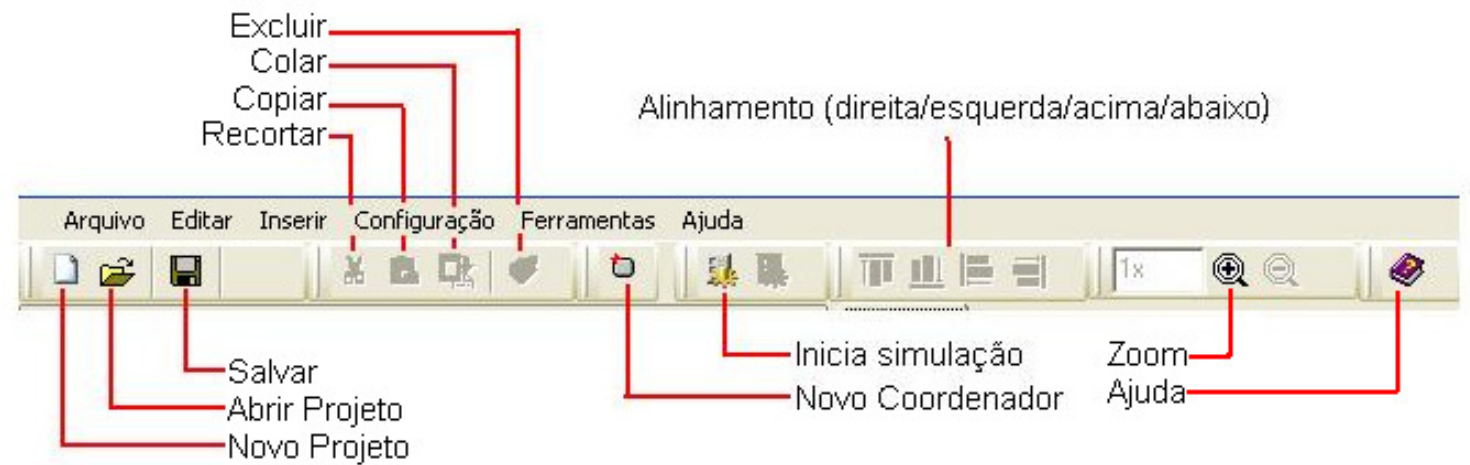

Figura 4-2 - Apresentação Visual da barra de menu do simulador.

\subsubsection{2 Área de Trabalho}

A área de trabalho, mostrada na Figura 4-3, representa a área física retangular, na qual é alocada a rede de sensores e onde o nó coordenador irá transitar. Nela está presente uma representação de todos os nós da RSSF em posições geográficas proporcionais, segundo uma escala definida pelo usuário. Durante a fase de simulação ela indica o alcance de cada sensor e o nó gateway transitando.

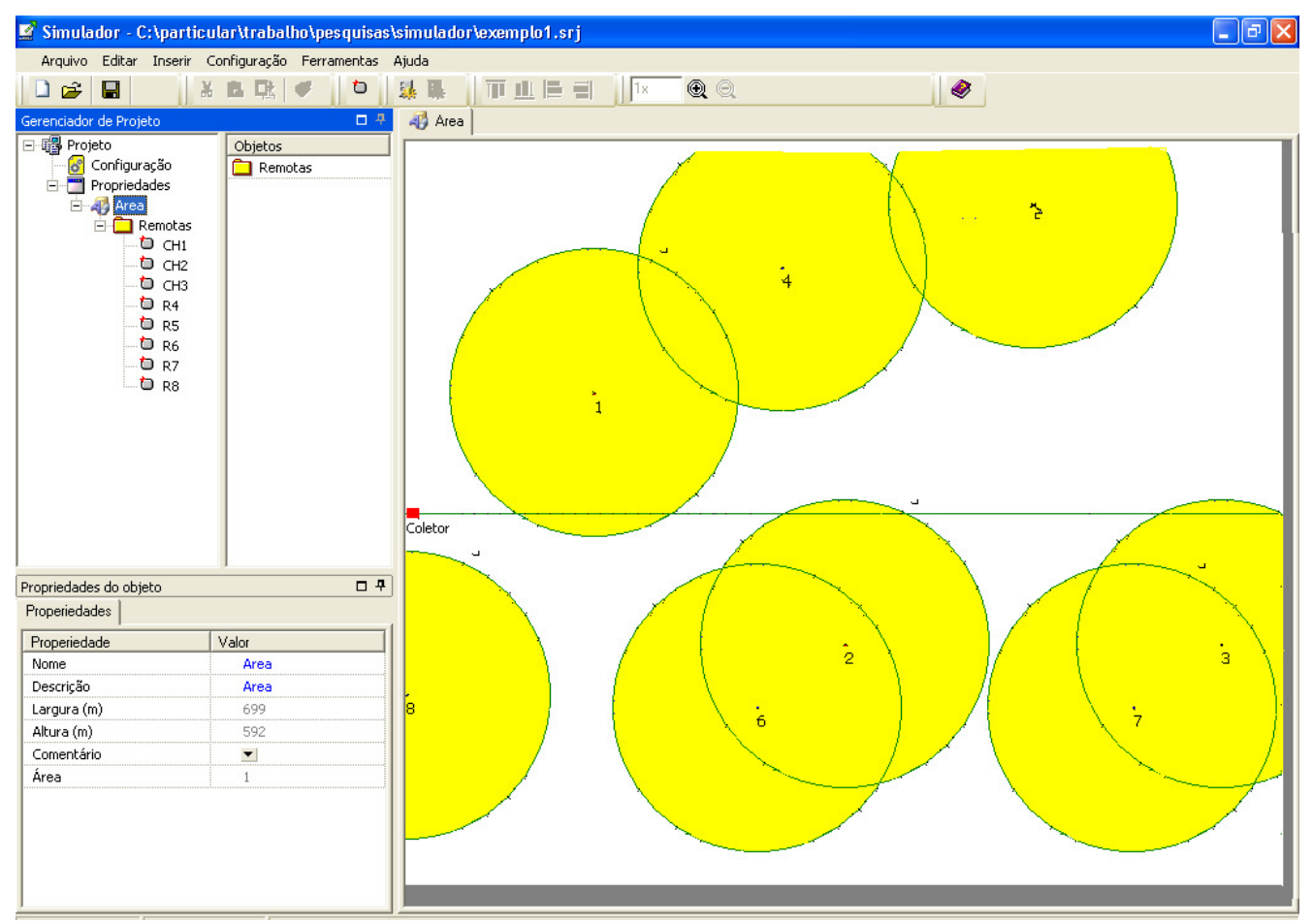

Figura 4-3 - Apresentação Visual da Área de Trabalho do Simulador. 


\subsubsection{Janelas de Definição dos Objetos}

São definidos como objetos:

- os projetos de simulação;

- a área física na qual é montada a rede de sensores;

- a interconexão com a rede ISOBUS em um nó embarcado no trator;

- os sensores sem fio.

Todos os objetos podem ser classificados em tipos ou categorias criados pelo usuário e salvos em uma biblioteca. Para cada tipo ou categoria associa-se um conjunto de propriedades. Por exemplo, na Figura 4-4, apresenta-se a janela de definição de propriedades de um sensor sem fio.

\begin{tabular}{|c|c|c|}
\hline \multicolumn{2}{|l|}{ Propriedades do objeto } & \multirow[t]{2}{*}{$\square 7$} \\
\hline Properiedades & & \\
\hline Properiedade & Valor & \\
\hline Nome & MTS300 & A \\
\hline Descrição & Sensor da área 43 & \\
\hline$x$ & 52 & \\
\hline $\mathrm{Y}$ & 20 & \\
\hline RemoteID & 2 & \\
\hline Tipo Remota & † Remota Terminal & \\
\hline Tempo dorme (seg) & 15 & \\
\hline Raio alcance $(m)$ & 30 & \\
\hline Duração bateria (h) & 10 & \\
\hline Tipo Dado 01 & + Dado 16 bits & \\
\hline Número dados 01 & 6 & \\
\hline Tipo Dado 02 & † Näo programada & \\
\hline Tipo Dado 03 & † Não programada & \\
\hline Tipo Dado 04 & † Näo programada & \\
\hline Tipo Dado 05 & † Não programada & \\
\hline Tinn Dadnof & + Männronramada & 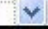 \\
\hline
\end{tabular}

Figura 4-4 - Janela de Propriedades de um Sensor sem Fio no Simulador.

\subsubsection{Descrição Geral}

O simulador permite: definir uma área de trabalho; distribuir sensores por ela; montar uma rede de comunicação entre os sensores (padrão ZigBee); e definir uma NIU que estará embarcada em um veículo móvel que, por sua vez, atravessará a área definida, em velocidade pré-estabelecida.

O guia do usuário do simulador é apresentado no Apêndice "A". 


\subsubsection{Fases do Trabalho de Simulação:}

Para que as simulações possam ser desenvolvidas deve-se:

- definir qual o problema que se quer avaliar com a simulação;

- definir a área de trabalho;

- definir a RSSF (tipos de sensores, posição geográfica etc.);

- definir o cenário inicial (carga das baterias, configuração dos sensores sem fio, etc.);

- selecionar as funções estatísticas entre as disponíveis no simulador, que melhor representem o comportamento das variáveis do cenário;

- executar as simulações;

- avaliar os resultados.

O número de simulações para cada cenário foi fixado em 30, pelo teorema dos limites mínimos. Nos próximos itens são detalhados os recursos que o simulador oferece para cada uma das fases.

\subsubsection{Definição da Área de Trabalho}

Com auxílio do gerenciador de projetos, as informações dos cenários previamente definidos devem ser inseridos no simulador.

Para definir a área de trabalho, deve-se alimentar o simulador com as seguintes informações:

- nome (ex.: Fazenda Santa Tereza);

- descrição (ex.: Fazenda com topografia em leve aclive, situada no município de Novo Horizonte-SP);

- dimensões da área de trabalho (largura x comprimento), em metros ou quilômetros;

- tipo de cultura (ex.: algodão);

- sistema de cultivo (ex.: curvas de nível);

- distância entre "ruas" (em metros);

- espaçamento entre as plantas (em metros).

\subsubsection{Definição da RSSF}

Nesta fase do trabalho, o simulador foi desenvolvido com apenas um nó de interconexão, com movimento retilíneo, plano e uniforme. Versões futuras poderão 
contemplar outros tipos de recursos, alguns dos quais são discutidos nas conclusões.

As simulações realizadas neste trabalho pressupõem uma NIU embarcada em um veículo agrícola cruzando uma determinada área em linha reta, no plano, a velocidades típicas das usadas pelos veículos agrícolas quando da execução de tarefas (entre 5 e $30 \mathrm{~km} / \mathrm{h}$ ).

Os nós sem fio podem conter diversos elementos sensores e podem ser definidos de dois modos:

- selecionando-os entre os já cadastrados;

- definindo-se suas propriedades em uma janela de propriedades, como ilustra a Figura 4-4.

Uma vez definidas as características de um novo nó, elas podem ser salvas na biblioteca interna do simulador, fazendo parte dela a partir de então.

Entre as características que definem o sensor tem-se:

- modelo;

- fabricante;

- protocolo de comunicação;

- alcance máximo do rádio;

- tipos de dados que o sensor fornece (ex.: temperatura em 16 bits);

- tempo entre 2 leituras consecutivas de cada elemento sensor.

Os nós da rede podem ser definidos com os seguintes parâmetros:

- modelo do sensor;

- número de série

- posição geográfica do nó;

- tipo de funções ZigBee (coordenador, roteador etc.);

- alcance real.

O simulador prevê o emprego de duas topologias: Cluster Tree e estrela.

\subsubsection{Definição da Rede ISOBUS}

Para definir a rede ISOBUS deve-se definir a quantidade de ECU, a quantidade de variáveis geradas por cada ECU, a prioridade de cada uma e a taxa de atualização 
destas variáveis. É pressuposta a existência de pelo menos um Terminal Virtual e uma ECU principal (ECU do trator) na rede. Não é considerada a existência de outras NIUs. A partir dessas variáveis o simulador estima uma taxa de ocupação do barramento ISOBUS. O simulador permite ao usuário editar a taxa de ocupação do barramento ISOBUS diretamente.

\subsubsection{Definição do Cenário inicial}

Um cenário é composto por um conjunto de variáveis cujo comportamento imaginase que possa influenciar no desempenho do sistema que se pretende analisar com as simulações. A ferramenta irá provocar variações aleatórias neste cenário e simular o resultado, ou seja, simulará diversas tentativas de comunicação utilizando a interconexão proposta, variando de modo aleatório as variáveis do cenário que podem ser:

- velocidade do trator (nó coletor);

- duração da bateria de cada sensor;

- alcance real de cada sensor;

- tempo de "dorme" de cada sensor (quando configurado no modo beacon);

- variáveis de sincronização entre sensores;

- quantidade de memória disponível para armazenamento de dados;

- número de variáveis de cada ECU;

- taxa de atualização das variáveis da ECU.

\subsubsection{Simulação}

Durante a simulação, ao mesmo tempo em que o nó coletor percorre o trajeto estabelecido, dados são gerados nos sensores e enviados ao nó coletor. Enquanto isto, as ECU geram e trocam dados entre si. Os sensores são configurados para gerar amostra de dados em intervalos fixos de tempo (tempo de amostragem) e armazená-la em um buffer interno, até que o equipamento coletor (veículo) entre no alcance do rádio do sensor. Nesse instante, a amostra é transferida para o veículo e dele a interconexão repassa a um dispositivo ISOBUS.

Os sensores foram configurados para gerar a primeira amostra em um tempo aleatório, inferior ao do tempo de amostragem configurado. As amostras, assim que 
são geradas, são armazenadas em um buffer até que seja possível transmiti-las na sequência em que foram geradas. Quando à capacidade de armazenamento do buffer é esgotada, a amostra mais antiga é descartada, dando lugar para a mais recente.

$\mathrm{Na}$ topologia cluster tree, as amostras geradas pelos sensores terminais são enviadas aos sensores cabeça de cluster, assim que estes "acordam". Então, são armazenadas no buffer do sensor cabeça de cluster, até a passagem do veículo ou até que o buffer esteja cheio, situação esta na qual a cada novo dado, o mais antigo é descartado..

O simulador gera todos os tempos de processamento, de espera do meio e de transmissão. Detecta possíveis colisões, perda de alcance do sinal de rádio, sobreposição ou perda de frames. Todos os dispositivos são inicializados em uma sequência aleatória, correspondente à função estatística definida para a variável.

Para simulação do uso do barramento ISOBUS, usa-se uma taxa de ocupação do barramento para gerar, também de modo aleatório, os instantes em que o barramento estará ocupado, O uso de uma taxa de ocupação é defendido por Godoy (2007), sendo este critério o utilizado para o simulador desenvolvido neste trabalho.

O simulador prevê dois modos de operação:

- um tiro: o veículo percorre a área uma única vez.

- contínuo: o simulador repete continuamente o modo um tiro, até receber o comando de parar. A partir de um cenário inicial, em que são definidos alguns parâmetros, o simulador gera pequenas variações no cenário de uma passada para outra do veículo coletor.

Para que o simulador possa gerar as variações no cenário, a cada uma das variáveis desse cenário deve-se definir uma função estatística que corresponda ao comportamento da variável. Dentre as funções disponíveis no simulador desenvolvido foram empregadas as funções:

- Retangular: a variável pode assumir qualquer valor no entorno do valor inicial, dentro de uma faixa pré-definida com igual probabilidade;

- Triangular: a variável pode assumir qualquer valor no entorno do valor inicial, dentro de uma faixa pré-definida com maior probabilidade para o valor central e decaindo linearmente até os limites da faixa; 
- Normal: a variável pode assumir qualquer valor no entorno do valor inicial, com probabilidade dada pela função normal.

Após definir o tipo de simulação deve-se ativá-la e, ao final, o simulador criará uma planilha com os dados obtidos. Com o auxílio de uma ferramenta para planilhas eletrônicas e ferramentas estatísticas, reorganizam-se os dados obtidos, de modo que se possa avaliá-los. Caso necessário, pode-se complementar as simulações iniciais com novas simulações e novos cenários.

\subsection{Caracterização das Simulações Executadas}

Os testes tiveram por objetivo demonstrar a viabilidade de aplicações com a interconexão proposta para o contexto da Agricultura de Precisão, ou seja, que é possível gerar mapas de variabilidade espacial por meio de sensoriamento sem fio, cujos dados são coletados por um veículo em movimento. Para isto as simulações executadas visaram avaliar aspectos de operabilidade da interconexão, a existência de perda de informações, os limites de velocidade e o alcance do nó coletor, a existência de congestionamento de dados no ISOBUS, a confiabilidade da comunicação e os efeitos das possíveis trocas de rotas.

Nos itens que seguem são apresentados os critérios usados para definir cada um dos cenários em função do aspecto avaliado.

\subsubsection{Topologias Utilizadas nas Simulações}

Foram duas as topologias empregadas: estrela, em que todos os nós sensores se comunicam diretamente com o nó coletor embarcado em um veículo, e a cluster na qual os nós sensores formam clusters de dois ou três sensores, sendo que o mais próximo do caminho do coletor foi definido como cabeça do cluster. Para a topologia estrela foi definida uma área de trabalho de $50 \mathrm{~m} \times 400 \mathrm{~m}$, onde o coletor trafega a cada duas filas. Os sensores são distribuídos nos espaçamentos das plantas segundo a Figura 4-5. 


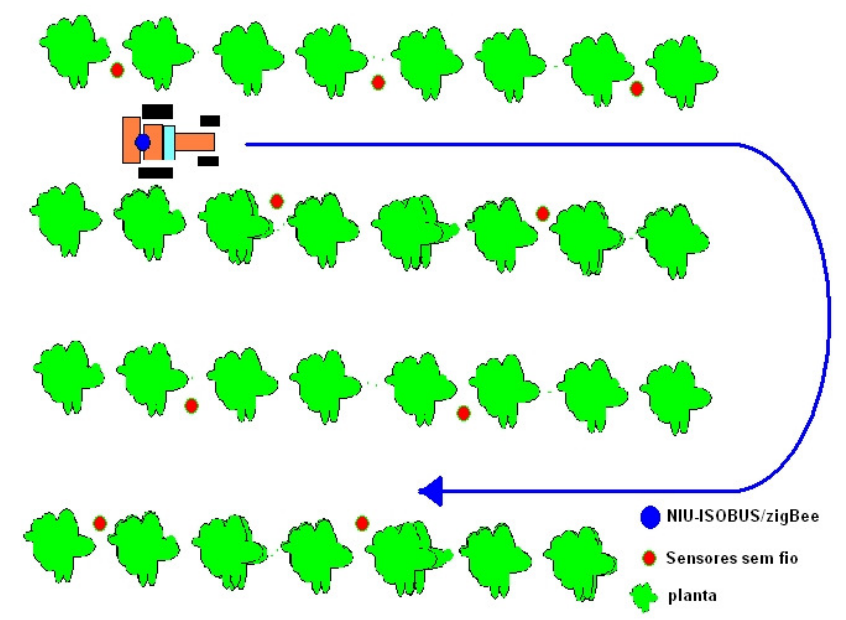

Figura 4-5 - Distribuição dos sensores na topologia estrela utilizada na simulação.

Para a topologia em cluster, foi definida uma área de $200 \mathrm{~m} \times 400 \mathrm{~m}$, onde o nó coletor trafega a cada oito filas; porém, os sensores estão formando clusters de dois ou três sensores, como na Figura 4-6.

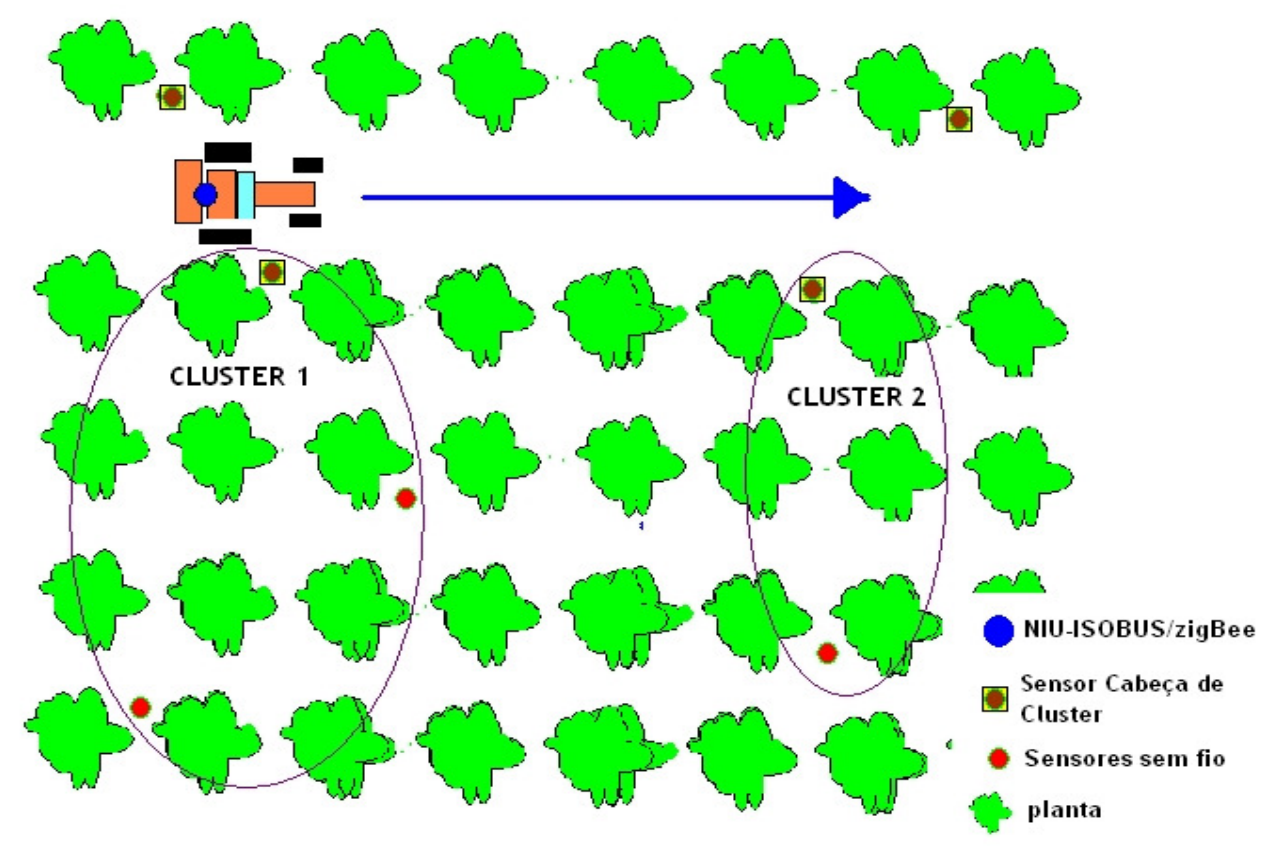

Figura 4-6 - Distribuição dos sensores na topologia cluster tree.

\subsubsection{Teste de Operabilidade e Temporização}

O objetivo da primeira simulação foi verificar se seria possível enviar dados dos sensores a um Terminal Virtual em um trator em movimento, em uma aplicação típica de agricultura. Os cenários para o estudo de operabilidade da interconexão com as respectivas faixas de valores de suas principais variáveis são apresentados 
no Quadro 4-1. Para cada cenário foram executadas dezenas de simulações com as variáveis assumindo valores aleatórios dentro das faixas de valores estabelecidas.

\begin{tabular}{|c|c|c|c|c|c|c|}
\hline Cenário & Topologia & $\begin{array}{c}\text { Velocidade } \\
\text { do coletor }\end{array}$ & $\begin{array}{c}\text { Número de } \\
\text { variáveis } \\
\text { monitoradas }\end{array}$ & $\begin{array}{c}\text { Taxa de } \\
\text { ocupação } \\
\text { do ISOBUS }\end{array}$ & $\begin{array}{c}\text { Intervalo de } \\
\text { coleta de } \\
\text { dados }\end{array}$ & $\begin{array}{c}\text { Alcance } \\
\text { dos sensores }\end{array}$ \\
\hline \hline 1.1 & estrela & $\begin{array}{c}10 \mathrm{~km} / \mathrm{h} \text { a } \\
30 \mathrm{~km} / \mathrm{h}\end{array}$ & 3 a 6 & $\begin{array}{c}15 \% \text { a } \\
25 \%\end{array}$ & $50 \mathrm{~ms}$ a $8 \mathrm{~s}$ & $25 \mathrm{~m}$ \\
\hline \hline 1.2 & cluster & $\begin{array}{c}10 \mathrm{~km} / \mathrm{h} \text { a } \\
30 \mathrm{~km} / \mathrm{h}\end{array}$ & 2 a 4 & $25 \%$ & $50 \mathrm{~ms}$ a $8 \mathrm{~s}$ & $25 \mathrm{~m}$ a $45 \mathrm{~m}$ \\
\hline
\end{tabular}

Quadro 4-1- Cenários criados visando ao estudo de operabilidade da interconexão.

\subsubsection{Teste de Perda de Informação}

Para determinar possíveis perdas de informação foram executadas simulações em seis cenários. Para cada um deles, a velocidade do coletor foi variada à razão de um quilometro por hora, dentro da faixa especificada no Quadro 4-2. As demais variáveis do Quadro 4-2 assumiram valores randômicos, exceto a taxa de ocupação do barramento ISOBUS, que foi fixada em $70 \%$ em todas as simulações.

\begin{tabular}{|c|c|c|c|c|c|c|}
\hline Cenário & Topologia & $\begin{array}{c}\text { Velocidade } \\
\text { do coletor }\end{array}$ & $\begin{array}{c}\text { Número de } \\
\text { variáveis } \\
\text { monitoradas }\end{array}$ & $\begin{array}{c}\text { Taxa de } \\
\text { ocupação } \\
\text { do ISOBUS }\end{array}$ & $\begin{array}{c}\text { Intervalo de } \\
\text { coleta de } \\
\text { dados }\end{array}$ & $\begin{array}{c}\text { Alcance } \\
\text { dos sensores }\end{array}$ \\
\hline 2.1 & estrela & $\begin{array}{c}10 \mathrm{~km} / \mathrm{h} \text { a } \\
15 \mathrm{~km} / \mathrm{h}\end{array}$ & 2 a 4 & $70 \%$ & $2 \mathrm{~s}$ a $5 \mathrm{~s}$ & $5 \mathrm{~m}$ a $10 \mathrm{~m}$ \\
\hline \hline 2.2 & estrela & $\begin{array}{c}15 \mathrm{~km} / \mathrm{h} \text { a } \\
25 \mathrm{~km} / \mathrm{h}\end{array}$ & 6 a 8 & $70 \%$ & $5 \mathrm{~s}$ a $50 \mathrm{~s}$ & $30 \mathrm{~m}$ \\
\hline \hline 2.3 & estrela & $\begin{array}{c}10 \mathrm{~km} / \mathrm{h} \text { a } \\
15 \mathrm{~km} / \mathrm{h}\end{array}$ & 6 a 8 & $70 \%$ & $2 \mathrm{~s}$ a $5 \mathrm{~s}$ & $5 \mathrm{~m}$ a $10 \mathrm{~m}$ \\
\hline \hline 2.4 & cluster & $\begin{array}{c}10 \mathrm{~km} / \mathrm{h} \text { a } \\
15 \mathrm{~km} / \mathrm{h}\end{array}$ & 6 a 7 & $70 \%$ & $2 \mathrm{~s}$ a $5 \mathrm{~s}$ & $30 \mathrm{~m}$ \\
\hline \hline 2.5 & cluster & $\begin{array}{c}15 \mathrm{~km} / \mathrm{h} \text { a } \\
25 \mathrm{~km} / \mathrm{h}\end{array}$ & 7 a 8 & $70 \%$ & $5 \mathrm{~s}$ a $50 \mathrm{~s}$ & $30 \mathrm{~m}$ \\
\hline \hline 2.6 & cluster & $\begin{array}{c}10 \mathrm{~km} / \mathrm{h} \text { a } \\
15 \mathrm{~km} / \mathrm{h}\end{array}$ & 7 a 8 & $70 \%$ & $2 \mathrm{~s}$ a $5 \mathrm{~s}$ & $30 \mathrm{~m}$ \\
\hline
\end{tabular}

Quadro 4-2 - Cenários criados visando ao estudo de perdas de informação na interconexão.

\subsubsection{Teste da Influência da Velocidade do Veículo}

Para estudar a influência da velocidade do veículo foram fixadas as condições do primeiro teste (operabilidade) e variou-se a velocidade do nó coletor à razão de um quilômetro por hora dentro da faixa especificada no Quadro 4-3 . 


\begin{tabular}{|c|c|c|c|c|c|c|}
\hline Cenário & Topologia & $\begin{array}{c}\text { Velocidade } \\
\text { do coletor }\end{array}$ & $\begin{array}{c}\text { Número de } \\
\text { variáveis } \\
\text { monitoradas }\end{array}$ & $\begin{array}{c}\text { Taxa de } \\
\text { ocupação } \\
\text { do ISOBUS }\end{array}$ & $\begin{array}{c}\text { Intervalo de } \\
\text { coleta de } \\
\text { dados }\end{array}$ & $\begin{array}{c}\text { Alcance } \\
\text { dos sensores }\end{array}$ \\
\hline \hline 3.1 & estrela & $\begin{array}{c}5 \mathrm{~km} / \mathrm{h} \mathrm{a} \\
40 \mathrm{~km} / \mathrm{h}\end{array}$ & 3 a 6 & $30 \%$ & $5 \mathrm{~s}$ a $50 \mathrm{~s}$ & $30 \mathrm{~m}$ \\
\hline \hline 3.2 & estrela & $\begin{array}{c}5 \mathrm{~km} / \mathrm{h} \mathrm{a} \\
40 \mathrm{~km} / \mathrm{h}\end{array}$ & 2 a 4 & $30 \%$ & $5 \mathrm{~s} \mathrm{a} 50 \mathrm{~s}$ & $30 \mathrm{~m}$ \\
\hline \hline 3.3 & cluster & $\begin{array}{c}5 \mathrm{~km} / \mathrm{h} \mathrm{a} \\
40 \mathrm{~km} / \mathrm{h}\end{array}$ & 3 a 6 & $30 \%$ & $5 \mathrm{~s}$ a $50 \mathrm{~s}$ & $30 \mathrm{~m}$ \\
\hline \hline 3 & cluster & $\begin{array}{c}5 \mathrm{~km} / \mathrm{h} \mathrm{a} \\
40 \mathrm{~km} / \mathrm{h}\end{array}$ & 2 a 4 & $30 \%$ & $5 \mathrm{~s} \mathrm{a} 50 \mathrm{~s}$ & $30 \mathrm{~m}$ \\
\hline
\end{tabular}

Quadro 4-4 - Cenários criados visando ao estudo da influência da velocidade do veículo na interconexão.

\subsubsection{Teste da Influência da Densidade de Tráfego da Rede ISOBUS}

Os cenários da simulação são semelhantes aos do Item 4.3.3 (teste de perda de informação), porém com variação na taxa de ocupação do barramento ISOBUS à razão de $5 \%$ dentro da faixa especificada no Quadro 4-5.

\begin{tabular}{|c|c|c|c|c|c|c|}
\hline Cenário & Topologia & $\begin{array}{c}\text { Velocidade } \\
\text { do coletor }\end{array}$ & $\begin{array}{c}\text { Número de } \\
\text { variáveis } \\
\text { monitoradas }\end{array}$ & $\begin{array}{c}\text { Taxa de } \\
\text { ocupação } \\
\text { do ISOBUS }\end{array}$ & $\begin{array}{c}\text { Intervalo de } \\
\text { coleta de } \\
\text { dados }\end{array}$ & $\begin{array}{c}\text { Alcance dos } \\
\text { sensores }\end{array}$ \\
\hline \hline 4.1 & estrela & $\begin{array}{c}10 \mathrm{~km} / \mathrm{h} \text { a } \\
15 \mathrm{~km} / \mathrm{h}\end{array}$ & 2 a 4 & 15 a $60 \%$ & $2 \mathrm{~s}$ a $5 \mathrm{~s}$ & $5 \mathrm{~m} \mathrm{a} 10 \mathrm{~m}$ \\
\hline 4.2 & estrela & $\begin{array}{c}15 \mathrm{~km} / \mathrm{h} \text { a } \\
25 \mathrm{~km} / \mathrm{h}\end{array}$ & 6 a 8 & 30 a $60 \%$ & $5 \mathrm{~s}$ a $50 \mathrm{~s}$ & $30 \mathrm{~m}$ \\
\hline 4.3 & estrela & $\begin{array}{c}10 \mathrm{~km} / \mathrm{h} \text { a } \\
15 \mathrm{~km} / \mathrm{h}\end{array}$ & 6 a 8 & 30 a $60 \%$ & $2 \mathrm{~s}$ a $5 \mathrm{~s}$ & $5 \mathrm{~m}$ a $10 \mathrm{~m}$ \\
\hline \hline 4.4 & cluster & $\begin{array}{c}10 \mathrm{~km} / \mathrm{h} \text { a } \\
15 \mathrm{~km} / \mathrm{h}\end{array}$ & 6 a 7 & 15 a $60 \%$ & $2 \mathrm{~s}$ a $5 \mathrm{~s}$ & $30 \mathrm{~m}$ \\
\hline \hline 4.5 & cluster & $\begin{array}{c}15 \mathrm{~km} / \mathrm{h} \text { a } \\
25 \mathrm{~km} / \mathrm{h}\end{array}$ & 7 a 8 & 30 a $60 \%$ & $5 \mathrm{~s}$ a $50 \mathrm{~s}$ & $30 \mathrm{~m}$ \\
\hline \hline 4.6 & cluster & $\begin{array}{c}10 \mathrm{~km} / \mathrm{h} \text { a } \\
15 \mathrm{~km} / \mathrm{h}\end{array}$ & 7 a 8 & 30 a $60 \%$ & $2 \mathrm{~s}$ a $5 \mathrm{~s}$ & $30 \mathrm{~m}$ \\
\hline
\end{tabular}

Quadro 4-5 - Cenários criados visando ao estudo da influência da densidade de tráfego no barramento ISOBUS. 


\subsubsection{Teste da Influência da Troca de Rotas}

Para avaliar a influência das trocas de rotas, foram repetidas as simulações do Item 4.3.2 (teste de operabilidade e temporização), porém com três trocas de rotas que ocorrem em intervalos de $5 \mathrm{~s}$. A cada simulação, as demais variáveis assumem valores aleatórios dentro da faixa especificada no Quadro 4-6.

\begin{tabular}{|c|c|c|c|c|c|c|}
\hline Cenário & Topologia & $\begin{array}{l}\text { Velocidade } \\
\text { do coletor }\end{array}$ & $\begin{array}{l}\text { Número de } \\
\text { variáveis } \\
\text { monitoradas }\end{array}$ & $\begin{array}{l}\text { Taxa de } \\
\text { ocupação } \\
\text { do ISOBUS }\end{array}$ & $\begin{array}{l}\text { Intervalo de } \\
\text { coleta de } \\
\text { dados }\end{array}$ & $\begin{array}{l}\text { Alcance } \\
\text { dos sensores }\end{array}$ \\
\hline \hline 1.1 & estrela & $\begin{array}{c}15 \mathrm{~km} / \mathrm{h} \text { a } \\
25 \mathrm{~km} / \mathrm{h}\end{array}$ & $3 \mathrm{a} 6$ & $30 \%$ & $5 \mathrm{~s}$ a $50 \mathrm{~s}$ & $30 \mathrm{~m}$ \\
\hline \hline 1.2 & cluster & $\begin{array}{c}15 \mathrm{~km} / \mathrm{h} \text { a } \\
25 \mathrm{~km} / \mathrm{h}\end{array}$ & $2 \mathrm{a} 4$ & $30 \%$ & $10 \mathrm{~s}$ a $60 \mathrm{~s}$ & $25 \mathrm{~m}$ a $40 \mathrm{~m}$ \\
\hline
\end{tabular}

Quadro 4-6 - Cenários criados visando ao estudo de operabilidade da interconexão durante troca de rota de um dos sensores.

Outras simulações foram executadas, porém não estão apresentadas neste trabalho porque os resultados foram similares. Os resultados das simulações foram organizados em planilhas e estão apresentados no próximo capítulo, onde são analisados e discutidos.

\subsection{Considerações sobre o Capítulo}

Com o objetivo de mostrar a viabilidade da proposta foram apresentadas neste capítulo as simulações realizadas. Inicialmente foram dadas as justificativas para o uso de simulação, assim como para a necessidade de desenvolver um novo simulador. O simulador desenvolvido é descrito também neste capítulo, assim como a sua operação, sendo que ao final do capítulo são mostrados, sob a forma de tabelas, os cenário configurados para as simulações.

Nos próximos capítulos são apresentados e discutidos os resultados das simulações. 


\section{RESULTADOS DAS SIMULAÇÕES DA INTERCONEXÃO ENTRE REDES DO PADRÃO ZIGBEE E ISOBUS}

Neste capítulo são apresentados os resultados das simulações, as suas análises e as discussões. Inicialmente são apresentados alguns exemplos dos relatórios gerados pelo simulador, assim como as tabelas geradas a partir dos dados destes relatórios e os gráficos gerados a partir das tabelas

Em seguida é apresentado o resultado das simulações, organizados em função dos objetivos de cada teste executado:

- teste da operabilidade geral;

- teste de desempenho (tempos de resposta);

- teste das possíveis perdas de dados;

- teste da influência da velocidade do coletor;

- teste da influência da taxa de ocupação do barramento ISOBUS.

No final do capítulo são feitas discussões comparando os resultados com os obtidos por trabalhos de outros pesquisadores.

\subsection{Apresentação dos Resultados}

Neste item são apresentados os relatórios gerados pelo simulador e a sequência de operações utilizada para gerar os gráficos a partir dos relatórios.

\subsubsection{Relatórios Gerados Pelo Simulador}

O simulador gera três tipos de relatório que podem ser abertos por qualquer ferramenta que trabalhe com planilhas eletrônicas, quais sejam:

- relatório log de eventos, aparece na própria tela do computador durante a simulação, como mostrado na Figura 5-1. O objetivo deste relatório é permitir ao usuário avaliar a operação do simulador, analisando a sequência de eventos gerados durante a simulação. As informações são salvas em arquivos no formato HTML. O guia de usuário do simulador (Apêndice "A") descreve os códigos que aparecem no relatório. 


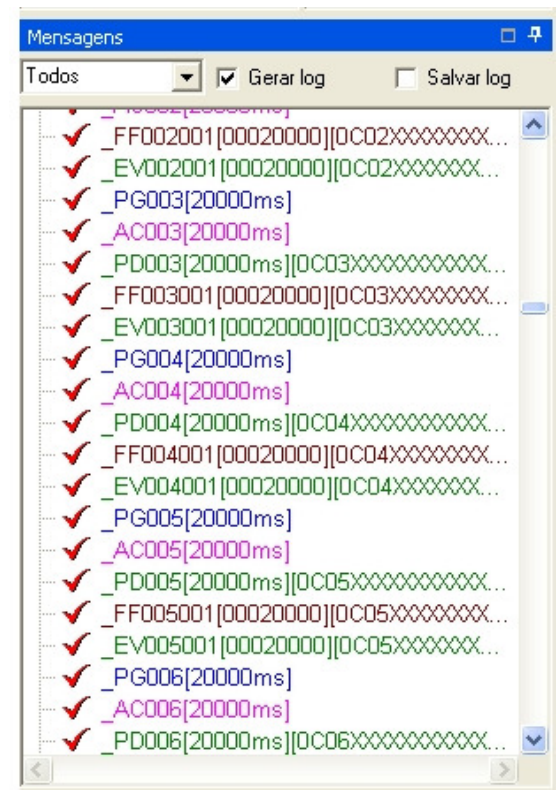

Figura 5-1 - Exemplo de relatório Log de eventos gerado na tela do simulador, durante uma das simulações.

- relatório da rede: arquivo no formato HTML contendo uma planilha com a descrição da rede montada pelo simulador para o cenário estabelecido. A Figura 5-2 mostra um exemplo deste relatório.

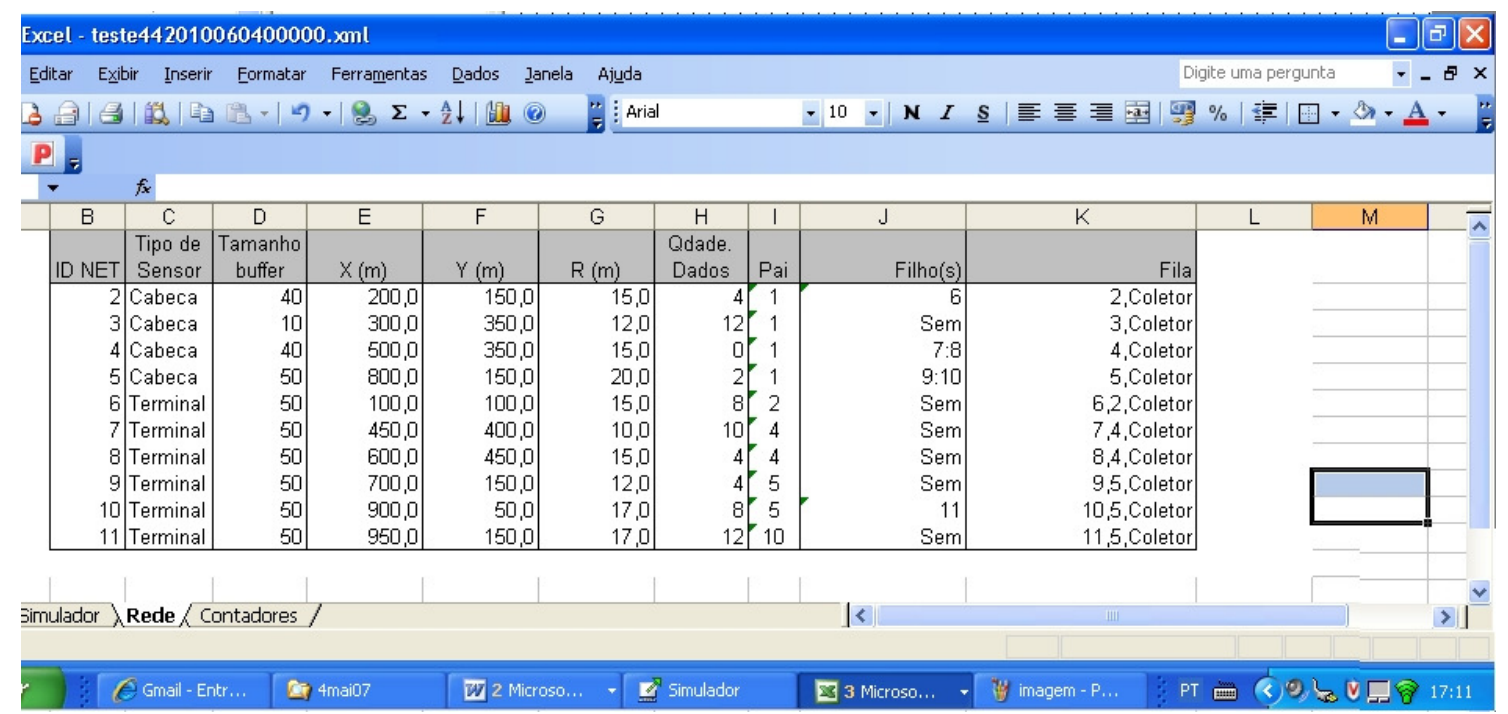

Figura 5-2 - Exemplo de relatório da rede gerada pelo simulador.

- relatório de resultados: relatório no formato HTML contendo uma planilha com o resultado das simulações, como o da Figura 5-3. Nesse relatório (coluna J), tem-se o resultado da tentativa de envio de um frame pela RSSF, até um nó coletor móvel. As colunas $\mathrm{E}, \mathrm{F}$ e $\mathrm{G}$ indicam os tempos de transmissão 
máximos, mínimos e médios, respectivamente. A coluna $D$ indica a média de frames recebidos por ciclo do veículo, que obteve o resultado indicado na coluna J.

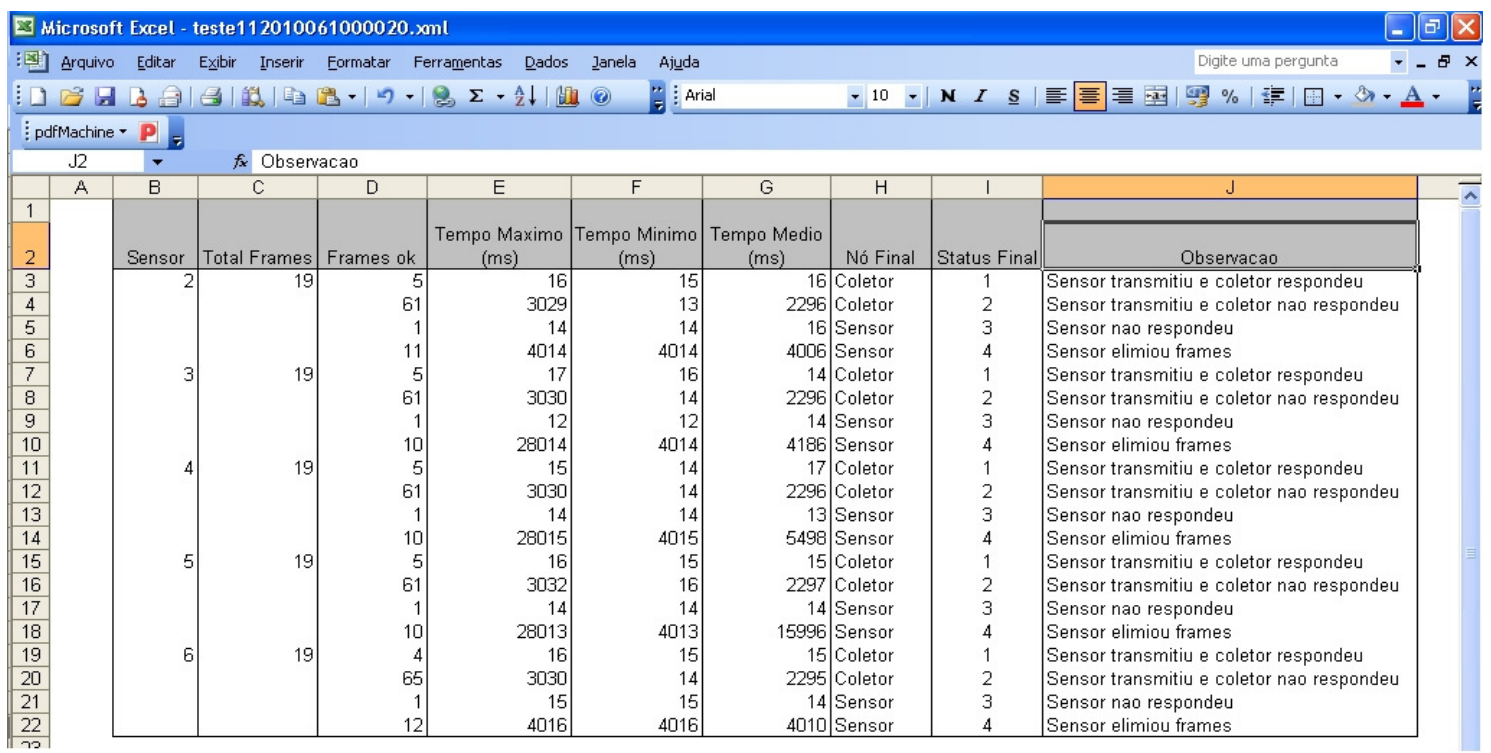

Figura 5-3 - Exemplo de relatório de resultados gerado pelo Simulador.

Por exemplo: a primeira linha do relatório da Figura 5-3 indica que o sensor de $\mathrm{ID}=2$ gerou em média 19 frames/ciclo, sendo que destes, 5 frames/ciclo chegaram ao dispositivo ISOBUS e que estes frames levaram de $15 \mathrm{~ms}$ a $16 \mathrm{~ms}$ para alcançar o dispositivo ISOBUS, tendo uma média de $16 \mathrm{~ms}$. Neste exemplo foram feitas cerca de 30 simulações, por aproximadamente meia hora.

\subsubsection{Tabela para Montagem dos Gráficos}

Para gerar os gráficos, foram obtidos 30 relatórios como os do item anterior (simulações). Para a obtenção desses relatórios, variou-se apenas uma das variáveis, no caso do exemplo, o intervalo de leitura de dados do ambiente pelos sensores entre 2 s e $50 \mathrm{~s}$. Desta forma pode-se elaborar tabelas como a Tabela 5-1: 
Tabela 5-1 - Exemplo de compilação dos dados obtidos pelas simulações com variação do intervalo entre as leituras de dados pelos sensores.

\begin{tabular}{cccc}
\hline $\begin{array}{c}\text { Intervalo entre } \\
\text { leituras (s) }\end{array}$ & $\begin{array}{c}\text { Média de } \\
\text { frames } \\
\text { ok (un.) }\end{array}$ & $\begin{array}{c}\text { tempo } \\
\text { máximo (s) }\end{array}$ & $\begin{array}{c}\text { tempo médio } \\
\text { dos frames } \\
\text { ok (s) }\end{array}$ \\
\hline 2,00 & 7,11 & 53,19 & 0,09 \\
4,00 & 4,49 & 53,19 & 0,12 \\
6,00 & 2,65 & 53,20 & 0,21 \\
8,00 & 2,18 & 53,19 & 0,25 \\
10,00 & 2,02 & 53,19 & 0,26 \\
12,00 & 1,79 & 53,20 & 0,30 \\
14,00 & 1,62 & 53,20 & 0,34 \\
16,00 & 1,48 & 53,19 & 0,36 \\
18,00 & 1,43 & 53,19 & 0,37 \\
20,00 & 1,42 & 53,19 & 0,37 \\
22,00 & 1,38 & 53,19 & 0,38 \\
24,00 & 1,36 & 53,20 & 0,39 \\
26,00 & 1,34 & 53,20 & 0,39 \\
30,00 & 1,30 & 53,21 & 0,42 \\
35,00 & 1,25 & 53,20 & 0,42 \\
40,00 & 1,21 & 53,20 & 0,43 \\
45,00 & 1,15 & 53,19 & 0,45 \\
50,00 & 1,09 & 53,20 & 0,48 \\
\hline
\end{tabular}

\subsection{Análise da Operabilidade}

Para avaliação da operabilidade foram executados testes gerais, de temporização, de perda de informação, de troca de rota, os quais são descritos e os resultados são apresentados em seguida.

\subsubsection{Testes de Gerais}

Foram criados dois cenários, típicos desta aplicação, cada qual com 30 simulações (Item 4.2.2.1). Nesses cenários, o valor das principais variáveis é gerado de forma aleatória pelo simulador, dentro de uma faixa compatível com as aplicações assim estabelecidas:

- alcance dos sensores: 25 a $45 \mathrm{~m}$;

- velocidade do veículo: 10 a $30 \mathrm{~km} / \mathrm{h}$;

- densidade de dados gerados pelos sensores: 0,125 a 20 dados/s;

- densidade de tráfego ISOBUS: 15 a 25\%;

- distância dos sensores ao trajeto do veículo: 3 a 6 m.

Os resultados obtidos mostraram que tanto na topologia estrela (sensores em linha) quanto na cluster tree não ocorreu sequer uma perda de informação e que a 
necessidade de se repetir as transmissões foi inferior a 0,01\%; mesmo nestes casos, ocorreu uma única retransmissão. O tempo gasto para que uma informação percorresse toda a rede foi, em média, inferior a $15 \mathrm{~ms}$ na topologia estrela e menor que $17 \mathrm{~ms}$ na topologia cluster tree. O maior tempo gasto foi da ordem de $53 \mathrm{~s}$, sendo praticamente o tempo que a informação permaneceu no buffer do sensor aguardando a passagem do veículo. Estes dados em conjunto com o tempo de amostragem adequado das variáveis escolhidas são relevantes para o correto dimensionamento do buffer.

As simulações executadas indicaram que a densidade de amostras geradas pelo sensor é a variável que possui maior influência sobre o tempo que um dado leva do instante em que é gerado no sensor até ser recebido pelo dispositivo ISOBUS. No próximo item são mostrados dois gráficos elaborados a partir das simulações.

\subsubsection{Testes de Temporização}

O Gráfico 5-1 e o Gráfico 5-2 apresentam os tempos médios de transmissão das amostras, em função da densidade de amostras geradas pelos sensores, para cada uma das topologias estudadas. Uma vez que em todas as simulações deste teste os sensores foram configurados para gerar sempre o mesmo número de frames (2 dados de 16 bits), tanto a densidade de amostras quanto a densidade de dados gerados é proporcional ao inverso do intervalo em que os dados são lidos do ambiente. Desta forma variou-se o intervalo entre as leituras do sensor para se obter uma maior ou menor densidade de amostras.

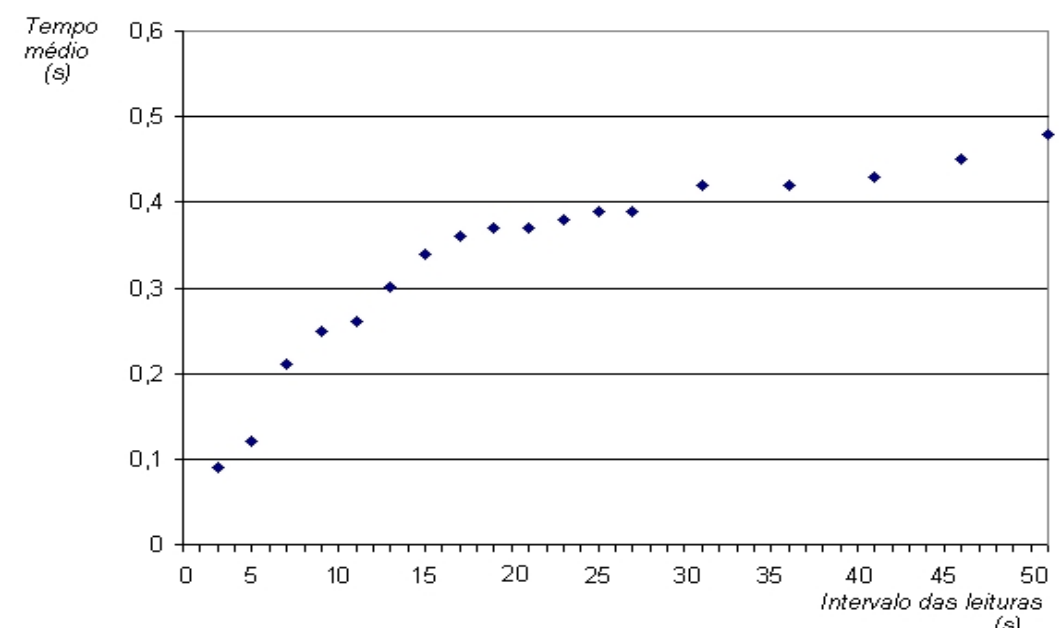

Gráfico 5-1 - Tempo médio de transmissão em função do Intervalo entre os dados gerados com a topologia estrela. 
Analisando-se o Gráfico 5-1 e o Gráfico 5-2, pode-se observar que dentro dos intervalos definidos para as simulações, os tempos médios de transmissão são totalmente aceitáveis para uma aplicação no contexto proposto.

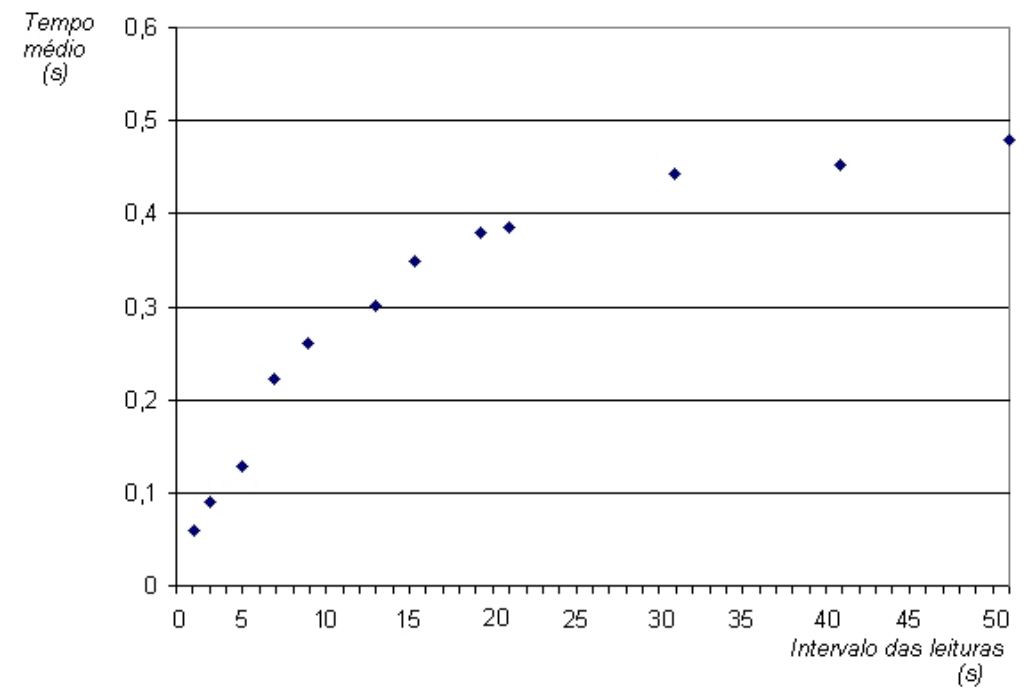

Gráfico 5-2 - Tempo médio de transmissão em função do Intervalo entre os dados gerados com a topologia cluster tree.

Considerou-se neste trabalho como tempo de transmissão o intervalo entre o instante em que o sensor lê um dado até o instante em que este dado é recebido por um dispositivo ISOBUS. Ou seja, tempo de transmissão é a soma do tempo em que o dado ou amostra permanece no buffer com o tempo em que a amostra leva para percorrer a rede ZigBee, até ser recebida pela interconexão no veículo, e com o tempo que a interconexão leva para enviá-la a um dispositivo ISOBUS.

Outra característica importante que se pode observar de ambas as figuras é uma discreta mudança de comportamento para intervalos de leituras menores que $14 \mathrm{~s}$. Acredita-se que isto possa se justificar pelo rápido descarregamento do buffer de dados, assim que o veículo entra no alcance do sensor. Neste teste foi calculado que o tempo de permanência do veículo dentro do raio de alcance do rádio do sensor foi de 10,64 s. Ou seja, o tempo de permanência do dado no buffer cai significativamente nessa situação, pois para tempos de amostragem menores que 10,64s sempre é gerada pelo menos uma amostra que é transmitida imediatamente, reduzindo o tempo médio de transmissão. 
Observa-se também que os tempos médios exigidos pela topologia cluster tree são alguns milissegundos superiores ao da topologia estrela; porém, não existem diferenças no tempo máximo, como mostra o Gráfico 5-3, pelo qual se pode observar que não houve variação significativa nesse tempo, em função da densidade de dados gerados pelo sensor. Isto ocorre porque os temporizadores do simulador contam os tempos dos dados perdidos até o valor configurado para o time out. Como este tempo é muito superior aos tempos gastos na comunicação, o resultado apresentado no gráfico refere-se praticamente aos time out dos dados perdidos, que são idênticos em ambas as topologias.

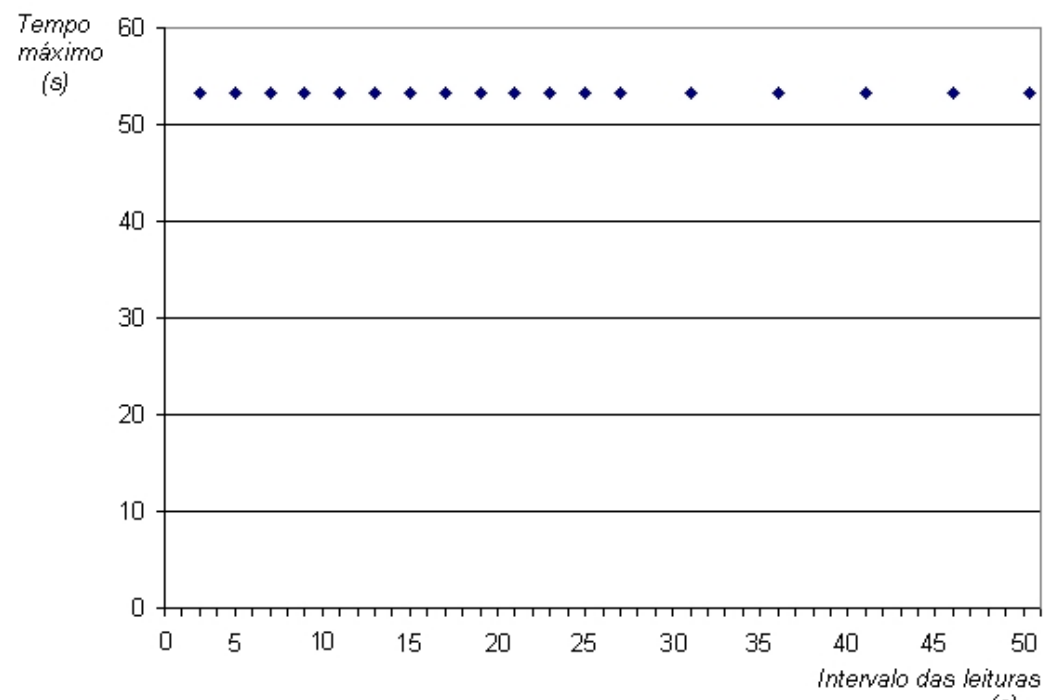

(s)

Gráfico 5-3 - Tempos máximos de transmissão em função do Intervalo entre os dados gerados.

\subsubsection{Testes de Perda de Informação}

Foram realizados dois testes, um com a topologia estrela no qual todos os sensores são colocados a $11 \mathrm{~m}$ do caminho do veículo coletor de dados e outro com a topologia cluster tree, na qual apenas os nós cabeça de cluster são colocados a 11 $\mathrm{m}$ do caminho do coletor. Também foram fixadas as seguintes variáveis e seus respectivos valores:

- alcance dos sensores: $30 \mathrm{~m}$;

- velocidade do veículo: $20 \mathrm{~km} / \mathrm{h}$; 
- tamanho do buffer dos sensores para a topologia estrela: 64 bytes para a topologia cluster tree; 16 bytes para os nós terminais; 128 bytes para os nós cabeça de cluster;

- densidade de amostras geradas pelos sensores: 10 amostras/s;

- densidade de tráfego ISOBUS: $30 \%$.

Fez-se, então, simulações variando uma destas variáveis de cada vez, apresentadas nos itens a seguir.

\subsubsection{Influência do Alcance dos Sensores na Perda de Informações}

O Gráfico 5-4 apresenta os resultados das simulações executados com os sensores gerando aleatoriamente dados em intervalos entre $0,1 \mathrm{~s}$ a $9 \mathrm{~s}$ e variando o alcance dos sensores. Os resultados foram idênticos para as duas topologias (estrela e cluster tree). Não foram testados alcances menores que $11 \mathrm{~m}$, pois para distâncias inferiores a essa o tempo de permanência do veículo no alcance dos sensores seria nula ou não seria suficiente para transmitir os dados.

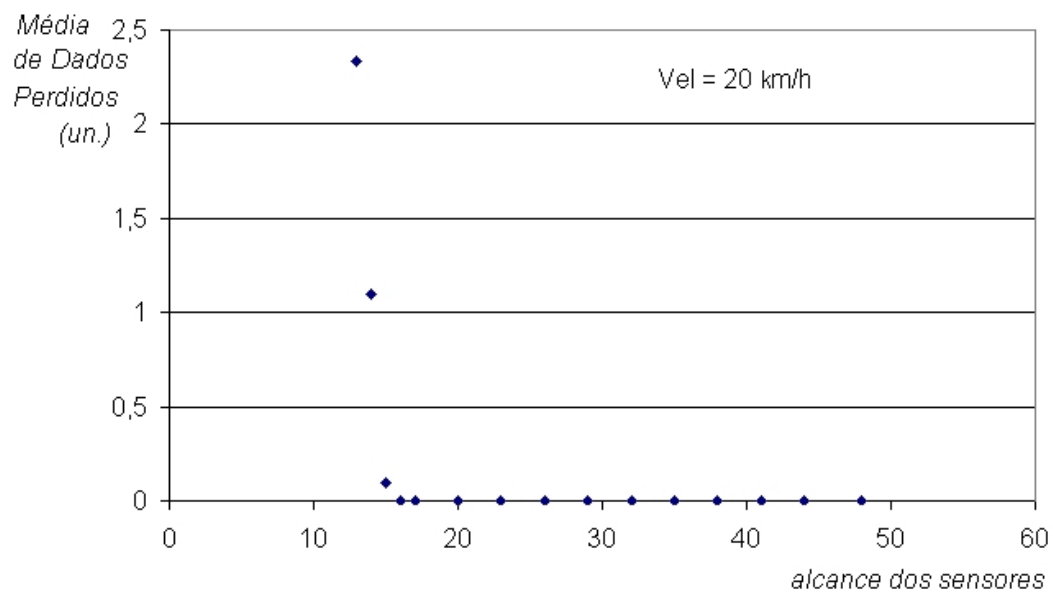

(m)

Gráfico 5-4 - Média de dados perdidos em função do alcance dos sensores colocados a $11 \mathrm{~m}$ do trajeto do veículo coletor a $20 \mathrm{~km} / \mathrm{h}$.

Pode-se observar no Gráfico 5-4 que não houve perda de frames para os sensores com alcance superior a $15 \mathrm{~m}$. Entre $15 \mathrm{~m}$ e $12 \mathrm{~m}$ ocorreram perdas, sendo maior quanto menor o alcance do sensor. A perda de frames ocorrida pode ser justificada pelo pouco tempo em que o veículo coletor permanece ao alcance dos sensores. 


\subsubsection{Influência da Velocidade do Veículo}

No Gráfico 5-5 apresentam-se os resultados da avaliação da influência da velocidade do veículo em relação à interconexão proposta. Observa-se que ocorreu uma única perda de frame em uma simulação com o veículo a $29 \mathrm{~km} / \mathrm{h}$. Os dados foram gerados em intervalos que variavam de $0,1 \mathrm{~s}$ a $7 \mathrm{~s}$.

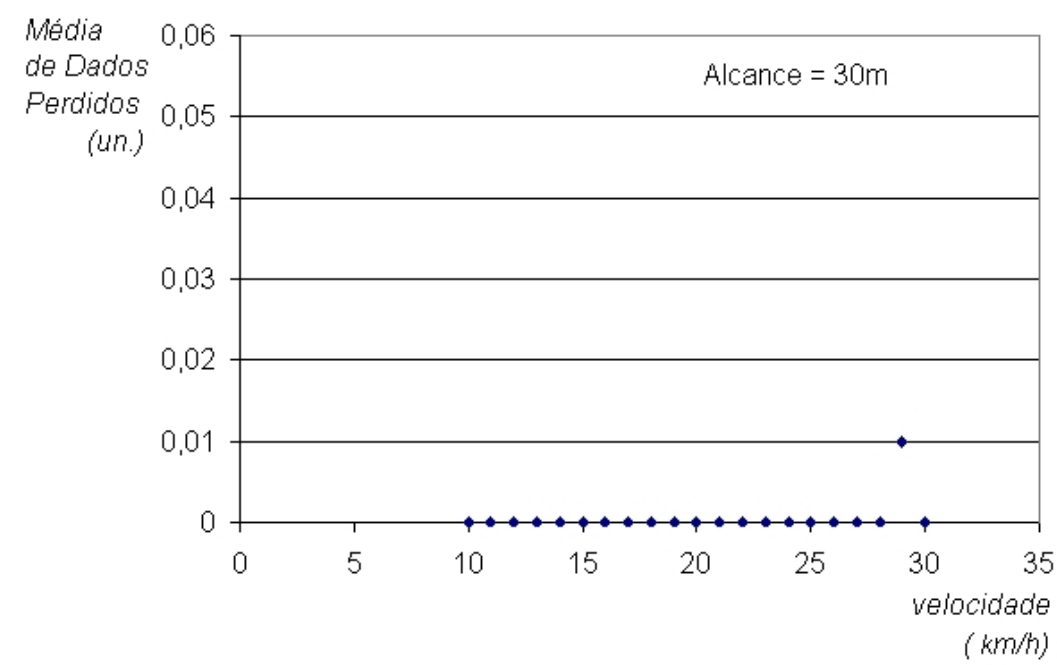

Gráfico 5-5 - Média de dados perdidos em função da velocidade do veículo com os sensores com $30 \mathrm{~m}$ de alcance.

\subsubsection{Influência do Tamanho do Buffer dos Sensores}

Foram feitas simulações com oito tamanhos de buffers: 256 , 128, 64, 32, 16, 8, 4 e 0 bytes. Os Gráficos 5-6 e 5-7 mostram a média de frames transmitidos que são recebidos pelo dispositivo ISOBUS.

A análise dos resultados permite verificar que:

- sensores em que um buffer não foi configurado (tamanho 0 no gráfico), raramente conseguiram transmitir um frame;

- para buffers menores que 15 bytes foi transmitido um único frame de dado;

- na topologia estrela para buffers maiores ou iguais a 15 bytes, a média de frames transmitidos foi praticamente constante (Gráfico 5-6), independente do tamanho do buffer;

- a topologia cluster tree mostrou-se sensível ao tamanho do buffer para buffers maiores que 15 bytes (Gráfico 5-7). 


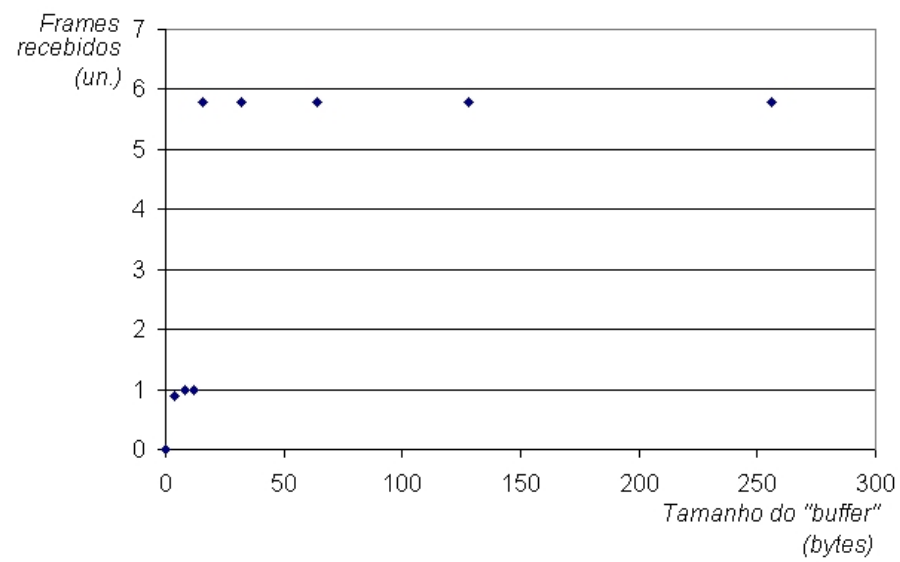

Gráfico 5-6 - Média de frames recebidos pelo dispositivo ISOBUS em função do tamanho do buffer dos sensores (FIFO) na topologia estrela.

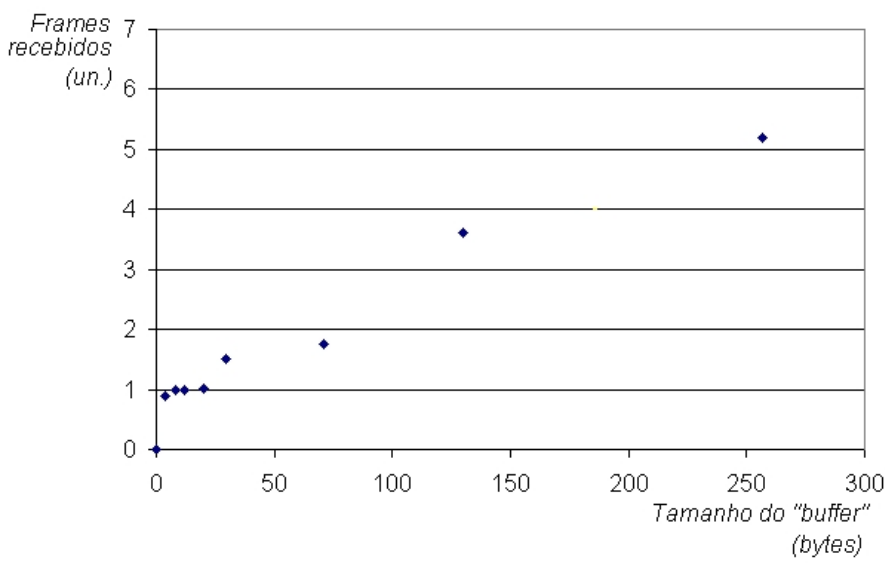

Gráfico 5-7 - Média de frames recebidos pelo dispositivo ISOBUS em função do tamanho do buffer dos sensores (FIFO) na topologia cluster tree.

\subsubsection{Influência da Densidade de Amostras Coletadas pelos Sensores}

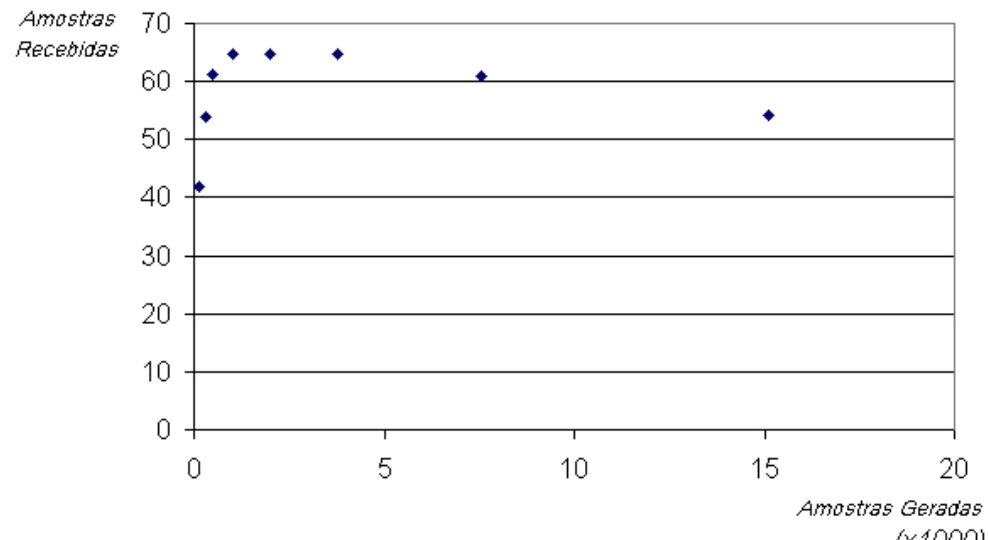

Gráfico 5-8 - Amostras recebidas em função de milhares de amostras geradas nos sensores. 
Do Gráfico 5-8 verifica-se que o sistema atinge seu melhor desempenho quando dimensionado para gerar em torno de 1.000 amostras de dados, situação em que o dispositivo ISOBUS recebeu 64 frames; porém, em todos os casos foram recebidas pelo menos uma amostra de cada variável. O comportamento foi idêntico para as duas topologias (estrela e cluster tree).

\subsubsection{Densidade de Tráfego da Rede ISOBUS}

Os dados da simulação são semelhantes aos do Item 4.3.3, porém com maiores restrições na taxa de ocupação do barramento ISOBUS. Dentro dos parâmetros testados, nas simulações não foi verificada perda de dados devida à taxa de ocupação. O Gráfico 5-9 mostra a influência da taxa sobre o tempo de comunicação na topologia estrela, ou seja, o intervalo de tempo desde o instante em que o dado é gerado pelo sensor, até o instante que ele é recebido por um dispositivo ISOBUS.

Neste teste, as simulações foram executadas com um único sensor, gerando um único dado antes de o coletor entrar no alcance do sensor e então transmitido assim que a comunicação se torna possível. Este procedimento foi definido para se evitar a influência dos demais parâmetros da rede ZigBee. Foram feitas simulações variando-se a taxa de utilização do barramento ISOBUS e a prioridade do frame transmitido pela interconexão.

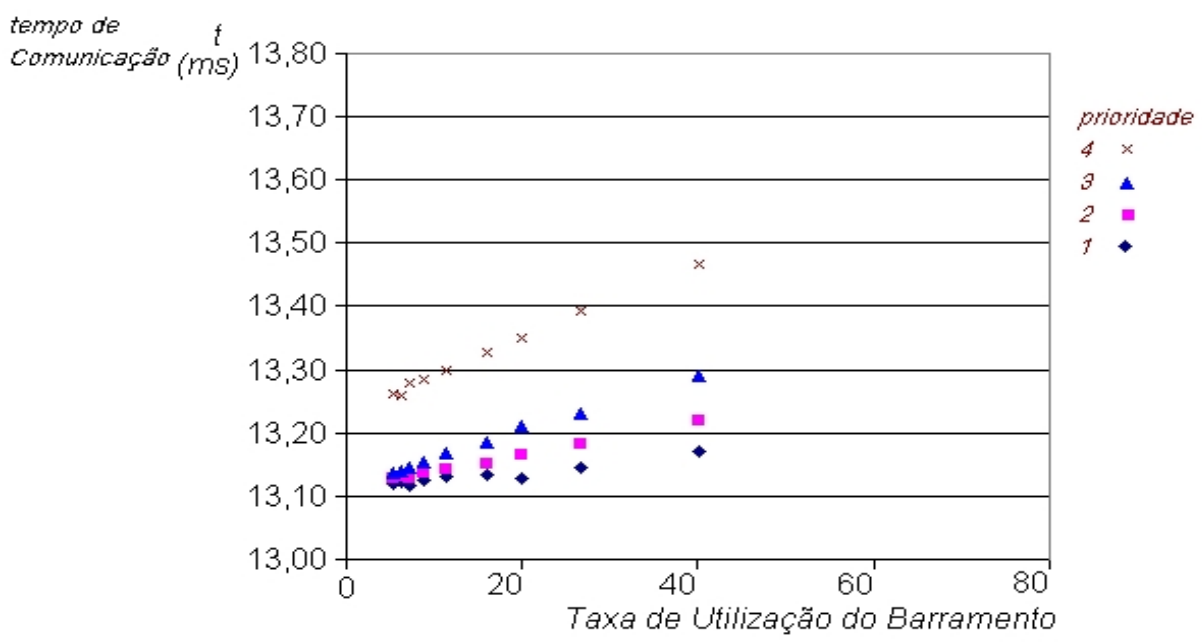

(\%)

Gráfico 5-9 - Tempo de comunicação em função da taxa de ocupação do barramento ISOBUS (topologia estrela).

Os resultados apresentados no Gráfico 5-9 mostram influência relativamente pequena da taxa de utilização do barramento ISOBUS, em especial quando o dispositivo de interconexão possui prioridade alta. 
Uma segunda simulação foi realizada repetindo o Item 5.2.2, porém com um único sensor e para taxas de ocupação do barramento ISOBUS de $10 \%, 20 \%$ e $40 \%$. Os resultados são apresentados no Gráfico 5-10.

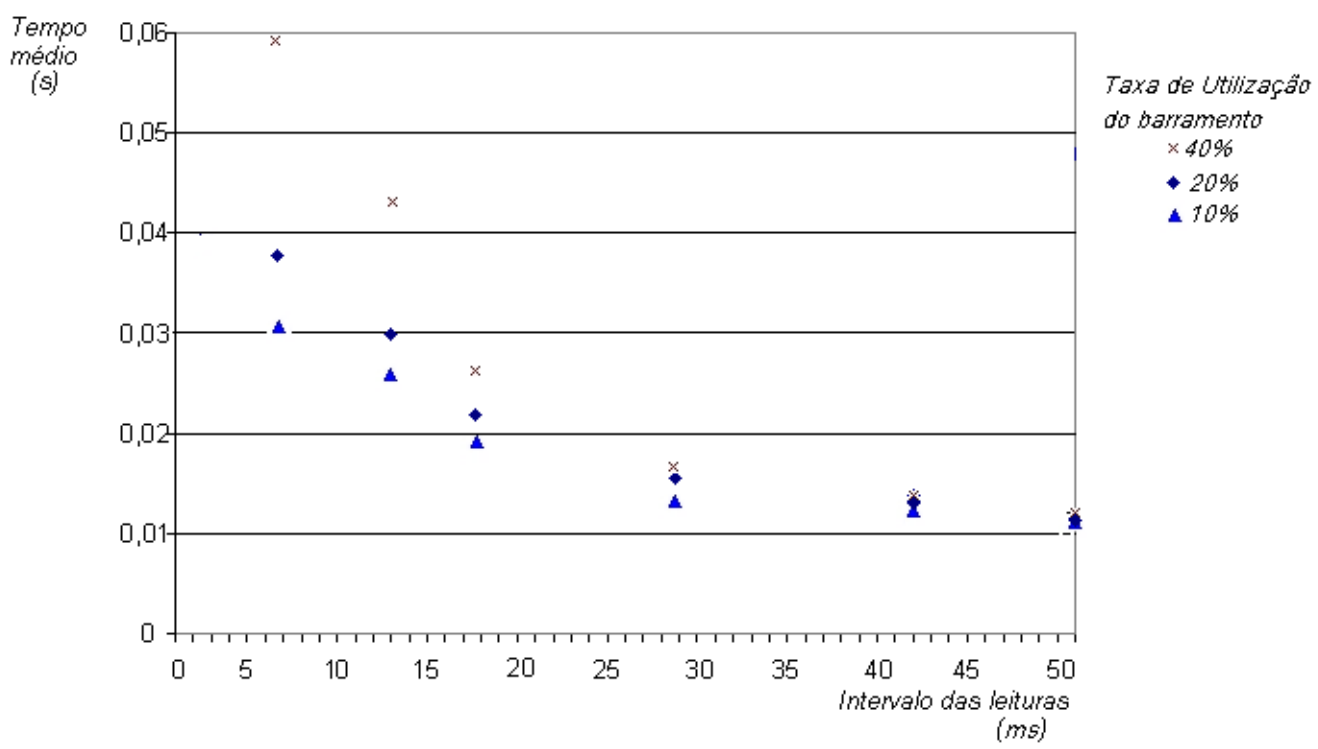

Gráfico 5-10 - Tempo de Comunicação em função do intervalo entre leituras para taxas de ocupação do barramento ISOBUS de $10 \%, 20 \%$ e $40 \%$.

Como mostrado no Gráfico 5-10, a influência do tráfego ISOBUS é pequena quando o fluxo de dados gerados pelos sensores também é pequeno (abaixo de um frame a cada 30 ms com dois dados cada), porém a partir deste valor a influência do tráfego ISOBUS cresce significativamente, em especial quando a interconexão possui uma baixa prioridade.

\subsubsection{Análise da Influência das Trocas de Rota}

Para a simulação das trocas de rotas, foram repetidas as simulações do Item 4.3.2, porém com uma troca de rota após 5 min de operação. Foram repetidos ciclos de passagem do veículo durante $10 \mathrm{~min}$, gerando dados a cada ciclo do veículo. $\mathrm{O}$ gráfico gerado por estas simulações (Gráfico 5-11) registra a quantidade média de frames recebidos pelo dispositivo ISOBUS por ciclo do veículo, em função do tempo de simulação. 


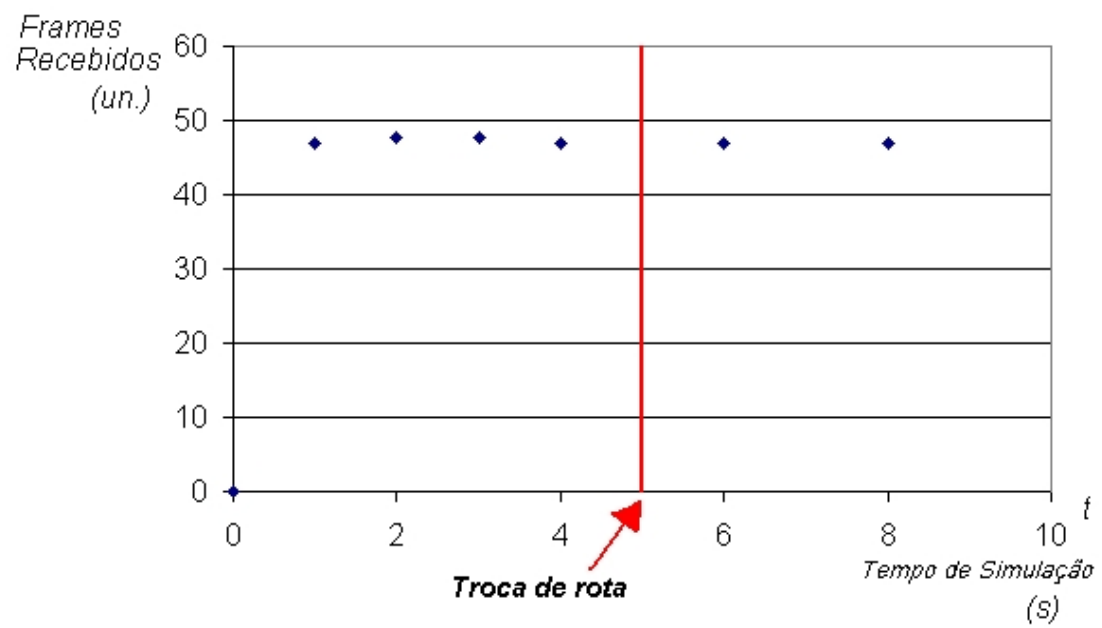

Gráfico 5-11 - Média de frames recebidos pelo dispositivo ISOBUS por ciclo em função do tempo de simulação, com uma troca de rota após 5 min de teste.

A quantidade frames recebida por ciclo do veículo praticamente não se altera em todo o período de teste, permanecendo entre 47,0 e 47,8. Porém, ao analisar o ciclo em que ocorreu a troca de rota, verificou-se que nele apenas 4,8 frames foram recebidos em média. Também se verificou que apenas um dos ciclos foi afetado (o que ocorreu a troca de rota).

O comportamento foi idêntico nas duas topologias e se justifica porque o ciclo do veículo é muito demorado - 1,4 min - tempo suficiente para a troca de rotas e para a RSSF voltar a operar.

\subsection{Considerações Gerais sobre os Resultados}

Neste item são feitas considerações gerais sobre os resultados apresentados e a sua comparação com os resultados de trabalhos correlatos.

\subsubsection{Quanto aos Tempos Obtidos}

Godoy (2007), baseando-se nos trabalhos de Lian et al. (2006), destaca que um dos fatores que mais influenciam no desempenho de uma rede é o intervalo de tempo em que os dados são gerados e transmitidos. Ou seja, quanto menor esse tempo, maior a quantidade de dados que trafegam no meio físico em um determinado intervalo de tempo e, consequentemente, pior o desempenho da rede. Isto acontece porque os frames disputam o meio entre si, gerando atrasos, uma vez que os frames "perdedores" da disputa têm de esperar os frames "vencedores". 
Os resultados apresentados no Item 5.2.2 mostram uma tendência inversa. Este resultado, aparentemente contraditório à afirmativa de Godoy (2007), é justificado porque na maior parte do tempo o sensor está fora do alcance do coletor; e apenas em um pequeno intervalo de tempo está no alcance deste, consequentemente, quanto menor o intervalo entre os dados, maior a probabilidade de alguns deles serem gerados e transmitidos neste intervalo de tempo.

\subsubsection{Quanto ao Desempenho Operacional}

Os tempos obtidos mostram que um dado pode levar de $10 \mathrm{~ms}$ a 0,5 s para alcançar o seu destino; porém, na maior parte do tempo, o dado está parado no buffer do sensor aguardando a sua vez de transmitir. Na realidade, o tempo efetivo em que o dado está transitando é de alguns poucos milissegundos, variando conforme a taxa de comunicação de ambas as redes.

Como as simulações foram realizadas com o ZigBee a 54 Kbps e o ISOBUS a 250 Kbps, ou seja a velocidade do ISOBUS foi quase cinco vezes maior que a do ZigBee, era de se esperar que a RSSF influenciasse mais no desempenho do sistema que a rede ISOBUS. Se, porém, for desconsiderado o tempo em que os dados permanecem no buffer do sensor aguardando o trator entrar no seu alcance, verifica-se que esta diferença não é muito relevante, pois a quantidade de dados gerada pelos sensores é muito pequena quando comparada com a gerada pelos dispositivos ISOBUS, além dos frames ZigBee serem mais simples, como mostrados no Capítulo 2.

\subsubsection{Quanto às Perdas de Dados}

Os resultados obtidos mostram uma importante perda de dados (Gráfico 5.8), justificada por ser inerente ao sistema, uma vez que o nó coletor está, na maior parte do tempo, fora do alcance dos sensores. O Gráfico 5.8 mostra, por exemplo, que apesar de terem sido gerados milhares de frames com as amostras dos dados, apenas 60 frames chegam ao dispositivo ISOBUS.

Os resultados apresentados no Item 5.2.3.3 mostram a necessidade da existência de um buffer com capacidade para armazenamento de pelo menos uma amostra de cada variável monitorada. Para os casos simulados, na topologia estrela, buffers acima de 16 bytes de dados permitem a recepção de pelo menos duas amostras. $\mathrm{Na}$ 
topologia cluster-tree, o buffer mínimo para duas amostras deverá ser em torno de 24 bytes. A inexistência do buffer pode inviabilizar algumas aplicações.

Apesar de não ser usual, para aplicações de monitoramento contínuo, chamadas de on-the-go, seria necessário que o veículo repetisse a trajetória de tempos em tempos e que o buffer fosse capaz de armazenar um histórico das amostras da variável entre uma passada e outra do veículo. Devido à baixa capacidade de memória dos sensores sem fio, este tipo de aplicação só seria viável na monitoração de variáveis com variação lenta, o que ocorre com a maioria das variáveis ambientais. Assim, poderia ser implementado um tempo de ciclo grande e, consequentemente, poucas amostras do dado necessitariam ser armazenadas no buffer.

\subsubsection{Quanto à Densidade de Tráfego ISOBUS}

Em seu trabalho, Godoy (2007) fez simulações de uma rede ISOBUS, avaliando a densidade de trafego de dados sob dois aspectos principais: tempo de resposta e taxa de utilização do barramento. Os tempos de resposta obtidos foram inferiores a $13 \mathrm{~ms}$, enquanto que o simulador deste trabalho obteve tempos sempre acima de 10 ms, alcançando tempos próximos a 0,5 s (Gráfico 5.1). Isto ocorre porque no simulador estão considerados os tempos em que o dado permanece armazenado no buffer dos sensores até que o veículo esteja ao seu alcance. Outra consideração importante é a prioridade em que o dado é colocado no barramento ISOBUS. Portanto os resultados aqui apresentados são semelhantes aos obtidos por Godoy (2007).

Apesar de o tempo médio que um dado leva para ser transmitido (tempo de transmissão) ser acima de $10 \mathrm{~ms}$, o simulador da interconexão conseguiu transferir dados que foram gerados a taxas inferiores, próximas a $5 \mathrm{~ms}$. Isto ocorre devido aos dois buffers implementados (no sensor e na interconexão) que retêm os dados até que possam repassá-los, evitando a sua perda.

\subsubsection{Quanto à Topologia}

Na proposta do presente trabalho são avaliados os resultados de duas topologias estrela e cluster tree - com o veículo em trajetórias padrão, como mostrado no Item 4.3.1. 
$\mathrm{Na}$ topologia estrela, a comunicação ocorre apenas quando o veículo está ao alcance dos sensores, ou seja, o consumo de energia é igual em todos os sensores e pode ser ajustado para um ponto no qual o ciclo de envio de dados seja o maior possível, desde que não prejudique a eficiência da aplicação.

A topologia em cluster tree é sugerida como opção para culturas nas quais o alcance é um fator crítico, seja porque o veículo passa longe de alguns nós sensores, seja porque o sinal sofre muita interferência de obstáculos. Nessas situações é comum que os nós cabeça de cluster tenham um consumo de energia maior, o que pode ser um limitante para algumas aplicações.

Os resultados mostram que as diferenças de tempos de transmissão entre as duas topologias variam de $1,5 \mathrm{~s}$ a $14 \mathrm{~s}$, a favor da topologia estrela, o que não inviabiliza aplicações na topologia cluster tree.

Um estudo semelhante à topologia estrela (todos se comunicam diretamente com o veículo) foi feito por Pereira et al. (2004), com o objetivo de propor uma metodologia para definir trajetória para o nó móvel aplicado a um robô agrícola percorrendo uma rede de sensores.

\subsection{Considerações sobre o Capítulo}

Neste capítulo foram apresentados os resultados obtidos com as simulações na forma de gráficos. O modo como os gráficos foram gerados e uma comparação entre os resultados obtidos pelo simulador como de outros pesquisadores em trabalhos semelhantes foram apresentados e discutidos. As diferenças apresentadas foram justificadas nas discussões apresentadas. 


\section{CONCLUSÕES}

Neste capítulo são apresentadas as conclusões obtidas das análises dos resultados, direcionadas pelos objetivos propostos, e considerando o contexto apresentado. Os Itens $6.1,6.2$ e 6.3 avaliam o alcance dos objetivos propostos. No Item 6.4 são citadas as duas maiores dificuldades encontradas neste trabalho. Finalmente no Item 6.5 são propostos novos trabalhos que poderão aprimorar os resultados obtidos ou que poderão abordar aspectos que este trabalho recomenda que sejam aprofundados.

\subsection{Quanto ao Desempenho da Interconexão Proposta}

Entre os objetivos propostos buscou-se demonstrar que se um nó ZigBee estiver conectado à rede ISOBUS poderá responder a esta como um nó seu, permitindo, assim, que dispositivos desta rede tenham acesso automático aos dados da rede ZigBee. Como abordado no Item 5.3.2, a interconexão, nas condições simuladas, mostrou-se viável, quando utilizada em aplicações com as características apresentadas, atendendo aos aspectos temporais e ao limite de perda de dados.

Como exposto no Item 4.1, as conclusões que são apresentadas são fundamentadas nas simulações executadas, limitadas às condições propostas (conforme itens 3.5 e 4.2.2) e às restrições impostas pelo simulador; porém, acredita-se que sejam válidas para um trabalho em fase exploratória.

Outro aspecto proposto nos objetivos foi uma avaliação das possíveis perdas de dados, cujos resultados foram discutidos no Item 5.3.3. Pode-se concluir que a perda de dados, motivada por densidade de tráfego, tanto na rede ZigBee, quanto na rede ISOBUS é irrelevante para as aplicações propostas, porém a perda de dados devida ao baixo tempo no qual o nó coletor permanece ao alcance dos sensores, em especial durante as trocas de rotas, é significativa e precisa ser considerada nos projetos de implementação comentados nesta proposta. Também deve ser considerado que as interferências externas na rede ZigBee foram simuladas somente por meio de limitações no alcance dos sensores.

Como proposto nos objetivos deste trabalho, foram feitos estudos sobre a confiabilidade do sistema proposto. As simulações mostraram que, sob as condições 
apresentadas, um projeto cuidadoso do sistema pode resultar em um sistema confiável e seguro (reliability); porém, projetos que não levem em consideração as limitações apresentadas podem ser ineficientes, inseguros e de baixa confiabilidade. Para aplicações críticas, que tenham uma maior exigência de confiabilidade e segurança (safety), a solução de uma segunda passagem do nó coletor (trator) deve ser vista com restrições, pois em muitas aplicações isto não é possível, além do que implica em um aumento de custo e de tempo. Não foram testados cenários que envolvam aspectos de segurança contra invasões externas, como roubo de dados (security).

\subsection{Limitações Importantes}

Conforme discutido no Item 5.2.3.5, pode-se concluir que alguns cuidados devem ser tomados na implementação da interconexão proposta, em relação ao ISOBUS:

- o buffer da interconexão deve ser dimensionado e configurado para conter uma imagem completa de todos os dados da rede de sensores, de modo a garantir a troca de informações sem perdas;

- a interconexão deve ter prioridade adequada na rede ISOBUS, sendo que prioridade muito baixa pode provocar queda no desempenho quando da aquisição de dados dos sensores, enquanto que prioridade muito alta pode afetar o desempenho dos demais dispositivos da rede.

A proposta apresentada neste trabalho limita-se a um fluxo de dados dos sensores da rede ZigBee para um dispositivo ISOBUS. A comunicação com fluxo em sentido contrário, ou seja, do dispositivo ISOBUS para um elemento na rede de sensores, requer uma abordagem diferente e poderá ser objeto de trabalho futuro.

As simulações permitiram avaliar diversos aspectos da interconexão proposta e, em todas as simulações, os resultados foram compatíveis com os esperados para a aplicação agrícola contextualizada neste trabalho. Porém, como demonstraram os resultados, alguns cuidados são exigidos na implementação, dentre os quais se destacam:

- necessidade de um buffer capaz de armazenar os dados gerados antes de o veículo estar ao alcance dos sensores; 
- correta configuração do tempo de ciclo em que os dados são gerados, garantindo o baixo consumo dos sensores, sem haver perda de informação;

- avaliação do desempenho em condições de falha;

- correto posicionamento dos sensores, garantindo que estejam em alcance adequado à velocidade do veículo.

Apesar de o simulador se restringir a trajetórias retilíneas e uniformes, é possível testar outras trajetórias não retilíneas, dividindo-as em pequenos segmentos, que poderão ser aproximados a movimentos retilíneos, simulando-os individualmente. Empregando-se ferramentas de interpolação das diversas simulações, é possível chegar ao resultado para o que inicialmente seria um trajeto não retilíneo. Trabalhos futuros poderão avaliar a eficácia desta técnica.

\subsection{Sugestões Para Discussão nos Comitês da Norma ISO 11783}

A proposta apresentada neste trabalho parte do princípio de que a interconexão trabalhará a partir da rede ISOBUS, ora como uma NIU fieldbus, ora como uma ECU de sensoriamento. $O$ trabalho poderia ser simplificado caso o padrão ISOBUS contemplasse dispositivos específicos para esta conexão. Sendo assim, sugere-se aos comitês da ISO 11783, que as próximas revisões da norma contemplem:

- a inclusão de funções que permitam configurar sensores sem fio utilizando-se uma interconexão com a rede ISOBUS;

- a inclusão de uma NIU de interconexão, nos moldes da NIU, para as redes fieldbus atualmente prevista pela norma; porém, como um gateway para redes de sensores sem fio padrão ZigBee;

- a inclusão de mensagens específicas para uma interconexão, como a proposta neste trabalho, de modo que uma ECU ou mesmo um Terminal Virtual pudessem reconhecer dados enviados por um sensor sem fio.

Essas sugestões afetam diversas partes da norma, algumas das quais ainda em fase de revisão. Sendo assim, recomenda-se que as sugestões sejam enviadas a todos os grupos de estudo da norma ISO 11783. 


\subsection{Dificuldades Encontradas}

Dentre as dificuldades encontradas, duas tiveram especial importância pois poderiam comprometer o resultado do trabalho: a validação dos dados do simulador; o desenvolvimento do algoritmo para gerar dados aleatórios.

O projeto do simulador sofreu algumas modificações durante o desenvolvimento, visando à simplificação do uso; porém, ferramentas para validá-lo eficiente e rapidamente não foram desenvolvidas. Como resultado, o processo de validação foi realizado manualmente e passo a passo. Isto demandou tempo excessivo, em especial quando erros de programação eram encontrados e o processo tinha que ser refeito.

\subsection{Trabalhos Futuros Recomendados}

Entre os principais trabalhos futuros que possam complementar este e que possam ser sugeridos tem-se:

- Implementação física da interconexão: como citado no Item 6.1 , as simulações realizadas precisam ser complementadas por testes em campo. Um futuro trabalho seria a implementação física da interconexão e a comparação dos resultados obtidos com a implementação física com os resultados das simulações.

- Avaliação da substituição de sensores inseridos em tratores e implementos por sensores sem fio: em algumas aplicações agrícolas, os sensores são instalados no próprio trator ou nos implementos a ele acoplados e enquanto percorrem o ambiente, vão coletando dados e enviando a uma ECU de sensoriamento. Um trabalho que se recomenda seria avaliar a substituição desses sensores por sensores sem fio e da ECU de sensoriamento pela interconexão proposta neste trabalho. Este tipo de implementação poderia facilitar muito a instalação dos sensores.

- Estudo do Desempenho da Interconexão da Rede ISOBUS com uma Rede Sem Fio de Sensores e Atuadores: este trabalho resumiu-se ao estudo da aquisição de dados de uma RSSF e a sua interconexão com a rede ISOBUS. Recomenda-se que possa ser complementado com um estudo de aplicações 
nas quais as demais fases do ciclo da Agricultura de Precisão sejam realizadas totalmente embarcadas no trator, ou seja, ao mesmo tempo em que o trator passa coletando informações, aciona os implementos para possíveis correções e intervenções, também conhecidas como on-the-go.

- Proposta para Melhorar a Eficiência Energética de uma Interconexão de uma RSSF com a rede ISOBUS; o consumo de energia em RSSFs é um fator crítico que não pode ser desconsiderado em qualquer aplicação; porém, este estudo não fez parte do escopo deste trabalho; portanto, recomenda-se que em trabalhos futuros tal consumo seja avaliado e que se proponham soluções para otimizar o consumo de energia no sistema aqui proposto.

\subsection{Considerações Finais}

As duas tecnologias emergentes, ISOBUS e RSSF, possuem grande potencial na agricultura e em especial na Agricultura de Precisão. A interconexão entre as redes ISOBUS e ZigBee pode representar uma mudança fundamental no processo tradicional da Agricultura de Precisão, pois possibilita, em algumas aplicações, que todo o ciclo seja executado por um veículo em tempo real (on-the-go), sem a necessidade de processamentos externos. Uma futura padronização da interconexão e a consequente disseminação pelos equipamentos agrícolas tornarão a tecnologia mais simples e mais acessível ao agricultor comum.

Como contribuições relevantes deste trabalho podem-se citar:

- comparação entre os protocolos de comunicação ISOBUS e ZigBee, segundo o modelo de referência ISO/OSI;

- proposta de uma arquitetura de interconexão dos padrões ISOBUS e ZigBee em sistemas agrícolas;

- sugestões para futuro projeto de uma NIU de interconexão entre as duas redes a partir de uma ECU de sensoriamento;

- programa computacional, o simulador, capaz de gerar variações aleatórias em torno de um cenário especificado e simular o comportamento da comunicação das duas redes. Este simulador é um produto que pode ser usado para novos trabalhos exploratórios, podendo ser melhorado e expandido, incluído novas funções e adaptações para outras aplicações. 


\section{REFERÊNCIAS}

ALVES FILHO, M.S.; CUNHA, R.A.; CUGNASCA, C.E. Application of reactive agents in automatic bindings of LonWorks networks devices. In: ICINCO 2009 - 6th INTERNATIONAL CONFERENCE ON INFORMATICS IN CONTROL, AUTOMATION AND ROBOTICS, 6., 2009, Milão - Itália. Proceedings... Milão: Springer-Verlag, 2009. p.1-5.

ATMEL. IEEE 802.15.4 MAC. 2006. 35p. User Guide - disponível em http://www.atmel.com/dyn/resources/prod documents/doc5182.pdf. 2004. Acesso em 10/07/2010.

AUERNHAMMER, H. The Role of Mechatronics in Crop Product Traceability. Agricultural Engineering International: the CIGR Journal of Scientific Research and Development, Chicago - USA, v.4, n.1, Invited Overview Paper. 2002.

BANZAL, S. Data and Computer Network Communication. Boston - USA: Firewall Media. 2007. p.460-461.

BATISTA E.A. et. al. Automação de casa de vegetação utilizando plataforma IEEE 1451 e comunicação sem fio. In: CONGRESSO SBIAgro, 7., 2009, Viçosa - Brasil. Anais... Viçosa: UFV, 2009. p.1-5.

BENAVENTE, J.C.C. et al. Uma Aplicação de Rede de Sensores Sem Fio para Monitoramento Ambiental em uma Cultura de Milho. In: CONGRESSO SBIAgro, 7., 2009, Viçosa - Brasil. Anais... Viçosa: UFV, 2009a. p.1-5.

BENAVENTE, J.C.C. et al. Uma proposta de arquitetura para monitoramento remoto de vinhedos em tempo real. In: CONGRESSO SBIAgro, 7., 2009, Viçosa - Brasil. Anais... Viçosa: UFV, 2009b. p.1-5.

BHATTI, S. et al. MANTIS OS: An Embedded Multithreaded Operating System for Wireless Micro Sensor Platforms. ACMKluwer Mobile Networks \& Applications (MONET) Journal, New York - USA, Special Issue on Wireless Sensor Networks, 2005. p.1-7.

BORBA, M. M. Z.; TORRES, A. O uso da informática nas empresas rurais da região de Jaboticabal/SP. In: CONGRESSO SBIAgro, 4., 2003, Porto Seguro - Brasil. Anais... Lavras: SBIAgro, 2003. p.1-5.

BORGELT, S.C. Sensing and measurement technologies for soil specific management. In: SOIL SPECIFIC CROP MANAGEMENT: A WORKSHOP ON RESEARCH AND DEVELOPMENT ISSUES, 1., 1992, Minneapolis - USA. Proceedings... Minneapolis: American Society of Agronomy (ASA), 1992. p.141-157.

BOURCIER, J.; ESCOFFIER, C.; LALANDA, P. Implementing home-control applications on service platform. In: IEEE CONSUMER COMMUNICATIONS and NETWORKING CONFERENCE, 4., 2007, Las Vegas - USA. Proceedings... Las Vegas: (CCNC'07), 2007. p.925-929.

CABRINI, F.H. Caracterização e análise de desempenho de uma rede de sensores sem fio. 2006. 102p. Dissertação (Mestrado) - Escola Politécnica-USP, São Paulo - Brasil, 2006.

CAMILLI, A. Um Estudo sobre o Aspecto da Utilização de Redes de Sensores Sem Fio em Aplicações para Agricultura de Precisão. 2004. 181p. Tese (Doutorado) - Escola Politécnica-USP, São Paulo - Brasil, 2004.

CAMILLI, A. et.al. From wireless sensors to field mapping: Anatomy of an application for precision agriculture. Computers and Electronics in Agriculture, Amsterdam Netherlands, v.58, n.1, p.25-36, 2007.

CARVALHO, M.A.; SILVA, C.R.L. Vulnerabilidade do comércio agrícola brasileiro. Revista de Economia e Sociologia Rural, Brasília - Brasil, v.43, n.1, p.9-28, 2005. 
CHENG, L. et al. Monitoring Wireless Sensor Networks by Heterogeneous Collaborative Groupware. In: SICON/04 - SENSORS for INDUSTRY CONFERENCE, 1., 2004, New Orleans - USA. Proceedings... New Orleans: IEEE Instrumentation and Measurement Society, 2004. p.1-5.

CHENG, L.; ZHANG, X.; BOURGEOIS, A.G. IEEE 802.15.4 Simulation Module in Network Simulator GTNetS. In: VEHICULAR TECHNOLOGY CONFERENCE, 63., 2006, Melbourne Austrália. Proceedings... Melbourne: IEEE, 2006. p.1308-1312.

COELHO, A.M. Agricultura de precisão: manejo da variabilidade espacial e temporal dos solos e das culturas. In: NOVAIS, R.F et al. (Eds.). Tópicos em ciência do solo. Viçosa: Sociedade Brasileira de Ciência do Solo, 2005. v.1, p.249-290.

COELHO, C.N. O Princípio do Desenvolvimento Sustentado na Agricultura Brasileira. Revista de Política Agrícola, Brasília - Brasil, v.7, n.2, p.2-66, 1998.

COSTA, R.A.G.; CUGNASCA, C.E. Proposta de uma arquitetura computacional para coleta de dados climáticos em comunidades ribeirinhas da Amazônia. In: CONGRESSO BRASILEIRO DE AGROINFORMÁTICA, 7., 2009, Viçosa - Brasil. Anais... Viçosa: UFV, 2009. p.1-5.

CUGNASCA, C.E.; SARAIVA, A.M. A Força Tarefa ISOBUS-Brasil e a padronização em eletrônica embarcada em máquinas agrícolas. In: CONGRESSO SBIAgro, 6., 2007, São Pedro - Brasil. Anais... Campinas: Embrapa Informática Agropecuária - ACN, 2007. p.1-5.

DALLAS SEMICONDUCTOR. DS80C400 Network Microcontroller. 2009. 7p. Data-sheet disponível em http://datasheets.maxim-ic.com/en/ds/DS80C400.pdf. Acesso em 10/07/2010.

DECOTIGNIE, J.D. Ethernet based real-time and industrial communications. In: ISIE'93 IEEE INTERNATIONAL SYMPOSIUM ON 93., 1993, Budapest - Hungary. Proceedings... Budapest: IEEE-ISIE'93, 2005. p.1102-1117.

DULMAN, S. et al. Trade-off between traffic overhead and reliability in multipath routing for wireless sensor networks. In: WIRELESS COMMUNICATIONS and NETWORKING CONFERENCE, 1., 2003, New Orleans - USA. Proceedings... New Orleans: IEEE-WCNC, 2003. p.1918-1922.

EADY, F. Hands-on ZigBee implementing 802.15.4 with Microcontrollers. Burlington USA: Linacre House, Oxford. 2007. p.29-31.

ERGEN, M. WLAN: Intelligent Wireless Local Area Networking. 2004. 33p. Dissertation (PhD) - UC Berkeley, California - USA, 2004.

FALL, K.; VARADHAN, K. Formerly NS Notes and Documentation. 2010. 430p. NS Manual - disponível em http://www.isi.edu/nsnam/ns/doc/ns doc.pdf. Acesso em 10/07/2010.

FARAHANI, S. ZigBee Wireless Network and Transceivers. Burlington - USA: Linacre House, Oxford. 2008. p.9.

FARIAS, P.R.S. et al. Agricultura de precisão: mapeamento da produtividade em pomares cítricos usando geoestatística. Revista Brasileira de Fruticultura, Jaboticabal - Brasil, v.95, n.2, p.235-241, 2003.

FLORIDO, I.R. Rede de Sensores Sem fio em Ambientes Veiculares baseada no padrão ZigBee. 2008. 120p. Dissertação (Mestrado) - Escola Politécnica-USP, São Paulo - Brasil, 2008.

GESSINGER, A.K.; HENNING, C.H. ZigBee - conectividade wireless para automação e controle. In: CONGRESSO ISASHOW/2005, 5., 2005, São Paulo - Brasil. Anais... São Paulo: ISA Distrito 4, 2005. p.1-6 
GODOY, E. P.; PORTO, A. J. V.; INAMASU, R.Y. Proposta de Utilização de Hardware-inthe-loop no Desenvolvimento de Sistemas de Controle via Redes CAN. In: CONFERÊNCIA INTERNACIONAL DE APLICAÇÕES INDUSTRIAIS, 8., 2008, Poços de Caldas - Brasil. Anais... Poços de Caldas: IEEE, 2008. p.1-7.

GODOY, E.P. Desenvolvimento de uma Ferramenta de Análise de Desempenho de Redes CAN (Controller Area Network) para Aplicações em Sistemas Agrícolas. 2007. 93p. Dissertação (Mestrado) - Escola de Engenharia de São Carlos -USP, São Carlos Brasil, 2007.

GODOY, E.P. et al. Programa Computacional para Simulação de Redes CAN Aplicadas em Máquinas Agrícolas. Revista Brasileira de Agroinformática, São Paulo - Brasil, v.8, n.1, p.36-52, 2006.

GONDA, L.; CUGNASCA. C.E. A Proposal of Greenhouse Control Using a Wireless Sensor Network. In: WORD CONGRESS CONFERENCE, 4., 2006, Orlando-USA. Proceedings... Orlando: ASABE, 2007. p.229-233.

GONDA, L.; CUGNASCA. C.E.; CAMILLI Aplicações Agrícolas para Redes de Sensores sem Fio. In: CONGRESSO SBIAgro, 5., 2005, Londrina - Brasil. Anais... Londrina: UEL, 2005. p.1-9.

GUIMARÃES, A.A.; SARAIVA, A. M. O protocolo CAN: entendendo e implementando uma rede de comunicação serial de dados baseada no barramento Controller Area Network. In: CONGRESSO SAE BRASIL, 11., 2002, São Paulo - Brasil. Anais... São Paulo: SAE Brasil, 2002. p.1-4.

GUIMARÃES, A.A. Análise da norma ISO 11783 e sua Utilização na Implementação do Barramento do Implemento de Um Monitor de Semeadora. 2003. 98p. Dissertação (Mestrado) - Escola Politécnica-USP, São Paulo - Brasil, 2003.

GUIMARÃES, A.A.; SARAIVA, A. M. A Norma ISO 11783 como padrão internacional e a sua utilização na agricultura. In: CONGRESSO da SOCIEDADE BRASILEIRA de INFORMÁTICA APLICADA à AGROPECUÁRIA e à AGROINDÚSTRIA, 4., 2003, Porto Seguro - Brasil. Anais... Lavras: Sociedade Brasileira de Informática Aplicada à Agropecuária e à Agroindústria, 2003. p.439-442.

HUANG, S.K. Target Tracking Using Adaptive Weighting Approach for Energy Saving in Sensor Network. 2007. 98p. Master's thesis (Master) - National Chung Cheng University, Chia-ye, Taiwan, 2007.

INAMASU, R. Y.; SOUSA, R. V. Projeto e implantação de um barramento CAN para suporte ao desenvolvimento de sistemas de automação para máquinas agrícolas. Revista Minerva, São Carlos - Brasil, v. 01, n. 01, p. 01-06, 2004.

ISO. INTERNATIONAL ORGANIZATION FOR STANDARDIZATION. ISO 11783-4, Tractors Machinery for Agriculture and Forestry - Serial Control and Data Communication Network. part 4: Network Layer, 1998.

ISO. INTERNATIONAL ORGANIZATION FOR STANDARDIZATION. ISO 11898-2, Road Vehicles- Controller Area Network (CAN). part 2: High Speed medium access.2003.

JENSEN, L. A.; SORENSEN C. G.; JORGENSEN R. N. Real-time Internet-based Traceability Unit for Mobile Payload Vehicles. In: CIOSTA-CIGR CONFERENCE ADVANCES in LABOUR and MACHINERY MANAGEMENT for a PROFITABLE AGRICULTURE and FORESTRY, 32., 2007, Nitra - Slovakia. Proceedings... Nitra: CIOSTA_CIGR, 2007.p.368-374.

JOHANSSON, K. H.; TÖRNGREN, M.; NIELSEN, L. Vehicle applications of Controller Area Networks. In: VARSAKELIS, D. H. LEVINE, W. S. Handbook of Networked and Embedded Control Systems Boston: Eds., Retrieved, 2007. v.6, p.741-765. 
KANESHIRO, P.J.I. et al. Modeling of Collision Resolution Algorithm in LonWorks Networks. In: INTERNATIONAL MECHANICAL ENGINEERING CONGRESS AND EXPOSITION (IMECE2007), 1., 2007, Seattle - USA. Proceedings... Seattle: ASME, 2007. p.743-749.

KANESHIRO, P.J.I. et al. Modelagem de Redes de Controle LonWorks em Edifícios Inteligentes. In: CIBIM CONGRESO IBEROAMERICANO DE INGENIERIA MECÁNICA, 8., 2007, Cuzco - Peru. Memórias... Lima: PUCP/FEIBIM, 2007. p.1-8.

KATO, M. et al. Evaluation of Latency Time for Class C High Speed LAN Protocols. In: SAE INTERNATIONAL CONGRESS \& EXPOSITION, 1., 1994, Detroit - USA. Proceedings... Detroit: SAE International, 1994. p.1-5.

KOUBAA, A.; CUNHA, A.; ALVES, M. A time division beacon scheduling mechanism for IEEE 802.15.4/ZigBee cluster-tree wireless sensor. In: EUROMICRO CONFERENCE on REAL-TIME SYSTEMS, 19., 2007, Piza - Itália. Proceedings... Piza: Euromicro ECRTS-07, 2007. p.1-7.

LANDI, D.C.; CUGNASCA, C.E.; CAMILLI, A. Study on Implementation Viability of ISO 11783 Virtual Terminal and Task Controller Using Handheld Devices. In: INTERNATIONAL CONFERENCE ON PRECISION AGRICULTURE - ASA/CSSA/SSSA, 7., 2004, Minneapolis - USA. Proceedings... Minneapolis: ASA/CSSA/SSSA, 2004. p.219-230.

LANE, N.D.; CAMPBELL, A. The influence of Microprocessor instructions on the energy consumption of wireless sensor networks. In: Third WORKSHOP on EMBEDDED NETWORKED SENSORS (EmNets 2006), 3., 2006, Cambridge - England. Proceedings... Cambridge: Harvard Division of Engineering and Applied Sciences, 2006. p.34-39.

LAV. LANDTECHNIK-VEREINIGUNG. DIN 9684, LBS Documentation. v.2.0-2.8, Frankfurt Germany, 2000.

LEE, K.; KIM, S.; PARK, H. Cluster Labelbased ZigBee Routing Protocol with High Scalability. In: INTERNATIONAL CONFERENCE on SYSTEMS and NETWORKS COMMUNICATIONS, 2., 2007, Cap. Esterel - França. Proceedings... Cap. Esterel: IEEE (ICSNC 2007), 2007. p.1-12.

LEVIS, P. et al. TinyOS: An operating system for wireless sensor networks. Ambient Intelligence. Springer-Verlag, Berlin - Germany, v.1, n.1, p.115-142, 2005.

LEVIS, P.; LEE, N. TOSSIM: a simulator for TinyOS Network. 2003. Manual técnico disponível em

http://citeseerx.ist.psu.edu/viewdoc/download?doi=10.1.1.10.5619\&rep=rep1\&type=pdf. Acesso em 10/07/2010.

LIAN, F.L. et al. Network architecture and communication modules for guaranteeing acceptable control and communication performance for networked multi-agent system. IEEE Transactions on Industrial Informatics, New York - USA, v.2 , n.1, p12-24, 2006.

LIU, H. et al Integration of RFID and Wireless Sensor Networks. In: 5th ACM SenSysWORKSHOPS, 5., 2007, Sydney - Australia. Proceedings... Sydney: ACM Press, 2007. p.1-27.

MCKINION, J.M. et al. High speed wireless local area networking for farm applications. American Society of Agricultural Engineers Meetings Papers, Washington - USA, v.1, n.033057, p.1-25, 2003.

MEIRA, C. A. A. et al. Agroinformática: qualidade e produtividade na agricultura. Cadernos de Ciência e Tecnologia, Brasília - Brasil, v. 13, n. 2, p. 175-194, 1996.

MOLIN, J.P. Agricultura de precisão, parte I: o que é e estado da arte em sensoriamento. Engenharia Agrícola, Jaboticabal - Brasil, v.17, n.2, p.97-107, 1997. 
MOLIN, J.P. Utilização de GPS em agricultura de precisão. Engenharia Agrícola, Jaboticabal - Brasil, v.17, n.3, p.121-32, 1998.

MOLIN, J.P. Geração e Interpretação de Mapas de Produtividade para Agricultura de Precisão. In: BORÉM, A. et al. Agricultura de Precisão. Viçosa: UFV, 2000. p.237-258

MOLIN, J.P. Tendências da Agricultura de Precisão no Brasil. In: CONBAP -CONGRESSO BRASILEIRO DE AGRICULTURA DE PRECISÃO, 1., 2004, Piracicaba - Brasil. Anais... Piracicaba: ESALQ-USP, 2004. p.1-10.

MONICO, J.F.G. Posicionamento pelo NAVSTAR-GPS Descrição, fundamentos e Aplicações. São Paulo - Brasil: UNESP. 2000. p.21-22.

MOREIRAS, A.M.; CUGNASCA, C.E. Arquitetura de uma Rede de Instrumentação Inteligente Baseada em CAN e TCP/IP e Aplicada ao Estudo de Meliponíneos. In: CONGRESSO SBIAgro, 4., 2003, Porto Seguro - Brasil. Anais... Porto Seguro: SBIAgro, 2003. p.170-173.

NAJM, L.H. et. al. Arquitetura de sistemas para aquisição de dados com redes de sensores para realização de experimentos com weblabs. In: CONGRESSO SBIAgro, 7., 2009, Viçosa - Brasil. Anais... Viçosa: UFV, 2009. p.1-5.

NAKAMURA, E.; FIGUEIREDO, C.; LOUREIRO, A. Disseminação de Dados Adaptativa em Redes de Sensores sem Fio Auto-organizáveis. In: SIMPÓSIO BRASILEIRO DE REDES DE COMPUTADORES, 22., 2004, Gramado - Brasil. Anais... Gramado: SBRC2004, 2004. p.114.

NASCIMENTO, J.A. IEEE 802.15.4 - Rede de Sensores Sem Fio como Infra-estrutura para Comunicação entre Veículos e Sistema de Controle. 2007. 64p. Dissertação (Mestrado). Escola de Engenharia e Computação da UNICAMP. Campinas, 2007.

OKSANEN, T. et al. ISO 11783 - Standard and its Implementation. In: IFAC - WORD CONGRESS, 16., 2005, Prague - Czech Republic. Proceedings... Prague: IFAC, 2005. p.16.

ONDREJ, S. et al. ZigBee Technology and Device Design. In: IEEE INTERNATIONAL CONFERENCE on MOBILE COMMUNICATIONS and LEARNING TECHNOLOGIES, 5., 2006, Port Louis - Mauritius. Proceedings... Mauritius: IEEE Computers Society, 2006. p.129-129.

PAGNANO, N.B.; MAGALHÃES, P.S. Sugarcane yield measurement. In: EUROPEAN CONFERENCE on PRECISION AGRICULTURE, 3., 2001, Montpellier - France. Proceedings... Montpellier: AgroMontpellier-ENITAdeBordeaux, 2001. p.839-843.

PEREIRA, G. A. S.; SOARES, M. B.; CAMPOS, M. F. M. A potential field approach for collecting data from sensor networks using mobile robots. In: IEEE INTERNATIONAL CONFERENCE on INTELLIGENT ROBOTS and SYSTEMS, 1., 2004, Sendai - Japan. Proceedings... Sendai: IEEE Computer Society, 2004. p.3469-3474.

PIERCE, F.J.; NOWACK, P. Aspects of Precision Agriculture. Advances in Agronomy, New York - USA, v.67, s.n. p.1-85, 1999.

PIMENTEL, C.J.L. Comunicação Digital. Rio de Janeiro - Brasil: Brasport. 2007. p.226245.

RHEE, S.; LIU, S. An Ultra-low Power, Self-organizing Wireless Network and Its Applications to Noninvasive Biomedical Instrumentation. In: IEEE/SARNOFF SYMPOSIUM ON ADVANCED IN WIRED and WIRELESS COMMUNICATIONS, 1., 2002, West Trenton USA. Proceedings... West Trenton: IEEE/Sarnoff, 2002. p.2-5.

RUBINSTEIN, M.G.; REZENDE, J.F. Quality of Service in Ad Hoc 802.11 Networks. Journal of the Brazilian Computer Society, Porto Alegre - Brasil, V.9, n.1, p.41-52, 2003. 
SAE. ENGINEERING SOCIETY FOR ADVANCING MOBILITY LAND SEA AIR and SPACE. SAE J1939/2, Recommended practice for a serial control and communications vehicle network. Agricultural and Forestry Off-Road Machinery Control and Communication Network. 2003.

SANKARASUBRAMANIAM, Y.; AKAN, O.B.; AKYILDIZ, I.F. ESRT: event-to-sink reliable transport in wireless sensor networks. In: MobiHoc '03 INTERNATIONAL SYMPOSIUM ON MOBILE AD HOC NETWORKING \& COMPUTING, 4., 2003, Annapolis - USA. Proceedings... Annapolis: ACM Press, 2003. p.177-188.

SARAIVA, A.M.; CUGNASCA, C.E. Redes de comunicação serial em máquinas agrícolas: uma revisão. Revista Brasileira de Agroinformática, São Paulo - Brasil, v.8, n.1, p. 17-35, 2006.

SCHLOSSER, J.F. et al. Antropometria Aplicada aos Operadores de Tratores Agrícolas. Ciência Rural, Santa Maria - Brasil, v.32, n.6, p.983-988, 2002.

SCHUELLER, J.K.; WANG, M.W. Spatially-variable fertilizer and pesticide application with GPS and DGPS. Computers and Electronics in Agriculture, Gainesville - USA, v.11, n.1, p.69-83, 1994.

SHUAIB, K. et al. Performance Evaluation of IEEE 802.15.4: Experimental and Simulation Results. Journal of Communications, New York - USA, v.2, n.4, p.29-37, 2007.

SIGRIMIS, N. et al. Prospects in agricultural engineering in the information age. CIGRE Journal, invited paper, Hokkaido - Japan, v.1, n.1, p.1-20, 1999.

SILVA, L.F. Investigação do Impacto da Mobilidade de elementos na rede IEEE 802.15.4 Através do Desenvolvimento de uma Plataforma de Simulação. 2008. 121p. Dissertação (Mestrado) - Pontifícia Universidade Católica de Campinas. Campinas - Brasil, 2008.

SOUSA, R.V. CAN Controller Area Network:Uma abordagem para Controle e Automação na Área Agrícola. 2002. 83p. Dissertação (Mestrado) - Escola de Engenharia de São Carlos -USP, São Carlos - Brasil, 2002.

STRAUSS, C. et al. Application of the CAN and ISO 11783 protocols to a Planter Monitor. In: INTERNATIONAL MULTICONFERENCE ON CIRCUITS, SYSTEMS, COMMUNICATIONS AND COMPUTERS, IMACS/IEEE, 3., 1999, Atenas - Greece. Proceedings... Atenas: IMACS/IEEE, 1999. p.211-216.

SZILAGYI, R.; HERDON, M. Mobile Internet Applications, Infrastructure and Services. In: WORLD CONGRESS On COMPUTERS In AGRICULTURE, 4., 2008, Orlando - USA. Proceedings... Orlando: American Society of Agricultural and Biological Engineers, 2006. p.269-290.

VDMA. VERBAND DEUTSCHER MASCHINEN und ANLAGENBAU - GERMAN ENGINEERING FEDERATION - AGRICULTURAL MACHINERY ASSOCIATION. ISOBUS Specification, Implementation level 2. p.1, 2003.

VIEIRA, M.A. et al. Como obter Mapa de Energia em Redes de Sensores Sem Fio? Uma Abordagem Tolerante a Falhas. In: WORKSHOP de COMUNICAÇÃO sem FIO (WCSF), 5., 2003, São Lourenço - Brasil. Anais... São Lourenço: INATEL, 2003. p.183-189.

VOSS, W. A comprehensible Guide to J1939. Greenfield - USA: Copperhill Technologies Corporation. 2008. p.24.

WANG, N.; ZHANG, N.; WANG, M.. Wireless sensors in agriculture and food industry-Recent development and future perspective. Computers and Electronics in Agriculture, New York - USA, v.1, n.50, p.1-14, 2006. 
YE, F. et al. A two-tier data dissemination model for large-scale wireless sensor networks. In: ACM MobiCom'02, 8., 2002, New York - USA. Proceedings... New York: ACM Press, 2002. p.148-159.

ZANG, Y. et al. Location-Based Compromise-Tolerant Security Mechanisms for Wireless Sensor Network. IEEE Journal on Selected Areas in Communications, Edmonton Canada, v.24, n.02, p.247-260, 2006.

ZANG, Z. Investigation of wireless sensor networks for precision agriculture. American Society of Agricultural and Biological Engineers, St. Joseph - USA, v.300, n.4, p.31-35, 2004.

ZHANG, L.; WANG, Z. Integration of RFID into Wireless Sensor Networks: Architectures, Opportunities and Challenging Problems. In: INTERNATIONAL CONFERENCE on GRID and COOPERATIVE COMPUTING WORKSHOPS (GCCW'06), 5. 2006, Los Alamitos USA. Proceedings... Los Alamitos: IEEE Computer Society, 2006. p.463-469. 


\section{APÊNDICE A - Guia do Usuário do Simulador}

\section{A.1 Apresentação Geral da ferramenta}

\section{A.1.1 Tela Inicial:}

A Figura A-1 mostra a tela inicial.

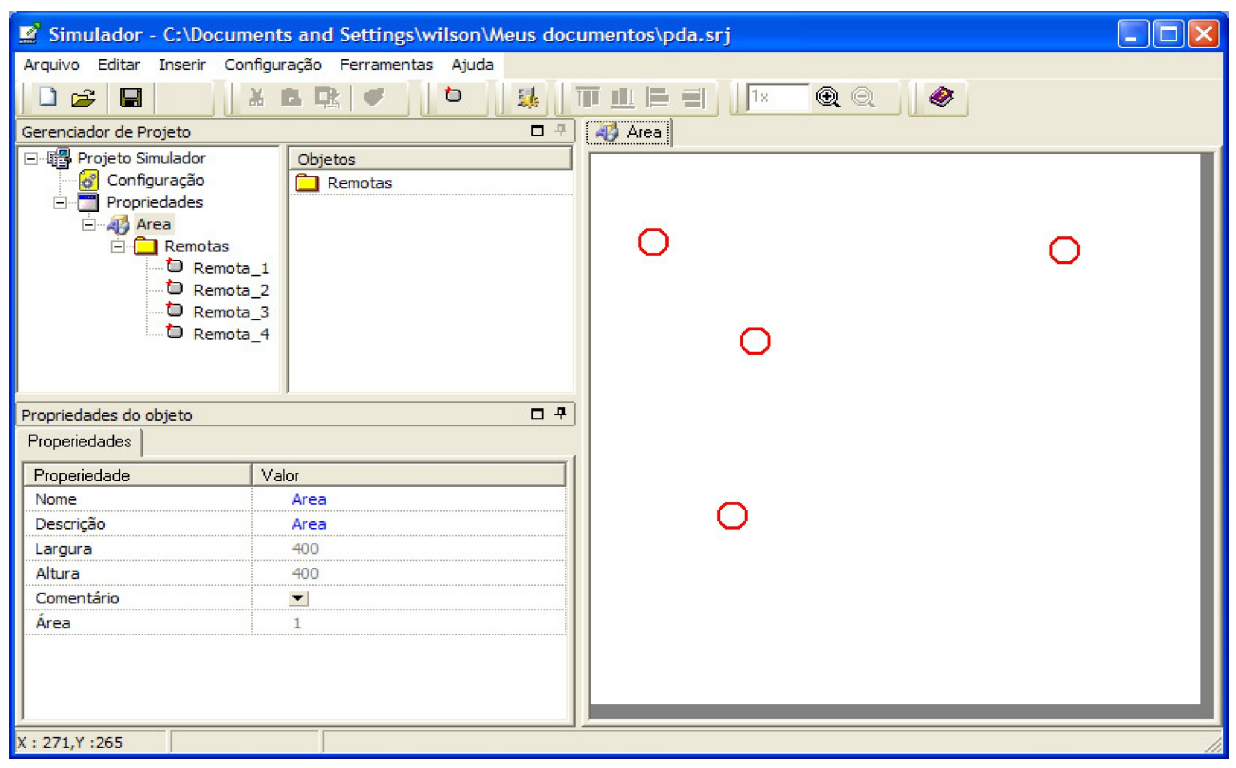

Figura A-1 - Tela Inicial.

\section{A.1.2 Menus:}

Arquivo; Editar; Inserir; Ambiente; Iniciar Simulação; Finalizar Simulação; Ajuda.

Arquivo:

- Novo Projeto;

- Abrir Projeto;

- Reabrir;

- Salvar;

- Salvar como;

- Fechar;

- Sair.

Editar:

- Recortar;

- Copiar;

- Colar;

- Excluir;

- Desfazer;

- Alinhar acima;

- Alinhar abaixo;

- Alinhar esquerda; 
- Alinhar direita.

Inserir:

- Remota;

- Configuração.

Ambiente:

- Modelos;

- Ferramentas.

Iniciar Simulação.

Finalizar simulação.

Ajuda:

- Ajuda;

- Sobre Simulador.

\section{A.2 Descrição dos menus.}

\section{A.2.1. Arquivo}

O menu Arquivo é mostrado na Figura A-2

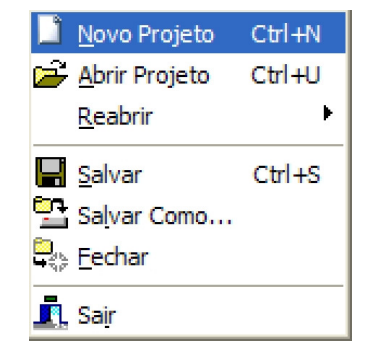

Figura A-2 - Menu Arquivo.

- Novo Projeto.

Este item serve para inicializar um novo projeto. Será mostrada a janela para definir os parâmetros padrão do projeto, conforme indica a Figura A-3.

Nesta janela têm-se duas listas "Drive" e "Descrição", sendo que:

- drive refere-se às configurações criadas anteriormente pelo usuário;

- descrição refere-se a uma frase contendo informações que possibilitem o usuário identificar a configuração. 


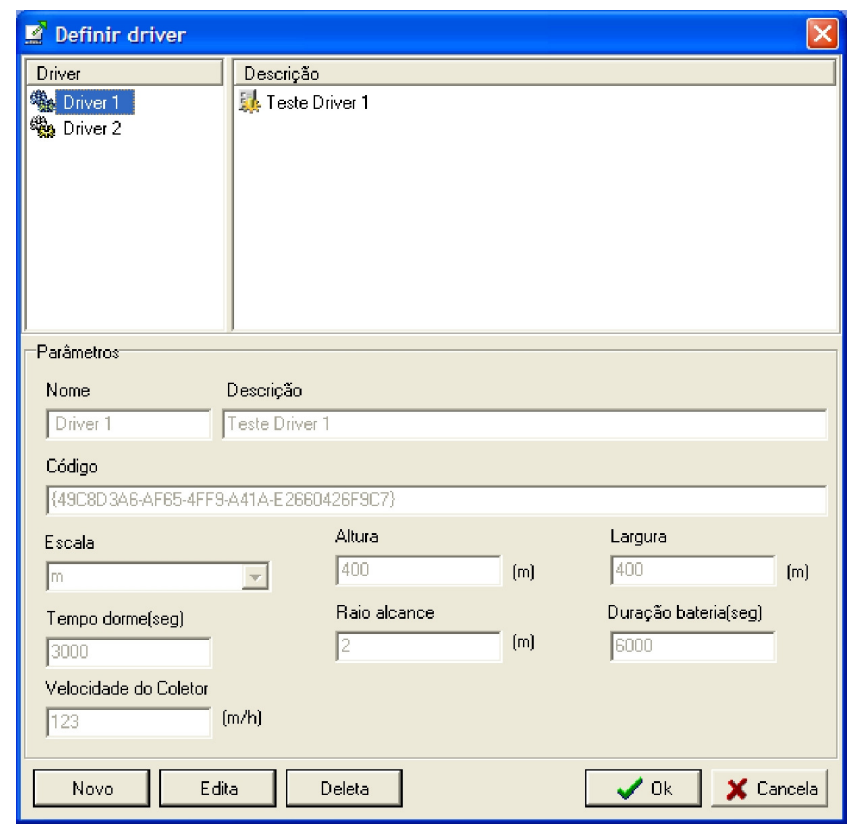

Figura A-3 - Janela para definir um novo projeto.

Ao selecionar um drive na parte inferior da janela, é mostrada a configuração existente, como:

- Nome: Nome do arquivo;

- Descrição: Descrição conforme parágrafo anterior;

- Código: valor gerado internamente para identificar o drive;

- Escala: será definida pelo usuário em metros $(\mathrm{m})$ ou quilômetros $(\mathrm{Km})$.

- Altura: altura da área;

- Largura: largura da área;

- Tempo dorme: tempo em que o sensor fica desligado.

- Raio de alcance: raio de alcance do rádio do sensor

- Duração bateria: tempo remanescente de duração da bateria, em horas;

- Velocidade do coletor: Velocidade que o trator deverá atravessar à área.

Botões:

- Novo: gera um novo drive;

- Edita: altera drive selecionado na lista;

- Deleta: deleta drive selecionado na lista.

- Ok: cria um novo projeto com o drive selecionado da lista;

- Cancela: cancela operação.

Caso o projeto atual não esteja salvo, será solicitada confirmação para continuar, pois o projeto tem que ser fechado. Conforme indica Figura A-4. 


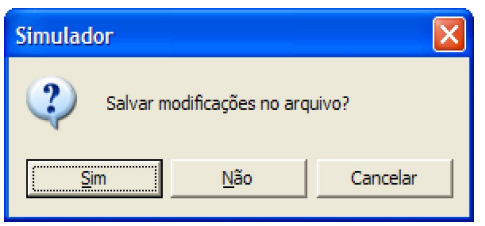

Figura A-4 - Janela para confirmar o salvamento das alterações de um novo projeto.

- Abrir Projeto.

Esta opção abre um projeto existente com a extensão do arquivo “ *.sjr” (Figura A-5).

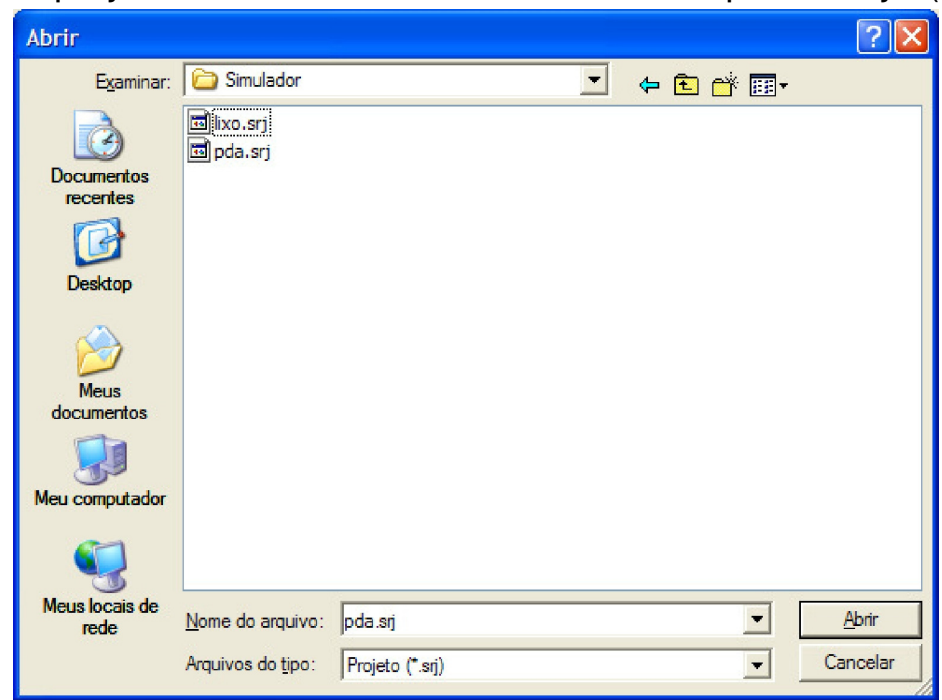

Figura A-5 - Janela para abrir um projeto.

Caso o projeto atual não esteja salvo, será solicitada confirmação para continuar, pois o projeto tem que ser fechado. Conforme indica Figura A-6.

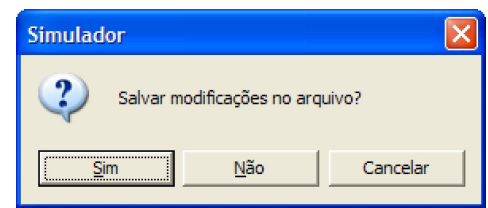

Figura A-6 - Janela para confirmar o salvamento do projeto.

- Reabrir.

A opção Reabrir mostra os últimos seis projetos utilizados, os quais podem ser selecionados para serem reabertos, conforme indica Figura A-7:

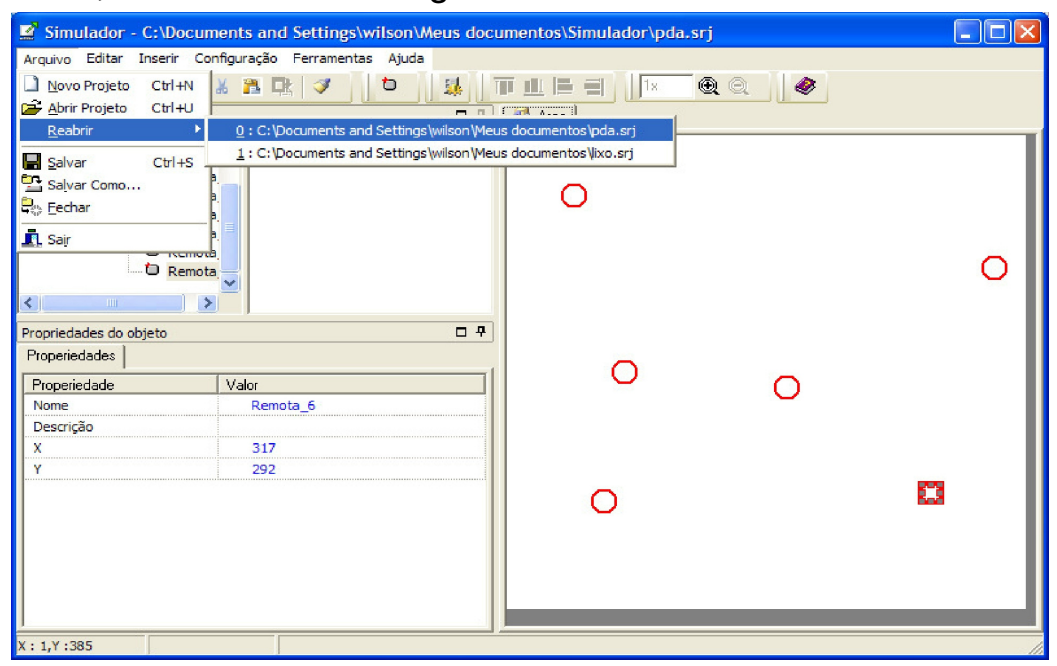

Figura A-7 - Lista dos projetos abertos. 
Caso o projeto atual não esteja salvo, será solicitada confirmação para continuar, pois o projeto tem que ser fechado. Conforme indica Figura A-8.

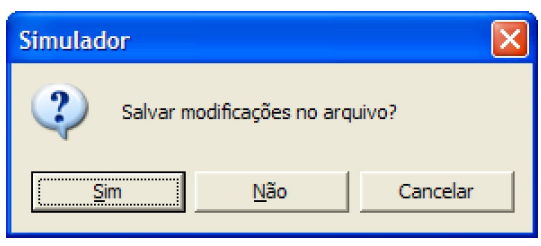

Figura A-8 - Janela de confirmação para salvar arquivo.

- Salvar como

Para salvar o projeto atual com outro nome, é aberta uma janela do Windows para o usuário localizar a pasta e criar um novo arquivo, conforme e indicado na Figura A-9:

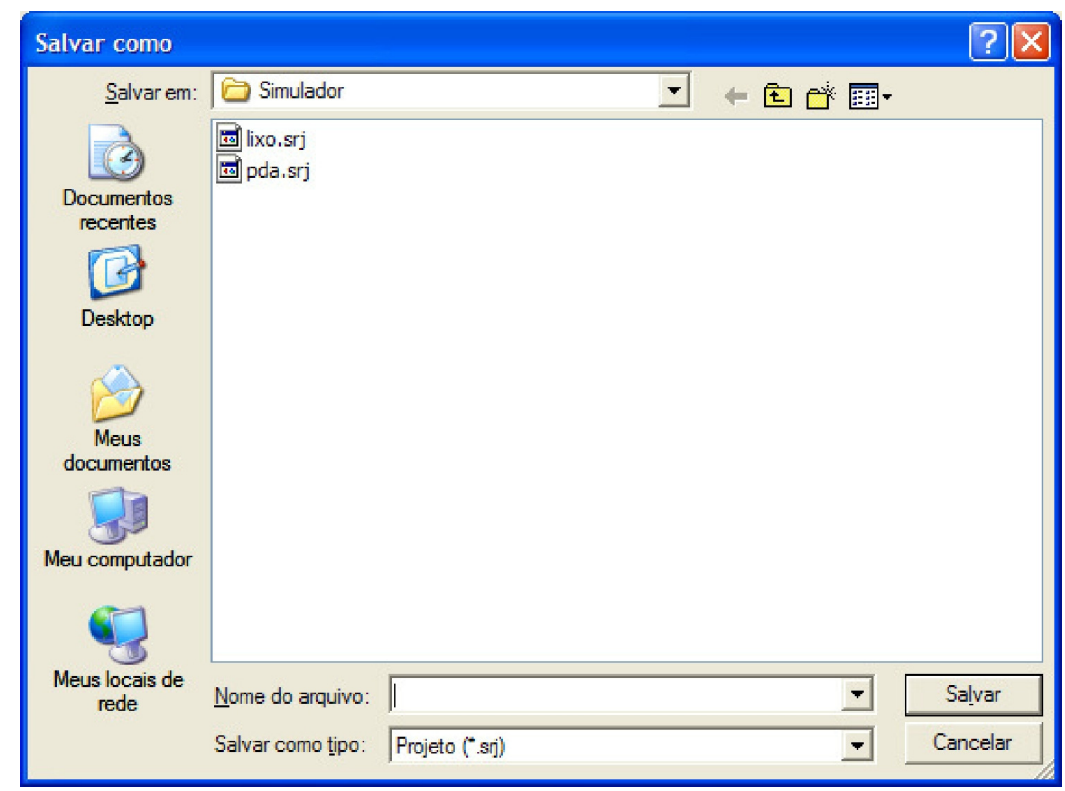

Figura A-9 - Janela para salvar arquivo com novo nome.

- Fechar

Fecha o projeto atual. Caso o projeto não esteja salvo, será solicitada uma confirmação se o usuário realmente deseja fechar o simulador.

- Sair

Utilizado para fechar o programa simulador. Caso o projeto não esteja salvo, será solicitada confirmação, conforme indica a Figura A-10.

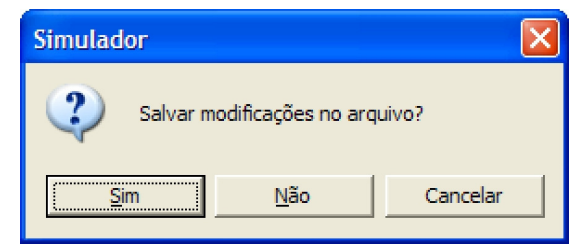

Figura A-10 - Janela de confirmação de salvamento das modificações em arquivo antes de fechar o programa simulador. 


\section{A.2.2. Editar}

A Figura A-11 mostra o menu Editar.

\begin{tabular}{|c|c|}
\hline Recortar & Ctrl $+\mathrm{X}$ \\
\hline Copiar & $\mathrm{Ctrl}+\mathrm{C}$ \\
\hline 무뇨 Colar & $\mathrm{Ctrl}+\mathrm{V}$ \\
\hline 3 Excluir & Del \\
\hline 4) Desfazer & $\mathrm{Ctrl}+\mathrm{Z}$ \\
\hline \multicolumn{2}{|c|}{ Тाप्र Alinhar acima } \\
\hline \multicolumn{2}{|c|}{ 미르 Alinhar abaixo } \\
\hline \multicolumn{2}{|c|}{ 局 Alinhar esquerda } \\
\hline \multicolumn{2}{|c|}{ 듬 Alinhar direita } \\
\hline
\end{tabular}

Figura A-11 - Menu Editar.

Todas as opções deste menu serão utilizadas na área de trabalho, conforme mostra a figura A-12:

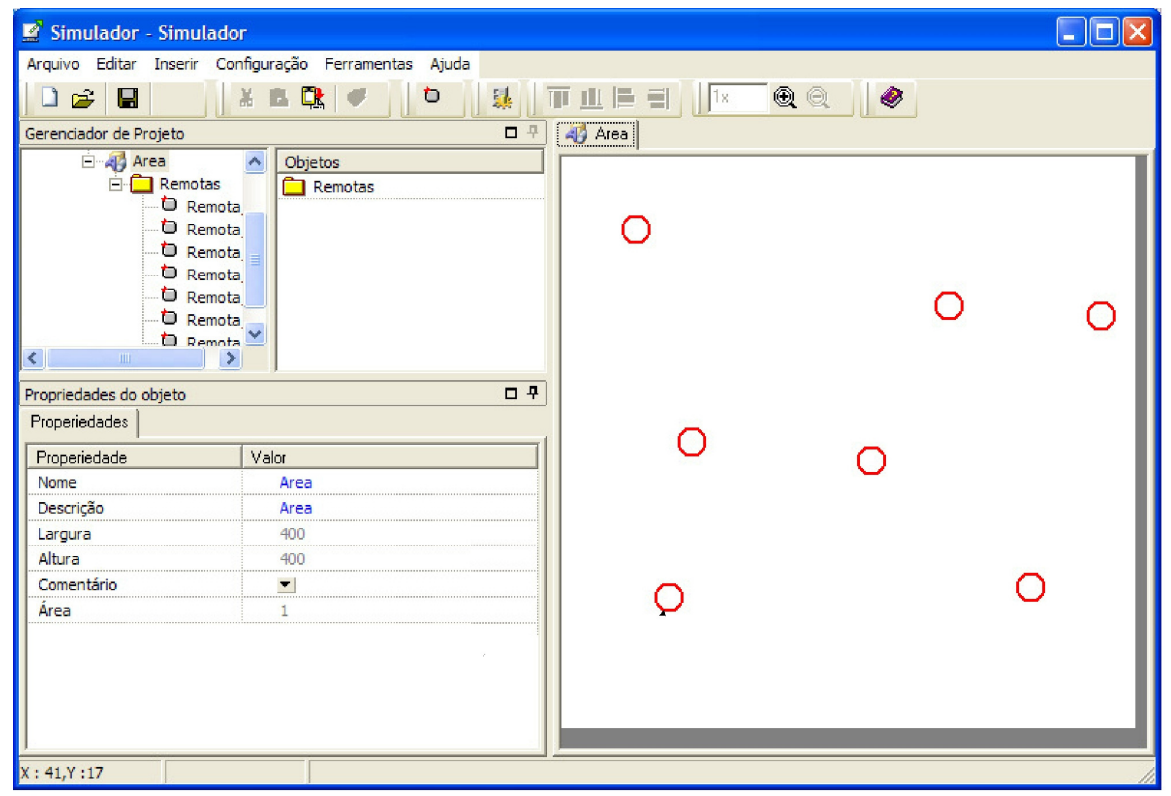

Figura A-12 - Área de Trabalho.

As funções do menu Editar são:

- Recortar: recorta o sensor selecionado;

- Copiar: copia sensores selecionados;

- Colar: cola os sensores copiados no item anterior;

- Excluir: exclui sensores selecionados;

- Desfazer: desfaz a última operação com um sensor. Válido apenas para operações de inclusão, exclusão e movimentação dos sensores;

- Alinhar Acima: alinha os sensores selecionados com o topo do sensor guia;

- Alinhar Abaixo: alinha os sensores selecionados com a base do sensor guia;

- Alinhar esquerda: alinha os sensores selecionados com a esquerda do sensor guia;

- Alinhar direita alinham os sensores selecionados com a direita do sensor guia. 


\section{A.2.3. Inserir}

As funções do menu Inserir são:

- Remota: insere um sensor sem fio na área livre de trabalho quando for acionado;

- Configuração: ativa a janela para inserir nova configuração.

\section{A.2.4. Ambiente}

Abre janela para configurar o sistema, conforme mostra a Figura A-13:

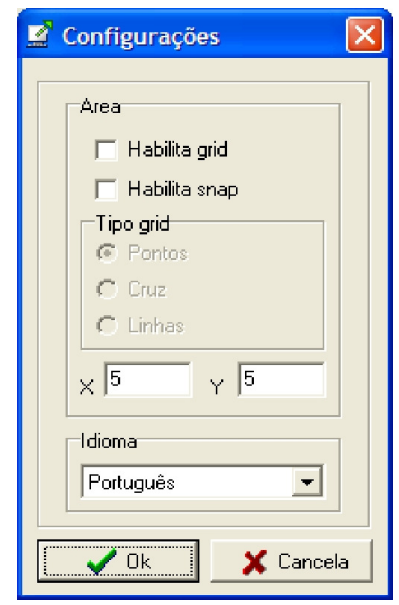

Figura A-13 - Janela para configurar o ambiente de trabalho.

Os seguintes parâmetros são possíveis de serem configurados para a área de trabalho:

- Habilita grid: habilita o grid nas áreas do projeto;

- Habilita snap: habilita o posicionamento automático dentro do grid;

- $\quad(X, Y)$ : definem a distância horizontal e vertical entre os pontos do grid;

- Tipo de grid: Pontos, Cruz ou Linhas (Figura A-14).

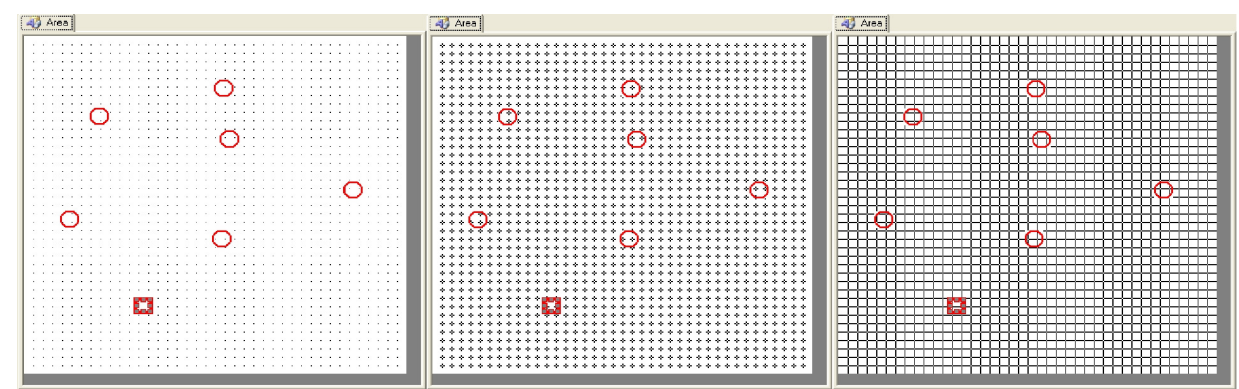

Figura A-14 - Tipos de grids: pontos (à direita), cruzes (ao centro) e linhas (à esquerda).

\section{A.2.5. Cenários}

Abre a mesma janela da Figura A-3. Permite definir um cenário ou fazer alterações em um pré-existente. Conforme indicado na janela também permite associar um cenário ao projeto atual. 


\section{A.2.6. Ferramentas}

O menu Ferramentas possui duas opções (Figura A-15)

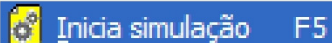

Finaliza simulaçẫo

Figura A-15 - Opções do menu Ferramentas.

\section{A.2.7. Ajuda}

O menu Ajuda aciona:

- o help (ajuda) com as informações deste guia

- Informações sobre a versão do simulador (Figura A-16):

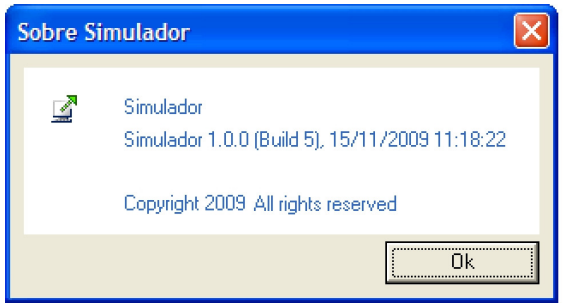

Figura A-16 - Janela com a versão do simulador.

\section{A.3 Simulação.}

OBS.: A simulação deve ser executada, apenas após definido os cenários e a rede.

1. Selecione o tipo de simulação, contínua ou one-shot (Figura A-17).

\begin{tabular}{|cc|}
\hline $\begin{array}{c}\text { Ferramentas } \\
\text { Inicia simulação } \\
\text { Finaliza simulação }\end{array}$ & F5 \\
\hline Simulaçăo continua & F7 \\
\hline
\end{tabular}

Figura A-17 - Ativa a simulação.

2. No modo one-shot, aguarde o nó coletor percorrer a área de trabalho (Figura A-18).

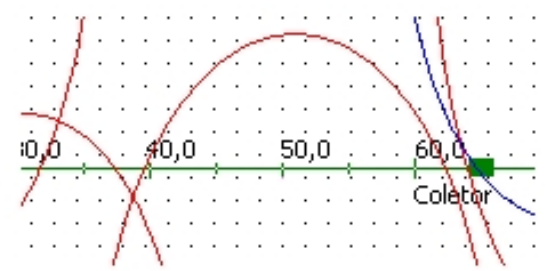

Figura A-18 - Nó Coletor percorrendo área de trabalho.

3. No modo continuo, aguarde o cronometro alcançar o tempo desejado (Figura A-19).

\begin{tabular}{l|c|c|}
\hline Continua... & 63 & $6337,89 \mathrm{~m} \mid 00: 03: 24: 641$ \\
\hline & \\
Cronômetro
\end{tabular}

Figura A-19 - Cronômetro. 
3. Finalize a simulação pelo menu Ferramentas (Figura A-17).

4. Verifique os relatórios gerados.

\section{A.4 Resultados das simulações}

Os seguintes relatórios são gerados após as simulações:

1. Log de eventos: mostra uma sequência códigos, correspondentes a sequência de eventos gerados pelo simulador. Permite avaliar a operação do simulador (Figura A-20).

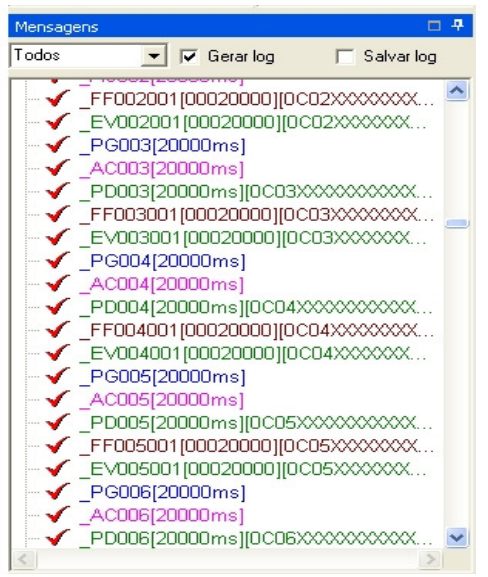

Figura A-20 - Relatório Log de eventos.

Os códigos possuem o formato mostrado no Quadro A-1.

\begin{tabular}{|c|c|c|c|c|}
\hline Tipo de evento & Destino & Origem & [Tempo] (us) & Tipo de frame \\
\hline \hline EE & 002 & 001 & {$[00000000]$} & TTTT \\
\hline \multicolumn{4}{|c}{ Quadro A-1 - Descrição dos códigos de eventos. }
\end{tabular}

A Tabela A-1 relaciona os códigos usados com o tipo de evento.

Tabela A-1 Descrição dos códigos de tipos de eventos.

\begin{tabular}{cc}
\hline $\begin{array}{c}\text { Código de } \\
\text { Evento }\end{array}$ & Descrição \\
\hline \hline$[\mathrm{FF}]$ & Frame enviado para FIFO do sensor \\
{$[\mathrm{EV}]$} & Transmitindo Frame \\
{$[\mathrm{RC}]$} & Frame Recebido \\
{$[\mathrm{AK}]$} & Transmitindo ACK \\
{$[\mathrm{AC}]$} & Sensor "acordou" \\
{$[\mathrm{BT}]$} & Bateria fraca \\
{$[\mathrm{DE}]$} & Sensor Dormindo \\
{$[\mathrm{DT}]$} & Timeout \\
{$[\mathrm{DP}]$} & Sensor dormiu \\
{$[\mathrm{PG}]$} & Sensor possui novos dados \\
{$[\mathrm{PN}]$} & Sensor aguardando \\
{$[\mathrm{FS}]$} & Fim de simulacao \\
{$[\mathrm{CY}]$} & Nó coletor respondendo (dentro do raio de alcance) \\
{$[\mathrm{CN}]$} & Nó coletor não responde (fora do raio de alcance) \\
{$[\mathrm{PD}]$} & Dado eliminado da FIFO \\
{$[\mathrm{PE}]$} & Mensagem ignorada \\
\hline
\end{tabular}


2. Relatório da rede descreve a rede montada para o cenário estabelecido (Figura A21).

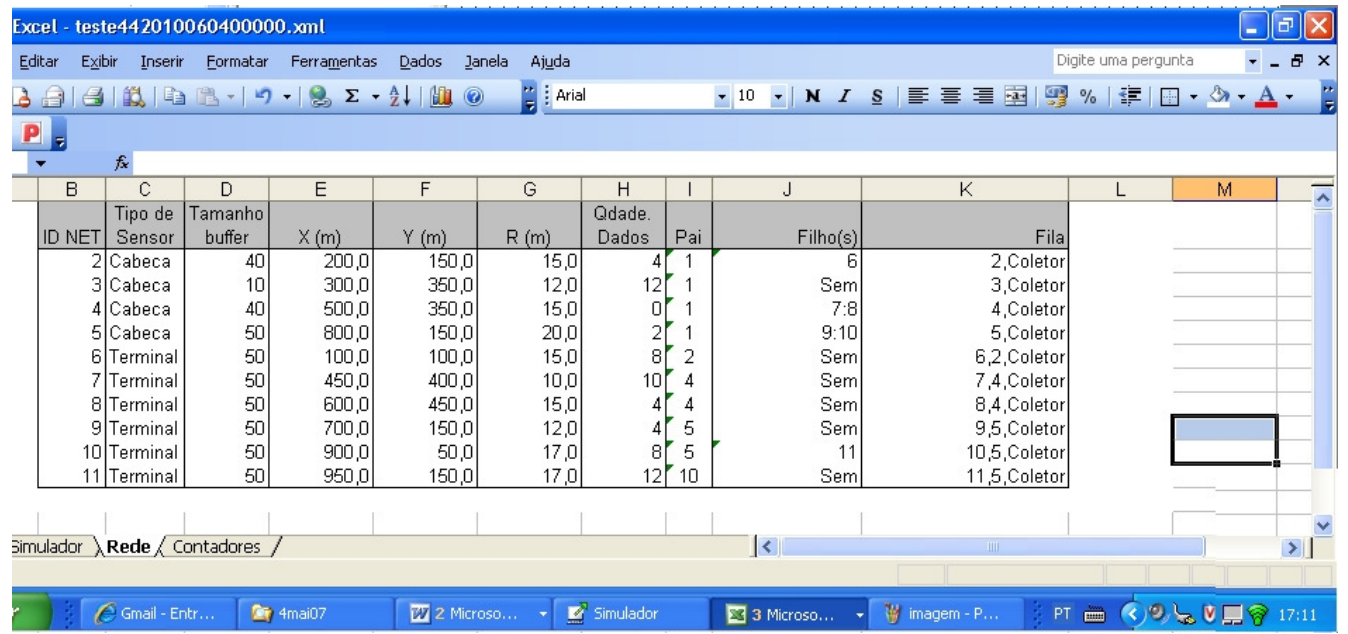

Figura A-21 - Relatório da rede gerada pelo simulador.

3. Relatório de resultados - contém o resultado das simulações (Figura A-22).

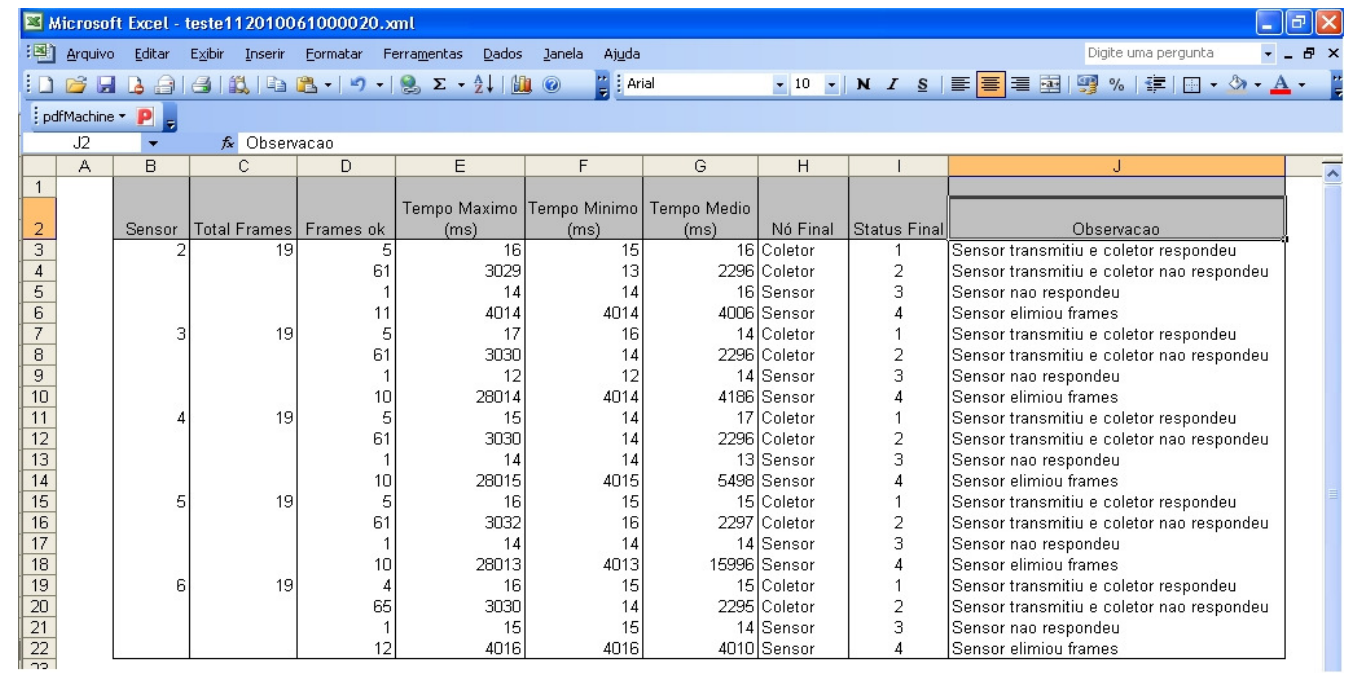

Figura A-22 - Relatório de resultados gerado pelo Simulador. 